Estudo do Impacto da Variabilidade Geométrica no Comportamento Cinemático e Dinâmico de Manipuladores Robóticos Paralelos com Redundância Cinemática

Renzo Fernandes Bastos

USP - São Carlos

Dezembro/2016 



\title{
Estudo do Impacto da Variabilidade Geométrica no Comportamento Cinemático e Dinâmico de Manipuladores Robóticos Paralelos com Redundância Cinemática
}

\author{
Renzo Fernandes Bastos
}

Orientadora: Profa. Dra. Maíra Martins da Silva

Dissertação apresentada à Escola de Engenharia de São Carlos - EESC-USP da Universidade de São Paulo, como parte dos requisitos para obtenção do título de Mestre em Engenharia Mecânica. Área de concentração: Dinâmica de Máquinas e Sistemas. EXEMPLAR DE DEFESA

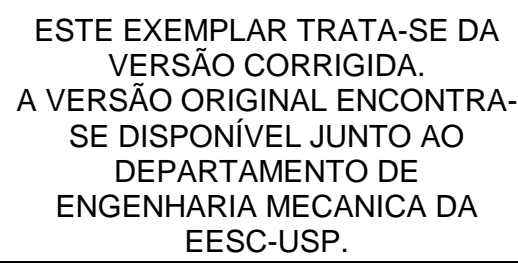

USP - São Carlos

Dezembro/2016 
AUTORIZO A REPRODUÇÃO TOTAL OU PARCIAL DESTE TRABALHO, POR QUALQUER MEIO CONVENCIONAL OU ELETRÔNICO, PARA FINS DE ESTUDO E PESQUISA, DESDE QUE CITADA A FONTE.

Bastos, Renzo Fernandes

Estudo do Impacto da Variabilidade Geométrica no Comportamento Cinemático e Dinâmico de Manipuladores Robóticos Paralelos com Redundância Cinemática / Renzo Fernandes Bastos; orientadora Maíra Martins da Silva. São Carlos, 2016.

Dissertação (Mestrado) - Programa de Pós-Graduação em Engenharia Mecânica e Área de Concentração em Dinâmica das Máquinas e Sistemas -- Escola de Engenharia de São Carlos da Universidade de São Paulo, 2016.

1. Manipulador de cinemática paralela. 2. Análise de intervalos. 3. Análise da cinemática e dinâmica. 4. Análise de singularidades. 5. Redundância cinemática. I. Título. 


\section{FOLHA DE JULGAMENTO}

Candidato: Engenheiro RENZO FERNANDES BASTOS.

Título da dissertação: "Estudo do impacto da variabilidade geométrica no comportamento cinemático e dinâmico de manipuladores robóticos paralelos com redundância cinemática".

Data da defesa: 09/11/2016.

Comissão Julgadora:

Resultado:

Profa. Dra. Maíra Martins da Silva

APROVADO

(Orientadora)

(Escola de Engenharia de São Carlos/EESC)

Prof. Associado Washington Luiz Marar

(Instituto de Ciências Matemáticas e de Computação/ICMC)

APROJADO

Prof. Dr. Fabricio Tadeu Paziani

APROVADO

(Universidade Federal de São Carlos/UFSCar)

Coordenador do Programa de Pós-Graduação em Engenheira Mecânica:

Prof. Associado Gherhardt Ribatski

Presidente da Comissão de Pós-Graduação:

Prof. Associado Luis Fernando Costa Alberto 

Aos meus pais, Reinaldo Bastos e Rosiléa pelo apoio incondicional durante toda minha trajetória, e que com toda certeza continuará. Agradeço aos meus irmãos, Reinaldinho e Renan, pelo exemplo que eles foram e são.

À minha namorada Natália pelo carinho e paciência que me ajudam a tentar ser sempre uma pessoa melhor.

À orientação da $\operatorname{Prof}^{\mathrm{a}} \operatorname{Dr}^{\mathrm{a}}$ Maíra Martins da Silva, que me ajudou bastante no amadurecimento técnico e científico.

Aos amigos e professores do LABDIN (laboratório de Dinâmica de Máquinas e Sistemas), que contribuíram com ensinamentos nas disciplinas e contribuiram na minha formação. Em especial a João Fontes pela ajuda tanto no projeto como matérias cursadas.

Aos amigos da Rep. Alabama: Rodolpho, Fabrício, Breno, Ronaldo, Nuno, Suetake, Renan e os agregados Daniel, Cuca e Luan! Pelas resenhas e convívio.

Aos amigos do Futebol de campo do CAASO, pela alegria de muitos títulos que conquistamos e os muitos outros que iremos conquistar. bol.

Aos amigos da pós-graduação pelas conversas e partidas de fute-

Aos meus amigos de longa data, meus primos e toda minha família.

Ao CNPq pelo apoio financeiro e à Escola de Engenharia de São Carlos.

A Deus por me proporcionar tudo isso. 

Bastos, R. F. Estudo do Impacto da Variabilidade Geométrica no Comportamento Cinemático e Dinâmico de Manipuladores Robóticos Paralelos com Redundância Cinemática 2016. Defesa (Mestrado) - Escola de Engenharia de São Carlos, Universidade de São Paulo, São Carlos, 2016

Manipuladores robóticos com cinemática paralela apresentam alta rigidez, alta relação carga/peso próprio e boa precisão quando comparados a manipuladores de cinemática serial. No entanto, a região de trabalho dos manipuladores paralelos é limitada devido à presença de singularidade. Com o objetivo de aumentar a região de trabalho, redundâncias cinemáticas podem ser introduzidas nas cadeias cinemáticas. Devido à sua arquitetura paralela, a incerteza nos parâmetros geométricos pode ter grande influência no comportamento cinemático e no desempenho dinâmico. O estudo do impacto dessas incertezas quando redundâncias são introduzidas em uma manipulador robótico planar de cinemática paralela é o objetivo desse trabalho. Distribuições normais foram adotadas para a avaliação do comprimento dos elos. O impacto dessas variações foi avaliado numericamente através da comparação de resultados da simulação de trajetórias para os diferentes manipuladores robóticos. Além disso, verificou-se o impacto dessas variações nas regiões de singularidades dos sistemas robóticos. Essas avaliações numéricas foram realizadas para o manipulador robótico 3(P)RRR. Este manipulador consiste de 3 cadeias cinemáticas em paralelo. Cada cadeia apresenta uma junta prismática ativa $(\underline{P})$, uma junta de revolução ativa $(\underline{R})$ e duas juntas de revolução passivas (RR). Através desse trabalho, uma metodologia de avaliação do impacto de incerteza geométricas em manipuladores robóticos paralelos com redundância de atuação foi proposta e investigada.

Palavras Chave: Manipulador de cinemática paralela, Análise de intervalos, Análise da cinemática e dinâmica, Análise de singularidades, Redundância cinemática. 

Bastos, R. F. A study on the impact of geometrical variability on the kinematic and dynamic behavior of parallel kinematic manipulators with kinematic redundancies 2016. Defesa (Mestrado) - Escola de Engenharia de São Carlos, Universidade de São Paulo, São Carlos, 2016

Parallel kinematic manipulators present higher rigidity, better load capacity and improved accuracy when compared to serial kinematic manipulators. However, the workspace of parallel kinematic manipulator is usually limited due to the presence of singularity regions. In order to enlarge the workspace, kinematic redundancy can be introduced in the kinematic chains. Due to its parallel architecture, the uncertainty and variability of some geometric parameters may have great influence on its kinematic behavior and dynamic performance. The impact of these variabilities when redundancies are considered should also be verified. The aim of this study is to evaluate some geometric uncertainties in the links' dimensions of a planar parallel robot manipulator with kinematic redundancy. Normal distributions are adopted for evaluating the variability of length of the links. The impact of these changes was evaluated numerically by comparing the results obtained by simulating trajectories for different robotic manipulators. In addition, the impact of these variabilities in the singularity regions is also assessed. These numerical evaluations have been performed for the redundant manipulator $3(\underline{P}) \underline{R} R R$. This manipulator consists of three kinematic chains in parallel. Each chain has an active prismatic joint $(\underline{P})$, an active revolute joint $(\underline{R})$ and two passive revolute joints (RR). Through this work, a methodology for assessing the impact of geometric uncertainty in parallel robotic manipulators with kinematic redundancy has been proposed and investigated.

Keywords: Parallel kinematic manipulators, Interval analysis, Kinematic and dynamic analysis, Singularities analysis, Kinematic redundancy. 

$\begin{array}{lll}\text { Abstract } & \text { v }\end{array}$

1 Introdução $\quad 1$

1.1 Contextualização . . . . . . . . . . . . . . . . . . . . 1

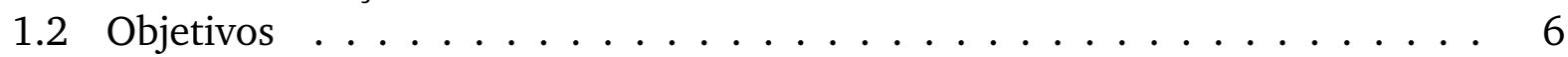

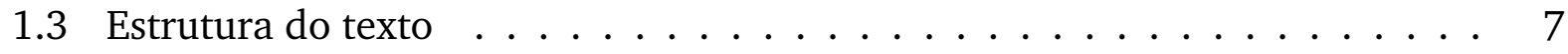

2 Revisão de literatura e conceitos $\quad 9$

2.1 Informações iniciais . . . . . . . . . . . . . . . . 9

2.2 Manipuladores robóticos . . . . . . . . . . . . . . . . 9

2.2.1 Manipuladores paralelos: definição e características . . . . . . . . . . 9

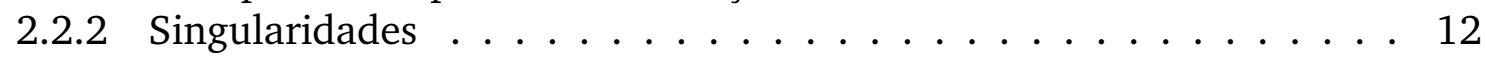

2.2.3 Redundância Cinemática . . . . . . . . . . . . . 13

2.3 Estatística na Engenharia . . . . . . . . . . . . . . 15

2.4 Considerações Finais . . . . . . . . . . . . . . . . 17

3 Metodologia e Modelagem 19

3.1 Considerações iniciais . . . . . . . . . . . . . . . . . . . . . . . . . . . . . . . .

3.2 Análise Cinemática . . . . . . . . . . . . . . . . . 20

3.2.1 Cinemática inversa . . . . . . . . . . . . . 20

3.2 .2 Jacobiana . . . . . . . . . . . . . . . . . 22

3.3 Modelo Dinâmico Baseado no Princípio do Trabalho Virtual . . . . . . . . . 23

3.3.1 Velocidades Parciais Lineares e Angulares . . . . . . . . . . . . . 23

3.3.2 Análise da Aceleração . . . . . . . . . . . . . . . . . . 25

3.3.3 Forças Inerciais e Momentos das Partes Móveis . . . . . . . . . . . 25

3.4 Abordagem Probabilística . . . . . . . . . . . . . . . 26

3.4.1 Distribuição Gaussiana de Probabilidades . . . . . . . . . . . . . 26

3.4 .2 Intervalo de Confiança . . . . . . . . . . . . . . . . . 28

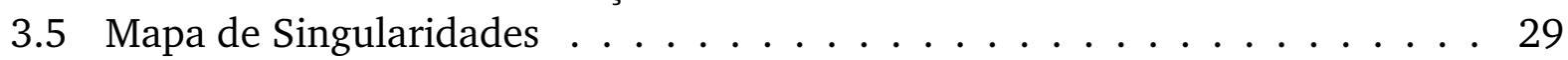




4 Resultados e Discussões $\quad 33$

4.1 Considerações iniciais . . . . . . . . . . . . . . . . 33

4.2 Dados da simulação . . . . . . . . . . . . . . . . . . . . . . . . . . . . . . . . . . 34

4.3 Máximo torque calculado . . . . . . . . . . . . . . 37

4.3.1 Influência de parâmetros com incerteza geométrica considerando $\boldsymbol{\alpha}$ constante e nulo . . . . . . . . . . . . . . . 37

4.3.2 Influência de parâmetros com incerteza geométrica considerando alfa variável . . . . . . . . . . . . . . . . . . 44 42

4.4 Diferença entre áreas sujeitas a singularidades . . . . . . . . . . . 47

5 Conclusão e considerações para trabalhos futuros $\quad 51$

$\begin{array}{llr}\text { A Tabela IT16 } & 59\end{array}$

$\begin{array}{lll}\text { B Tabela Z } & 61\end{array}$ 
1.1 IRB 360 FlexPicker: manipulador de cinemática paralela fabricado pela ABB (Bengtsson e Manager, 2013). . . . . . . . . . . . . . 2

1.2 KR 6 R700 FIVVE: manipulador de cinemática em série fabricado pela KUKA roboter $\mathrm{GmbH}$ (kuka robotics, 2015). . . . . . . . . . . . . . 2

1.3 Modelo de manipulador: $3 \underline{R R R}$ não redundante; (4) $\underline{R} R R$ com redundância de atuação; $(\underline{P}) \underline{R R R}+2 \underline{R} R R$ com redundância cinemática. . . . . . . . . . 3

2.1 Combinações possíveis de juntas de manipuladores completamente planares de cinemática paralela de três graus de liberdade com cadeias idênticas retirado de Merlet (1996). . . . . . . . . . . . . . . . . . . . . . 12

2.2 Reconfiguração do manipulador para que a trajetória seja realizada livre de singularidades (linha vermelha) retirada de Kotlarski et al. (2009). . . . . . 14

2.3 Reconfiguração do manipulador para que a trajetória seja realizada longe de áreas com precisão não aceitável (região amarela) (Kotlarski et al., 2009). 14

2.4 protótipo do manipulador planar $(\underline{\mathrm{P}}) \underline{\mathrm{R} R R}+2 \underline{R} R R$ construido por Kotlarski et al. (2011) e utilizado na sua pesquisa. . . . . . . . . . . . . 15

2.5 Número de amostras $=50$ à esquerda, e número de amostras $=10^{4}$ à direita da imagem (retirado de Donatelli e Konrath (2005)). . . . . . . . . . . . . 16

2.6 Função de densidade da posição do efetuador: Resultado analítico, na esquerda, e resultados da simulação, na direita da imagem (retirado de Rao e Bhatti (2001)). . . . . . . . . . . . . . . . . 17

2.7 Distribuição da repetibilidade da orientação do efetuador em graus (retirado de Mooring e Pack (1986)) . . . . . . . . . . . . . . . 17

3.1 Manipuladores $3 \underline{R} R R$ e seu derivado redundante $3(\underline{P}) \underline{R} R$. . . . . . . . . . 19

3.2 Modelo do manipulador $3(\mathrm{P}) \underline{R} R$. . . . . . . . . . . . . . . . 20

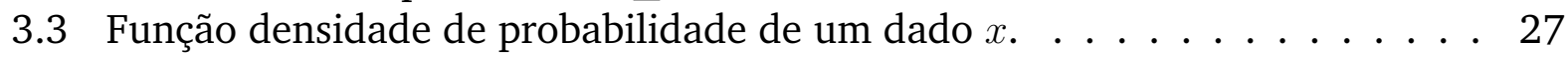

3.4 Probabilidade de $\mathrm{x}=[-\infty, \mathrm{X}]$ representada pela área em turquesa. . . . . . 27

3.5 Intervalo de confiança para $f(x)$ de $95 \%$ representada pela área em cinza. . 28

3.6 Probabilidade de $Z=[-\infty, Z]$ representada pela área em cinza. . . . . . . . 29

3.7 Intervalo de confiança para $f(Z)$ de $95 \%$ representada pela área em cinza. . 29

$4.13(\underline{\mathrm{P}}) \underline{R} R \mathrm{R}$ e a trajetória executada (vermelho) . . . . . . . . . . . 35

4.2 Função de densidade probabilidade para os possíveis comprimentos de: $\mathrm{h}$ à esquerda e dos elos à direita. . . . . . . . . . . . . . 36 
4.3 Intervalo de valores do torque necessário para realizar a trajetória para o 3RRR com alfa constante e nulo. . . . . . . . . . . . . . 38

4.4 Intervalo de valores do torque necessário para realizar a trajetória do 3(ㅁ) $\underline{R} R R$ com Otimização offline com alfa constante e nulo. . . . . . . . . . . 40

4.5 Intervalo de valores do torque necessário para realizar a trajetória do 3( $\underline{P})$ RRR com Otimização online com alfa constante e nulo. . . . . . . . . . . . 41

4.6 Intervalo de valores do torque necessário para realizar a trajetória do 3 RRR com alfa variando. . . . . . . . . . . . . . . . . . . . . . . 43

4.7 Intervalo de valores do torque necessário para realizar a trajetória do 3(P)RRR com Otimização offline com alfa variando. . . . . . . . . . . . . . . 45

4.8 Intervalo de valores do torque necessário para realizar a trajetória do 3(ㅁ)RRR com Otimização online com alfa variando. . . . . . . . . . . . 46

4.9 Áreas singulares para $A_{1}=(0.00,0.20), A_{2}=(0.17,-0.10)$ e $A_{3}=(-0.17,-0.10)$, considerando variações nos parâmetros $h, l_{1}$ e $l_{2}$. A orientação do efetuador

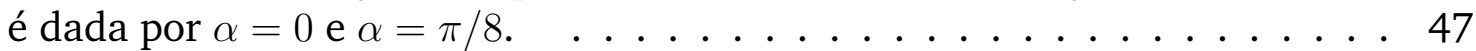

4.10 Áreas singulares para $A_{1}=(0.15,0.20), A_{2}=(0.10,-0.23)$ e $A_{3}=(-0.25,0.03)$, considerando variações nos parâmetros $h, l_{1} \mathrm{e} l_{2}$. A orientação do efetuador é dada por $\alpha=0$ e $\alpha=\pi / 8 \ldots \ldots \ldots \ldots \ldots \ldots \ldots$. . . . . . . . . . . . .

4.11 Áreas singulares para $A_{1}=(0.20,0.20), A_{2}=(0.22,-0.01)$ e $A_{3}=(-0.17,-0.10)$, considerando variações nos parâmetros $h, l_{1} \mathrm{e} l_{2}$. A orientação do efetuador é dada por $\alpha=0$ e $\alpha=\pi / 8 \ldots \ldots$. . . . . . . . . . . . . 49

4.12 Áreas singulares para $A_{1}=(0.30,0.20), A_{2}=(0.17,-0.10)$ e $A_{3}=(-0.10,-0.23)$, considerando variações nos parâmetros $h, l_{1}$ e $l_{2}$. A orientação do efetuador é dada por $\alpha=0$ e $\alpha=\pi / 8 \ldots \ldots \ldots \ldots \ldots$. . . . . . . . . 49

A.1 Tabela IT16, ISO $286-1: 2010$ (E) . . . . . . . . . . . . . . . . . . . . . 59

B.1 Retirado de http://www.ufvjm.edu.br/disciplinas/eco009/files/2012/03/TABELAdistribui\%C3\%A7\%C3\%A3o-normal.pdf. . . . . . . . . . . . . . . 61

B.2 Retirado de http://www.ufvjm.edu.br/disciplinas/eco009/files/2012/03/TABELAdistribui\%C3\%A7\%C3\%A3o-normal.pdf). . . . . . . . . . . . 62 


\section{Lista de Tabelas}

4.1 Representação dos parâmetros fixos . . . . . . . . . . . . . . . . 33

4.2 Comprimento dos elos e do parâmetro $h$ do efetuador, o valor nominal e sua respectiva variação devido à manufatura. . . . . . . . . . . . . . . 34

4.3 Tolerância e limites . . . . . . . . . . . . . . . . . . . . . . . . . . 34

4.4 Variação do valor nominal e a probabilidade entre esses valores. . . . . . . . 35

4.5 Comprimento de $h$ e dos Elos do manipulador, o valor nominal e seu respectivo limite do intervalo de valores devido a manufatura $( \pm 3 \delta) \ldots \ldots . .36$

4.6 Torque máximo (N.m), em módulo, para cada cadeia cinemática (c1, c2 ou c3) e guia linear (g1, g2 ou g3), para realizar trajetória pré-determinada considerando otimização para o parâmetro incerto, mas os valores correspondem ao comprimento nominal dos parâmetros, correspondente às linhas tracejadas dos gráficos. . . . . . . . . . . . . . . . . 37

4.7 Torque máximo (N.m), em módulo, para cada cadeia cinemática ( $\mathrm{c} 1, \mathrm{c} 2$ ou c3) e guia linear ( $\mathrm{g} 1, \mathrm{~g} 2$ ou g3), para realizar trajetória pré-determinada considerando um parâmetro incerto. . . . . . . . . . . . . . . 37

4.8 Torque máximo (N.m), em módulo, para cada cadeia cinemática (c1, c2 ou c3) e guia linear ( $\mathrm{g} 1, \mathrm{~g} 2$ ou g3), para realizar trajetória pré-determinada considerando otimização para o parâmetro incerto, mas os valores correspondem ao comprimento nominal dos parâmetros. . . . . . . . . . . . . 42

4.9 Torque máximo (N.m), em módulo, requerido por cada cadeia cinemática (c1, c2 ou c3) e guia linear ( $\mathrm{g} 1, \mathrm{~g} 2$ ou g3), para realizar trajetória prédeterminada considerando um parâmetro incerto. . . . . . . . . . . . . . 42 


\subsection{Contextualização}

Manipuladores de cinemática paralela (PKMs, Parallel kinematic manipulators) tem atraído atenção da comunidade acadêmica e industrial devido as suas vantagens em relação aos de arquitetura serial. Dentre essas vantagens, pode ser mencionada a leveza, a capacidade de alcançar alta aceleração/velocidade, a rigidez e capacidade de carga (Merlet, 1996). Clavel (1988) foi pioneiro no estudo de manipuladores paralelos com capacidade de velocidades mais elevadas. A aplicação mais promissora na área industrial a essa arquitetura, é a tarefa de pega-e-põe na área alimentícia, farmacêutica e indústrias eletrônicas (da Silva et al., 2010; da Silva e Gonçalves, 2013).

Manipuladores paralelos são caracterizados por suas cadeias cinemáticas fechadas. Em outras palavras, dada a base do manipulador, pode-se chegar ao efetuador por mais de um caminho através de cadeias cinemáticas distintas (Donelan, 2007). A consequência dessa arquitetura são suas interessantes características já citadas. A Fig. 1.1 ilustra um manipulador industrial de três cadeias cinemáticas paralelas fabricado pela ABB (Bengtsson e Manager, 2013).

Apesar de características vantajosas, o manipulador de cinemática paralela também possui características indesejadas, tais como: baixa relação da área de trabalho em comparação com a área de montagem do manipulador e a presença de singularidades. Apresentando singularidades, dificulta o cumprimento de determinadas tarefas e trajetórias em seu espaço de trabalho, causando instabilidade e erros. 


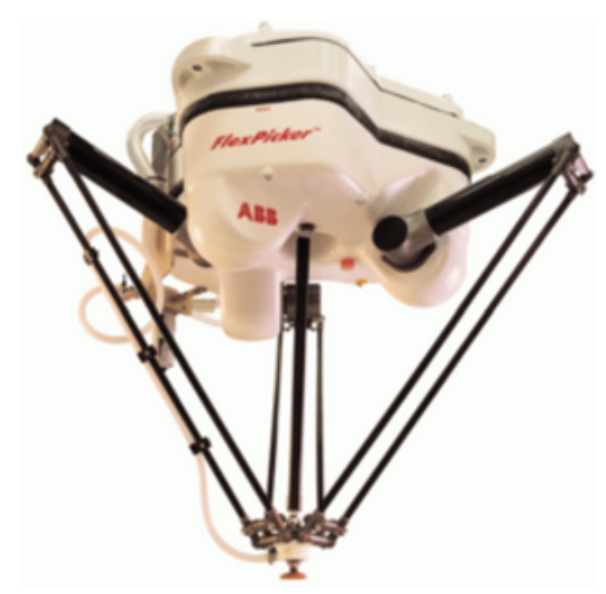

Figura 1.1: IRB 360 FlexPicker: manipulador de cinemática paralela fabricado pela ABB (Bengtsson e Manager, 2013).

Já manipuladores de cinemática em série têm seus componentes conectados de forma serial da base até o efetuador, e por esse fato tem-se maior área de trabalho. A Fig. 1.2 ilustra um manipulador serial com seis motores e uma cadeia cinemática.

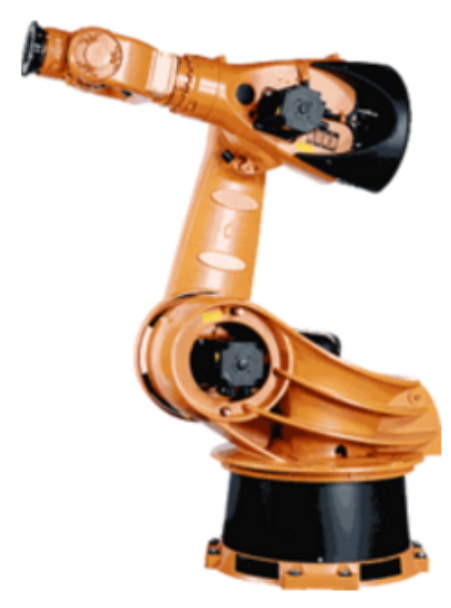

Figura 1.2: KR 6 R700 FIVVE: manipulador de cinemática em série fabricado pela KUKA roboter $\mathrm{GmbH}$ (kuka robotics, 2015).

Pelo fato das singularidades terem grande influência na cinemática e dinâmica dos manipuladores paralelos, alternativas para a sua redução ou remoção devem ser investigadas. Uma alternativa é o uso de redundância como um meio para conseguir uma melhora no desempenho desses manipuladores (Fontes et al., 2014). Essa alternativa faz com que as regiões de singularidade dos manipuladores sejam reduzidas ou evitadas. Como as singularidades tem efeitos diretos na cinemática e dinâmica dos manipuladores, esse conceito deve ser tratado com grande importância. Com isso, Merlet (1996) dividiu esse conceito de redundância em três tipos: 
- Redundância de medidas: ocorre quando se obtem mais medidas de dados sobre o manipulador do que grau de liberdade do efetuador;

- Redundância de atuação: ocorre quando há mais cadeias cinemáticas no manipulador se comparado ao número de graus de liberdade do efetuador;

- Redundância cinemática: ocorre quando há introdução de pelo menos uma junta ativa em uma cadeia cinemática, possibilitando múltiplas opções tanto nos esforços dos atuadores quando no posicionamento do mecanismo, e consequentemente habilita o mecanismo a novas configurações evitando as singularidades.

A Fig. 1.3 mostra as mudanças no manipulador 3RRR por meio da adição de redundância de atuação e cinemática. Esse manipulador é composto por três (3) cadeias cinemáticas contendo três juntas de revolução cada (RRR). A letra sublinhada ( $\underline{R})$ destaca a junta ativa. O efetuador do manipulador apresenta três graus de liberdade (dois de translação e um de rotação). Na Fig. 1.3 também estão representados um manipulador com redundância de atuação, 4RRR, com quatro (4) cadeias cinemáticas e três juntas de revolução em cada. Já a redundância cinemática é representada pelo $(\underline{P}) \underline{R} R R+2 \underline{R} R R$, que adiciona uma junta prismática ativa (P) em uma cadeia cinemática do $3 \underline{R} R R$.
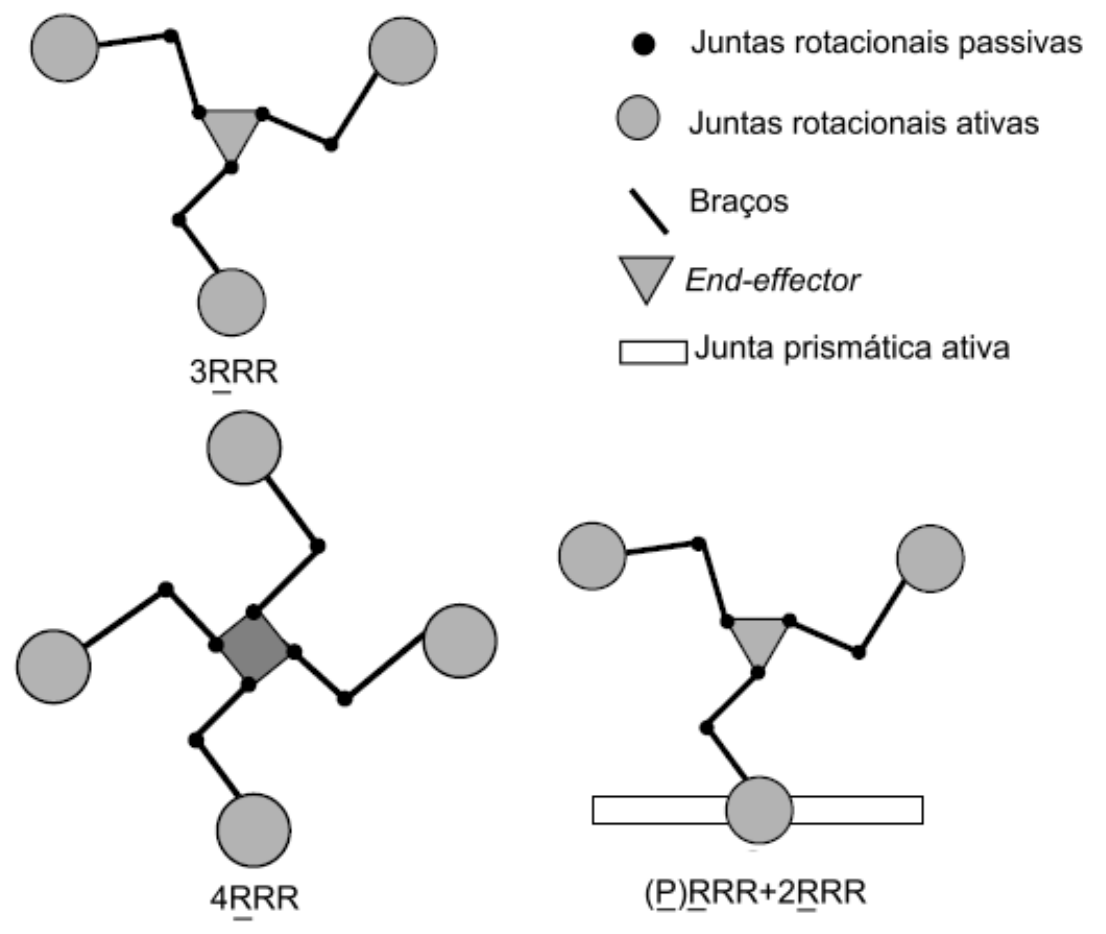

Figura 1.3: Modelo de manipulador: $3 \underline{R} R R$ não redundante; (4) $\underline{R} R R$ com redundância de atuação; $(\underline{P}) \underline{R R R}+2 \underline{R R R}$ com redundância cinemática.

A redundância pode melhorar o desempenho das PKMs. Além disso, Kotlarski et al. (2009) demonstram como esse tipo de manipulador pode se reconfigurar (devido ao grau 
de liberdade a mais no sistema) evitando as regiões de singularidade, antes presente em sua trajetória.

Kotlarski et al. (2008, 2010, 2011) propuzeram métodos de otimização para manipuladores cinematicamente redundantes. A otimização offline é feita de modo que o manipulador reconfigure sua cadeia redundante antes do movimento do efetuador. Enquanto a otimização online é feita com o atuador da cadeia redundante se movendo ao mesmo tempo em que o efetuador se movimenta. Com os resultados numéricos, foi concluído que redundância cinemática melhora o desempenho do manipulador.

Fontes et al. (2014) fizeram um estudo comparativo do $3 \underline{R} R R$ variando as configurações cinematicamente redundantes e com redundância de atuação. Nesse estudo foi feita uma estratégia de otimização para os atuadores funcionarem em alto desempenho dinâmico. E foi concluído que a redundância cinemática é capaz de se adaptar e pode cumprir a tarefa desejada. Portanto os resultados mostraram que a redundância cinemática pode aumenta o desempenho dinâmico do manipulador.

Müller (2010) estudou o efeito de parâmetros geométricos incertos no controle de PKM com redundância de atuação. Com o estudo feito, concluiu-se que as forças de perturbação, causadas pela incerteza geométrica não podem ser compensadas pelos atuadores. Para superar esse efeito, o artigo indica o necessidade do uso de um controle robusto, no caso de um PKM de atuação redundante com parâmetros geométricos incertos.

Em relação ao desempenho de PKMs, as dispersões de alguns parâmetros podem ter um impacto enorme. Desta forma, estes parâmetros devem ser claramente identificados. Os parâmetros mais relevantes devem ser cuidadosamente escolhidos e manufaturados de forma a evitar problemas indesejados sobre a precisão e desempenho em relação cinemática e dinâmica do sistema robótico em estudo. Por esta razão, é importante investigar a sensibilidade no desempenho do mecanismo em relação às suas propriedades geométricas e dinâmicas (Caro et al., 2009).

Fatores que corroboram com o surgimento de incerteza são dados pelas tolerâncias de manufatura e montagem assim como desvios nos atuadores e controladores. Incerteza nas posições e direções do efetuador do manipulador podem ser originadas por várias fontes, entre elas estão: tolerância nas juntas do atuador e controlador, erros na manufatura e montagem, diferentes tipos de medidas (paquímetro e laser, por exemplo) e erros de controle e erros não geométricos como deformações elásticas nos componentes do robô. $\mathrm{E}$ o efeito dessa incerteza deve ser analizado com muito cuidado para obter uma visão clara no que se refere a performance do manipulador (Wu e Rao, 2007).

Binaud et al. (2011) avaliaram a sensibilidade da plataforma móvel do 3RPRR considerando seus parâmetros geométricos sujeitos a variabilidade. Com a introdução de índices de sensibilidade, que caracterizam a sensibilidade intrínseca da plataforma móvel à variação dos parâmetros, os manipuladores puderam ser avaliados em seu espaço de trabalho. 
Os valores dos índices indicam se há amplificação de erro causado pela variação dos parâmetros, mas os valores permaneceram sempre inferiores a um, e isso significa que não há amplificação dos erros devido à variação dos parâmetros geométricos nesse manipulador em estudo.

Um estudo similar foi feito por Caro et al. (2009). Neste trabalho há uma análise da sensibilidade do 3RPR com variações na geometria e em sua atuação, e há uma comparação entre essas variações na configuração de atuação. São determinados dois índices agregados de sensibilidade, um relacionado à orientação da plataforma móvel do manipulador e outra relacionada à sua posição. É feita uma metodologia para comparar os 3RPR com variações de atuação no que diz respeito à destreza, tamanho da área de trabalho e sensibilidade do manipulador. Os resultados apresentados mostraram diferença entre a sensibilidade comparando as diferentes variações na configuração de atuação e isso deve ajudar no projeto de manipuladores 3RPR no seu estágio conceitual.

Tannous et al. (2014) fizeram uma análise da sensibilidade do $3 \underline{R} R R$ às variações de parâmetros geométricos usando um método de linearização de intervalos. Para o estudo dessa influência, foi usada a análise de intervalos, um método numérico muito poderoso que permite a resolução de uma vasta gama de problemas, de resolução de sistemas até a otimização global (Merlet, 2011).

Em análise de intervalos, o parâmetro incerto é denotado por uma faixa de valores, e a resposta também é quantificada como um intervalo de valores (Wu e Rao, 2007). Por se tratar de uma gama de valores, a análise de intervalos é bastante usada em estudos de incerteza em juntas sujeitas a folga e entradas incertas(Chen et al., 2013; Tsai e Lai, 2004, 2008).

Além disso, a análise de intervalo tem sido utilizada para estudar os efeitos de tais variabilidades no desempenho da cinemática e dinâmica de manipuladores. A finalidade dessa técnica é determinar limites garantidos de mínimo e máximo de uma dada função com incógnitas consideradas intervalos (Merlet, 2011).

Dependendo da natureza da incerteza presente, a análise do sistema pode ser conduzido utilizando análise de intervalos, teoria fuzzy ou uma abordagem probabilistica. Dessa forma, dependendo da maneira em que a informação sobre a variável é passada, a forma de estudo mais conveniente deve ser a adotada (Wu e Rao, 2007).

Variações na geometria podem ser tratadas como incerteza física, e essa incerteza é dependente de observação física, que pode ser descrito em termos de distribuições de probabilidades (Noh et al., 2011). Probabilidade esta, que pode ser relacionada com a tolerância de manufatura de componentes robóticos, por exemplo.

Ramsli (1988) mostrou que a repetibilidade para a realização de tarefas de robôs industriais, se consideradas pelo menos 100 amostras, alguns dos casos estudados podem ser aproximadas da distribuição normal de probabilidade. 
Kluz e Trzepieciński (2014); Rao e Bhatti (2001) fizeram estudos onde chegaram a conclusão que a precisão e repetibilidade de robôs industriais podem ser aproximados a uma distribuição normal quando calculada a probabilidade do evento.

A fim de garantir precisão no posicionamento e orientação do efetuador do robô assim como reduzir o custo na manufatura do mesmo, é necessário quantificar a influência do fator de incerteza e optimamente alocar as tolerâncias (Wu e Rao, 2007).

Essa revisão foi feita com o foco em estudos que mostraram manipuladores redundantes e também com seus componentes sendo variados. Com isso, podemos definir uma base de conhecimento para auxiliar nesse trabalho. E percebe-se que não há trabalhos que mensuram o impacto da variação dos parâmetros na dinâmica e cinemática do manipulador.

\subsection{Objetivos}

O estudo da dinâmica e cinemática do manipulador $3(\underline{P}) \underline{R} R R$ considerando os elos e efetuador com incerteza geométrica, mostrou que os picos de torque nas juntas do manipulador são alterados devido a essa incerteza. E também mostrou que essa mesma variabilidade geométrica gera diferença entre as áreas de singularidades, assim como alterações na posição das juntas e orientação do efetuador também causa diferença entre essas áreas.

Tendo em vista a revisão bibliográfica feita, não foram encontrados estudos sobre o impacto da variabilidade geométrica dos componentes sobre o torque aplicado nas juntas ativas para uma mesma tarefa. Assim, são comparados os diferentes picos de torque nas juntas ativas do manipulador causados pelas variações dos parâmetros.

Portanto, os sequintes objetivos foram propostos para este projeto de mestrado:

- Modelar e simular cinemática e dinamicamente o manipulador $3 \underline{R R R}$, e seu derivado cinematicamente redundante, o $3(\underline{P}) \underline{R R R}$;

- Avaliar essa modelagem por meio de simulações considerando variabilidade geométrica dos componentes do manipulador;

- Mensurar e comparar qual dos componentes interfere mais no torque considerando variação geométrica;

- Realizar otimização online e offline (Kotlarski et al., 2009) para as posições das guias lineares, para obter melhor desempenho dinâmico;

- Mensurar o pico de torque considerando todos componentes nominais e comparar com os respectivos torques máximos devido às variações geométricas;

- E comparar a diferença nas regiões de singularidades para variações em $l_{1}, l_{2}$ e nas dimensões do efetuador. 


\subsection{Estrutura do texto}

Esta pesquisa está organizada da seguinte maneira:

- O capítulo 2 apresenta uma revisão dos conceitos de manipuladores robóticos e do uso da estatística na engenharia;

- O capítulo 3 apresenta mais detalhadamente a metodologia da pesquisa e a modelagem cinemática e dinâmica dos manipuladores em estudo;

- O capítulo 4 apresenta os resultados obtidos de simulações de algumas tarefas prédeterminadas;

- O capítulo 5 apresenta as conclusões deste trabalho com base nos resultados numéricos, sugestões para trabalhos futuros. 



\section{Revisão de literatura e conceitos}

\subsection{Informações iniciais}

Neste capítulo são apresentadas definições e características do manipulador planar de cinemática paralela que é o foco deste trabalho. Por se tratar de um manipulador paralelo, que possui cadeias cinemáticas fechadas e consequentemente têm seu movimento mais restrito, a modelagem cinemática é mais complicada se comparado aos manipuladores em série. Além disso, erros na manufatura dos componentes do manipulador são considerados. Um estudo probabilistico desse erro é proposto.

\subsection{Manipuladores robóticos}

\subsubsection{Manipuladores paralelos: definição e características}

Manipuladores paralelos são definidos por Merlet (1996) como sendo um sistema robótico de cadeia fechada cujo efetuador é ligado à base por mais de uma cadeia cinemática. Mas essa definição abrange muitas possibilidades de configurações para o manipulador. E com isso, algumas características desejadas para o manipulador em estudo são especificadas a seguir:

- O efetuador é sustentado por no mínimo duas cadeias cinemáticas;

- Cada uma das cadeias cinemáticas contém no mínimo um atuador e um sensor; 
- Quando travados os atuadores, o grau de liberdade do sistema vai para zero, implicando em uma posição nominal constante, independente do carregamento aplicado sobre o sistema.

Em relação a manipuladores paralelos não redundantes, algumas características são notáveis:

- O número de atuadores e sensores devem ser iguais ao número de graus de liberdade do efetuador;

- Consequentemente o número de atuadores e sensores é mínimo (um de ambos em cada cadeia);

- Duas cadeias cinemáticas já permitem a distribuição de carga.

Como consequência dessas características supracitadas, esse mecanismo obtém as qualidades desejadas para o uso prático, tais como:

- Carregamento dividido entre suas cadeias ligadas ao efetuador;

- Devido a sua configuração característica, há uma melhora na rigidez do sistema;

- Como há um atuador em cada cadeia (manipuladores não redundantes), a carga inercial móvel é reduzida, pois os atuadores necessitam mover apenas os braços, juntas e efetuador.

Manipuladores paralelos podem ser caracterizados de duas maneiras, diferenciados pelo seu movimento. E esses dois tipos são os manipuladores planares e os espaciais. Os manipuladores planares têm no máximo três graus de liberdade no plano (dois de translação e um de rotação), já os manipuladores espaciais podem ter no máximo seis graus de liberdade (três de translação e três de rotação). Nesse trabalho será utilizado o manipulador paralelo planar com três graus de liberdade. Completando a definição de manipuladores, tem-se a fórmula de Grübler que formaliza matematicamente o número de corpos necessários para o manipulador atingir uma mobilidade em todos os seus graus de liberdade, e essa equação (Merlet, 1996) é dada por:

$$
G l=3(c-1-j)+\sum_{i=1}^{j} g_{i}
$$

onde $G l$ é o número de graus de liberdade do efetuador, $c$ é o número total de corpos, incluindo a base, $j$ é o número total de juntas e $g_{i}$ é o número de graus de liberdade da junta $i$. 
Sabendo que o manipulador em estudo possui três graus de liberdade ( $G l=3$ ), pelas definições de manipulador não redundante e assumindo que suas cadeias cinemáticas são idênticas, $\operatorname{com} c_{r}$ sendo o número de corpos rígidos de cada cadeia, e $j_{c}$ o número de juntas independentes por cadeia, temos que:

$$
\begin{gathered}
c=2+3 c_{r} \\
j_{c}=\left(c_{r}+1\right) \\
j=3\left(j_{c}\right) \\
\sum_{i=1}^{j} g_{i}=1 j=3\left(c_{r}+1\right)
\end{gathered}
$$

Substituindo esses valores na Eq. 2.1, temos:

$$
\begin{gathered}
3=-6+3\left(c_{r}+1\right) \\
c_{r}=2 \quad j_{c}=3 \quad j=9
\end{gathered}
$$

Com isso, conclui-se que cada cadeia cinemática idêntica do manipulador possui dois corpos rígidos cada $\left(c_{r}=2\right)$ e três juntas independentes $\left(c_{r}+1\right)$. Com esses valores encontrados, pode-se definir o índice de paralelismo $d$ do manipulador, definido por (Earl e Rooney, 1983) como:

$$
d=\frac{k}{G l-1}
$$

Onde $k$ é a diferença entre o número total de juntas $(j=9)$ e a quantidade de corpos em movimento $\left(3 c_{r}+1\right.$ (efetuador $\left.)=7\right)$, e $G l=3$ é o número de graus de liberdade do sistema. $\mathrm{O}$ índice varia entre 0 e 1 , sendo o valor 0 para manipuladores em série e 1 para manipuladores completamente paralelos, e o resultado com os valores encontrados é de $d=1$ comprovando a definição de manipuladores completamente paralelos.

Tomando como base manipuladores planares não redundante de três graus de liberdade, considerando dois graus translacionais e um rotacional, pela equação de Grübler temos que esse sistema deve conter uma plataforma ligada a três cadeias cinemáticas e cada cadeia com dois corpos rígidos e três juntas, sendo uma dessas ativa.

Tendo isso como base e sabendo que em manipuladores planares podem ser usadas as juntas de revolução ou prismáticas, representadas por $\mathrm{R}$ e $\mathrm{P}$ respectivamente, conclui-se que as combinações desses tipos de juntas em trios formam manipuladores que contemplam as especificações desejadas. Como o efetuador do manipulador tem três graus de liberdade, sendo dois translacionais e um rotacional, consequentemente a combinação 
de juntas que não proporcionam o movimento rotacional é 3PPP, pois possibilita apenas movimento de translação.

Com isso, todas as outras combinações de juntas possíveis podem formar um manipulador completamente planar de cinemática paralela não redundante de cadeias idênticas, e essas configurações são dadas por: 3RRR, 3RPR, 3RRP, 3RPP, 3PRR, 3PPR e 3PRP (Fig. 2.1). Não há identificação da junta ativa desses manipuladores pelo fato de representarem apenas as possíveis combinações, e a atuação pode ser variada, dependendo de como o manipulador é estudado.

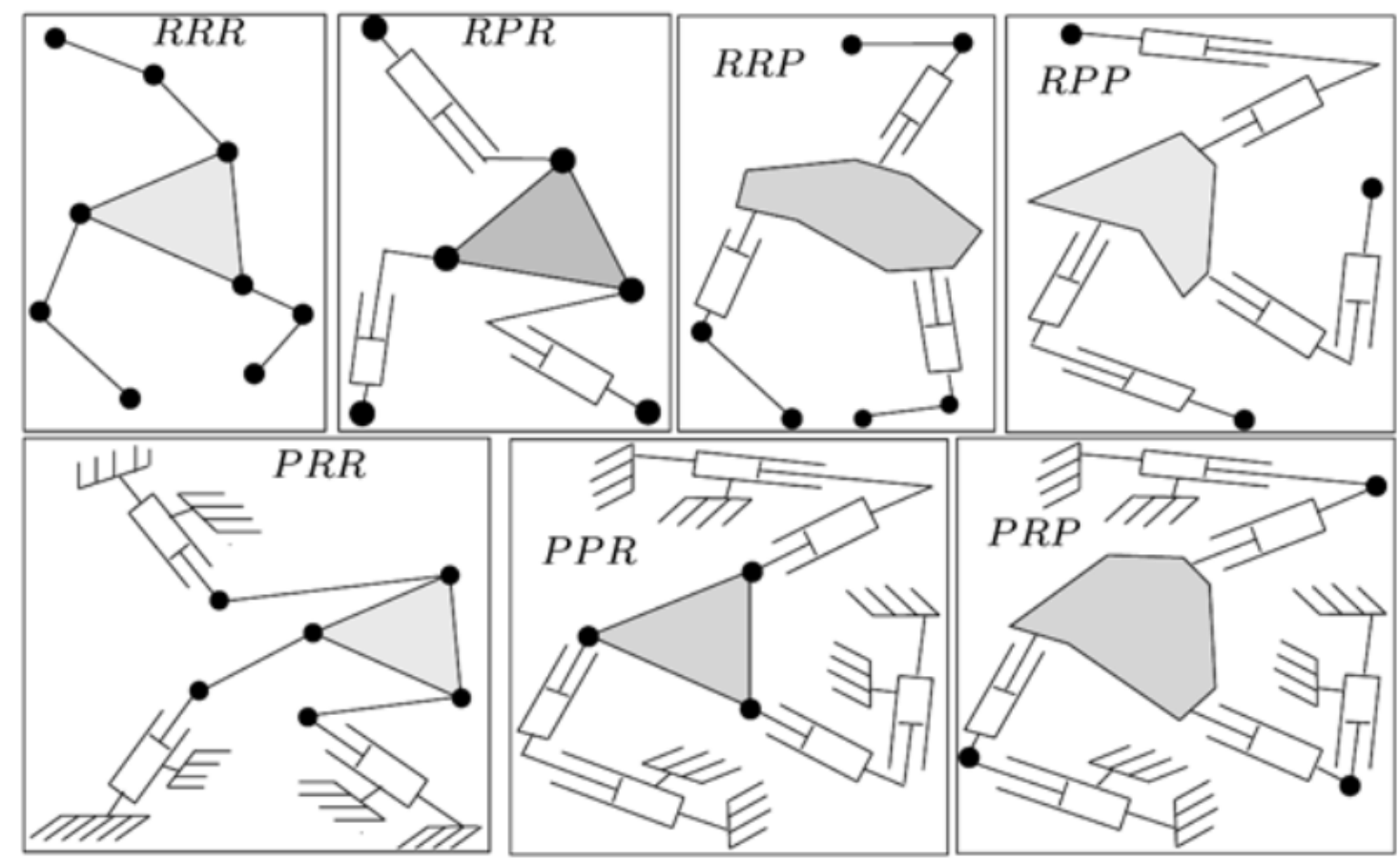

Figura 2.1: Combinações possíveis de juntas de manipuladores completamente planares de cinemática paralela de três graus de liberdade com cadeias idênticas retirado de Merlet (1996).

\subsubsection{Singularidades}

Singularidade na robótica paralela é dada quando há uma perda na rigidez própria do manipulador se comparado com configurações não singulares. Gosselin e Angeles (1990) apresentaram três tipos de classificações para singularidade, mas para isso eles primeiramente fizeram certas considerações a respeito do manipulador. Considere um manipulador com $n$ atuadores e $m$ graus de liberdade, $\Theta$ o vetor de variáveis de entrada e $\mathbf{X}$ o vetor de variáveis de saída. Caso o número de atuadores seja igual ao número do grau de liberdade, a dimensão de $\boldsymbol{\Theta}$ e $\mathbf{X}$ será a mesma, $n$. Essa relação pode ser dada considerando a função $F$, representada por: 


$$
F(\Theta, \mathbf{X})=\mathbf{0}
$$

onde 0 é o vetor de zeros com dimensão $n$.

No entanto, uma maneira de avaliar essas singularidades é calcular a relação entre as velocidades de entrada e saída do sistema, dada pela derivada da função $f$ :

$$
\mathbf{A} \dot{\mathbf{X}}+\mathbf{B} \dot{\Theta}=0
$$

onde $\mathbf{A}(\boldsymbol{\Theta}, \mathbf{X})$ e $\mathbf{B}(\boldsymbol{\Theta}, \mathbf{X})$ são matrizes $n \times n$ chamadas jacobianas. Com isso, a classificação apresentada por (Gosselin e Angeles, 1990) acontece quando a matriz A ou B é singular, em outras palavras, o determinante de alguma delas é zero ou de ambas. Com isso, podemos definir os três tipos de singularidades:

\section{1. $\operatorname{det}(\mathbf{B})=0$}

Esse tipo de singularidade é dado quando o efetuador está na fronteira da área de trabalho ou fronteira interna que limitam sub-regiões da área de trabalho, chamadas deadpoint. Esses deadpoints são pontos onde a cinemática inversa não pode ser determinada.

2. $\operatorname{det}(\mathbf{A})=0$

Já esse tipo de singularidade é dado quando um dos atuadores está em um deadpoint. Isso ocorre quando os atuadores estão fixados em determinada posição, mas o efetuador é localmente móvel. E isso ocorre dentro da área de trabalho, pois o problema se encontra na cinemática direta.

3. $\operatorname{det}(\mathbf{B})=0$ e $\operatorname{det}(\mathbf{A})=0$

Esse caso exige condições especiais sobre os parâmetros do braço do manipulador, pois isso ocorre para certas configurações onde A e B são simultaneamente singulares. Para isso acontecer é preciso que a cadeia cinemática chegue a uma posição onde o efetuador não chegaria de acordo com a Eq. 2.9 e, além disso, nessa mesma posição o efetuador deve ser localmente móvel mesmo com os atuadores fixos.

\subsubsection{Redundância Cinemática}

Manipuladores robóticos são propícios a sofrerem de singularidades na área de trabalho, e a redundância se mostra eficaz para minimizar ou até solucionar esse problema. Além disso, esta aplicação pode ser usada para conseguir outros objetivos. As pesquisas de Rocha e da Silva (2013), Fontes et al. (2014), entre outras, indicam que a redundância melhora o desempenho dinâmico de um manipulador. 
Nesse trabalho é estudado o manipulador planar de cinemática paralela com redundância cinemática. Uma característica importante desse tipo de manipulador é mostrado por Kotlarski et al. (2009), comparando o manipulador $3 \underline{R} R R$ com (P) $\underline{R} R R+2 \underline{R} R R$, onde este último, por se tratar de um manipulador cinematicamente redundante, pode reconfigurar a posição de uma junta ativa e assim desviar sua trajetória da singularidade que antes era um obstáculo (Fig. 2.2).
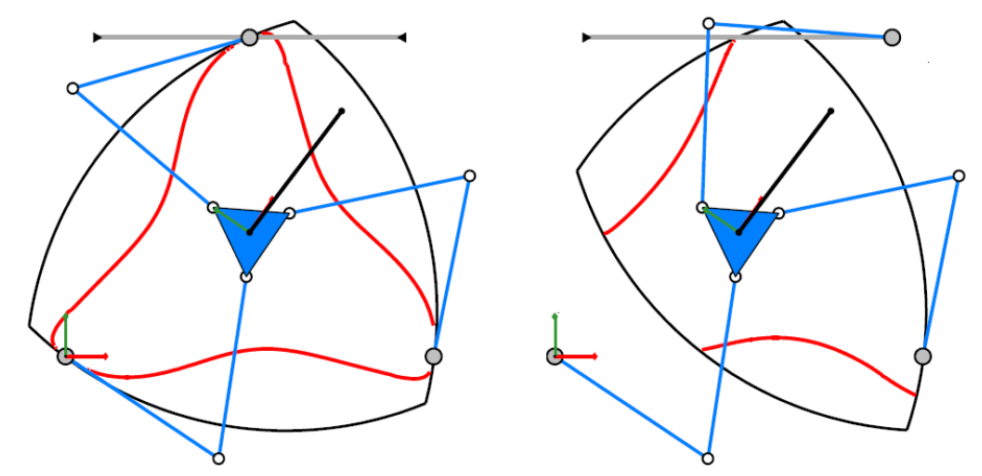

Figura 2.2: Reconfiguração do manipulador para que a trajetória seja realizada livre de singularidades (linha vermelha) retirada de Kotlarski et al. (2009).

Outra análise feita por Kotlarski et al. (2009) foi em relação à área de trabalho com precisão aceitável (Fig. 2.3), onde posições com precisão não aceitáveis estão representadas na cor amarela, e estas posições estão presentes em regiões próximas as singularidades.
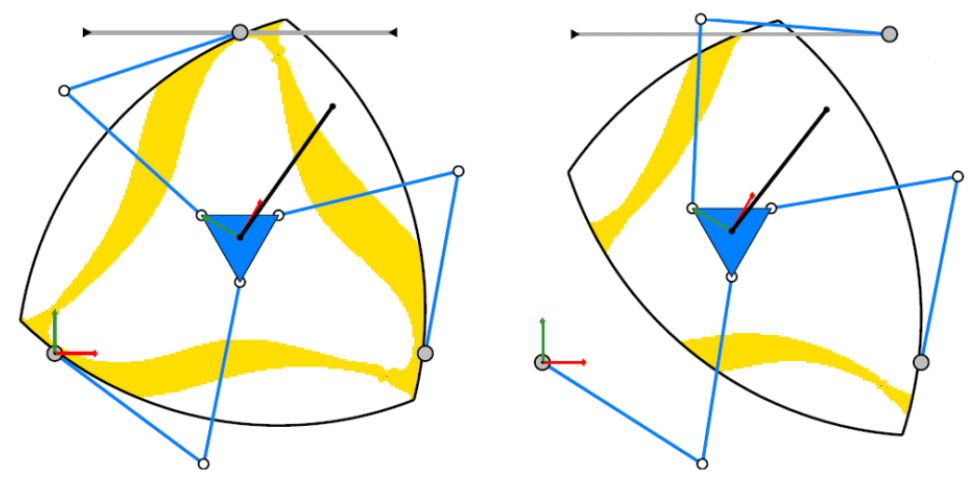

Figura 2.3: Reconfiguração do manipulador para que a trajetória seja realizada longe de áreas com precisão não aceitável (região amarela) (Kotlarski et al., 2009).

Fontes et al. (2014) fizeram um estudo teórico que comparou um manipulador $3 \underline{R} R R$ com suas derivações redundantes, acrescentando 1, 2 ou 3 guias lineares no mecanismo. E foi concluido que o torque máximo diminui em até $66 \%$. Mostrando que quando feita uma otimização bem elaborada do posicionamento das juntas ativas do manipulador redundante, este apresenta melhor desempenho dinâmico. 
Kotlarski et al. (2011) fizeram um estudo com um protótipo do (P)RRR + 2RRR (Fig. 2.4), e para fazer uma otimização na posição do atuador, baseou-se no máximo valor do determinante da matriz Jacobiana $\operatorname{det} \mathbf{A}$. E com os resultados encontrados provou-se há vantagens em empregar redundância cinemática.

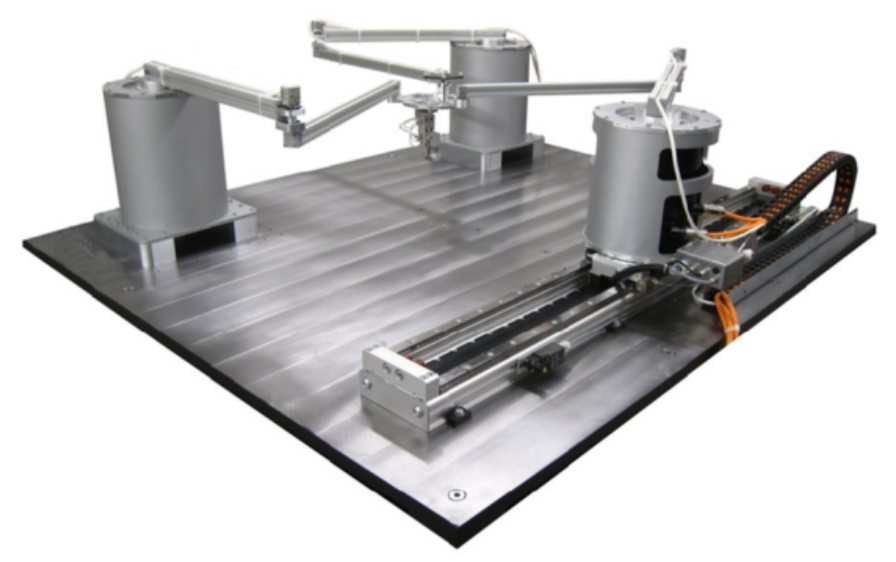

Figura 2.4: protótipo do manipulador planar $(\underline{P}) \underline{R} R R+2 \underline{R} R R$ construido por Kotlarski et al. (2011) e utilizado na sua pesquisa.

\subsection{Estatística na Engenharia}

Conceitos e métodos estatísticos não são apenas úteis, mas na verdade, muitas vezes indispensáveis na compreensão do mundo que nos rodeia. Eles fornecem maneiras de ganhar novas visões sobre o comportamento de muitos fenômenos que encontramos na área escolhida de especialização em engenharia ou ciência (Devore, 2015).

Com a estatística pode-se fazer julgamentos inteligentes e decisões informadas na presença de incertezas e variações. Incerteza física pode ser descrita em termos de distribuição de probabilidades, decorrente da observação física da aleatoriedade referente (Noh et al., 2011). Essas variações e incertezas motivam o uso da estatística, com o objetivo de conseguir algum padrão referente aos dados em estudo (Devore, 2015).

A precisão com que um robô industrial traz a carga para uma posição e mantém esse estado é talvez a mais importante característica de um robô industrial (Ramsli, 1988). Um método comum para a caracterização de um robô industrial é a capacidade para voltar a uma posição, e utiliza-se os termos "precisão"e "repetibilidade", onde a precisão caracteriza o grau para o qual o valor real medido corresponde a um valor ordenado e a repetibilidade é o grau de concordância entre os valores medidos repetidas vezes, sob as mesmas condições, para o mesmo valor ordenado (definições ISO).

Muitos desses métodos de calcular a precisão e repetibilidade se assimilam, pois podem ser aproximados a uma distribuição normal quando calculada a probabilidade (Ramsli, 
1988; Kluz e Trzepieciński, 2014; Rao e Bhatti, 2001). A exatidão dessa aproximação depende da repetibilidade do mecanismo que pode ser representada por uma distribuição gaussiana de probabilidades.

Para essa aproximação de dados coletados à uma distribuição normal, a informação colhida é fortemente afetada com a redução do tamanho amostral. O ruído amostral é intensificado e há redução significativa na amplitude de valores quando se trabalha com amostras de tamanho reduzido. E consequentemente isso afeta a tentativa de definir com mais exatidão os valores variáveis correspondentes a dada probabilidade (Donatelli e Konrath, 2005). Na Fig. 2.5 uma distribuição empírica foi obtida por geração de números aleatórios para uma distribuição normal (com média $=10$ e desvio padrão $=1$ ) com distintos tamanhos amostrais.
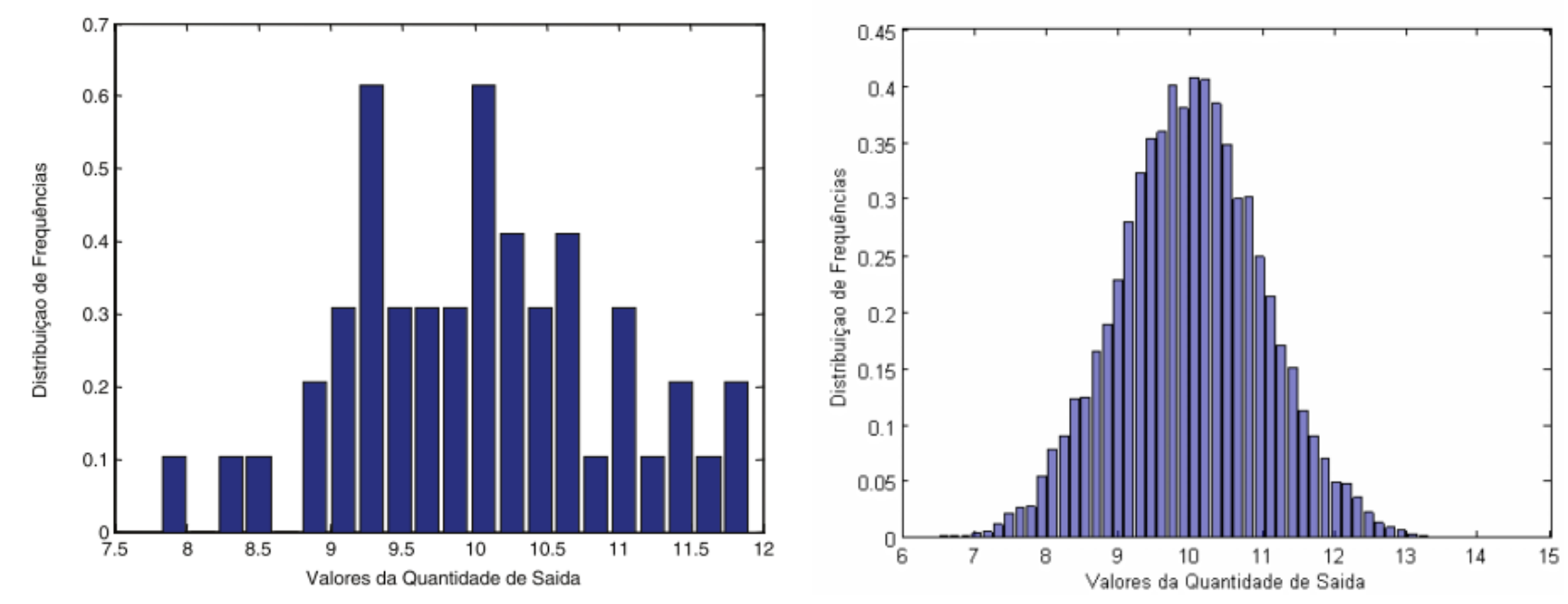

Figura 2.5: Número de amostras $=50$ à esquerda, e número de amostras $=10^{4}$ à direita da imagem (retirado de Donatelli e Konrath (2005)).

Rao e Bhatti (2001) fizeram um estudo sobre a incerteza na análise de manipuladores causadas pela tolerância de fabricação e operações de montagem e os erros nas juntas atuantes e controladores. Nesse estudo é comparada a função de densidade da posição do efetuador pelo método analítico com o numérico (Fig. 2.6). Essa simulação foi feita com 10000 experimentos. E os resultados numéricos encontrados para o manipulador planar de 2 elos tem grande confiabilidade quando comparado com os resultados teóricos.

Além de repetibilidade na posição, uma consideração importante que deve ser feita é a repetibilidade de orientação do efetuador. E Mooring e Pack (1986) mostraram em sua pesquisa que a orientação também segue uma distribuição normal de probabilidades (Fig. 2.7) 



Figura 2.6: Função de densidade da posição do efetuador: Resultado analítico, na esquerda, e resultados da simulação, na direita da imagem (retirado de Rao e Bhatti (2001)).

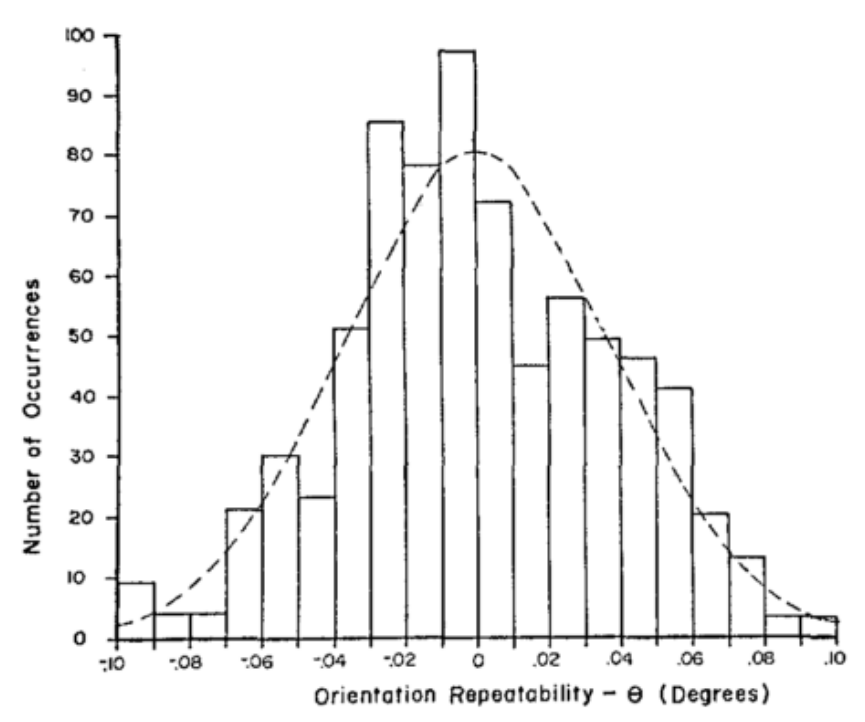

Figura 2.7: Distribuição da repetibilidade da orientação do efetuador em graus (retirado de Mooring e Pack (1986)).

\subsection{Considerações Finais}

Nesse capítulo foi apresentado uma revisão de literatura sobre manipuladores robóticos e o uso de métodos probabilisticos na engenharia. Uma visão geral do assunto foi abordada por meio de trabalhos relacionados à pesquisa para servir como base para este estudo. 



\section{3}

Metodologia e Modelagem

\subsection{Considerações iniciais}

Nesse trabalho, são adicionadas redundâncias cinemáticas no manipulador planar de cinemática paralela $3 \underline{R} R R$. Com isso cada cadeia cinemática recebe uma junta prismática ativa $\underline{P}$, resultando 3(P)RRR (Fig. 3.1). Como consequência dessa adição de graus de liberdade do sistema, o problema da cinemática inversa apresenta infinitas soluções. E a solução mais adequada pode ser encontrada por meio de um problema de otimização. E esse manipulador é avaliado considerando parâmetros geométricos com prováveis erros devido a manufatura.
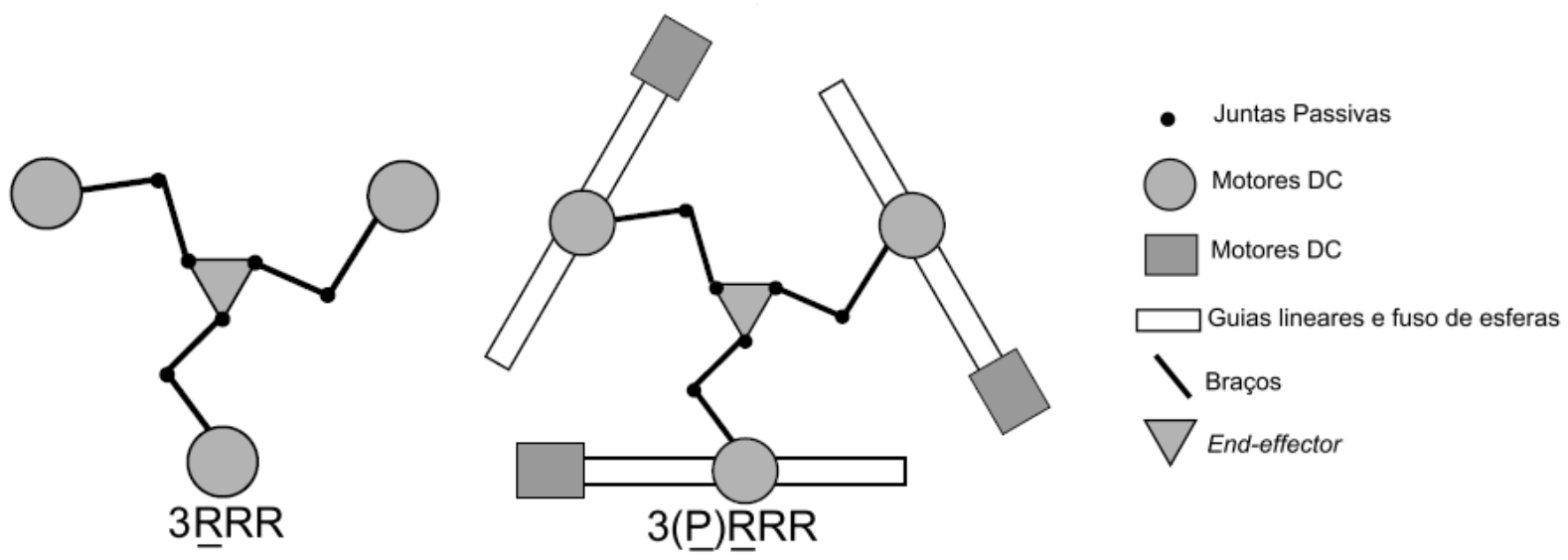

Figura 3.1: Manipuladores 3RRR e seu derivado redundante 3(P)RRR. 


\subsection{Análise Cinemática}

\subsubsection{Cinemática inversa}

A cinemática inversa se caracteriza na determinação das posições das juntas dada uma posição do efetuador. Com esse intuito, relações geométricas são determinadas a partir de parâmetros conhecidos, tais como o tamanho do efetuador e o comprimento dos elos $\mathrm{AB}$ e $\mathrm{CB}$, representados respectivamente por $l_{1}$ e $l_{2}$. O efetuador é feito de uma forma triangular, com ângulos iguais entre os seus lados e a distância entre um de seus vértices $\left(C_{i}\right)$ até o seu centroide é dado por $h$. Para manter uma simetria, as posições das juntas ativas $\left(A_{i}\right)$ quando $\delta_{i}=0$, representada por $A_{x_{0 i}}$ e $A_{y_{0 i}}$, formam um triângulo equilátero. Onde $\delta_{i}$ é a posição da junta ativa da respectiva guia linear. $B_{i}$ é a posição da primeira junta passiva da cadeia cinemática $i=1,2$ ou 3 (Fig. 3.2(a)).

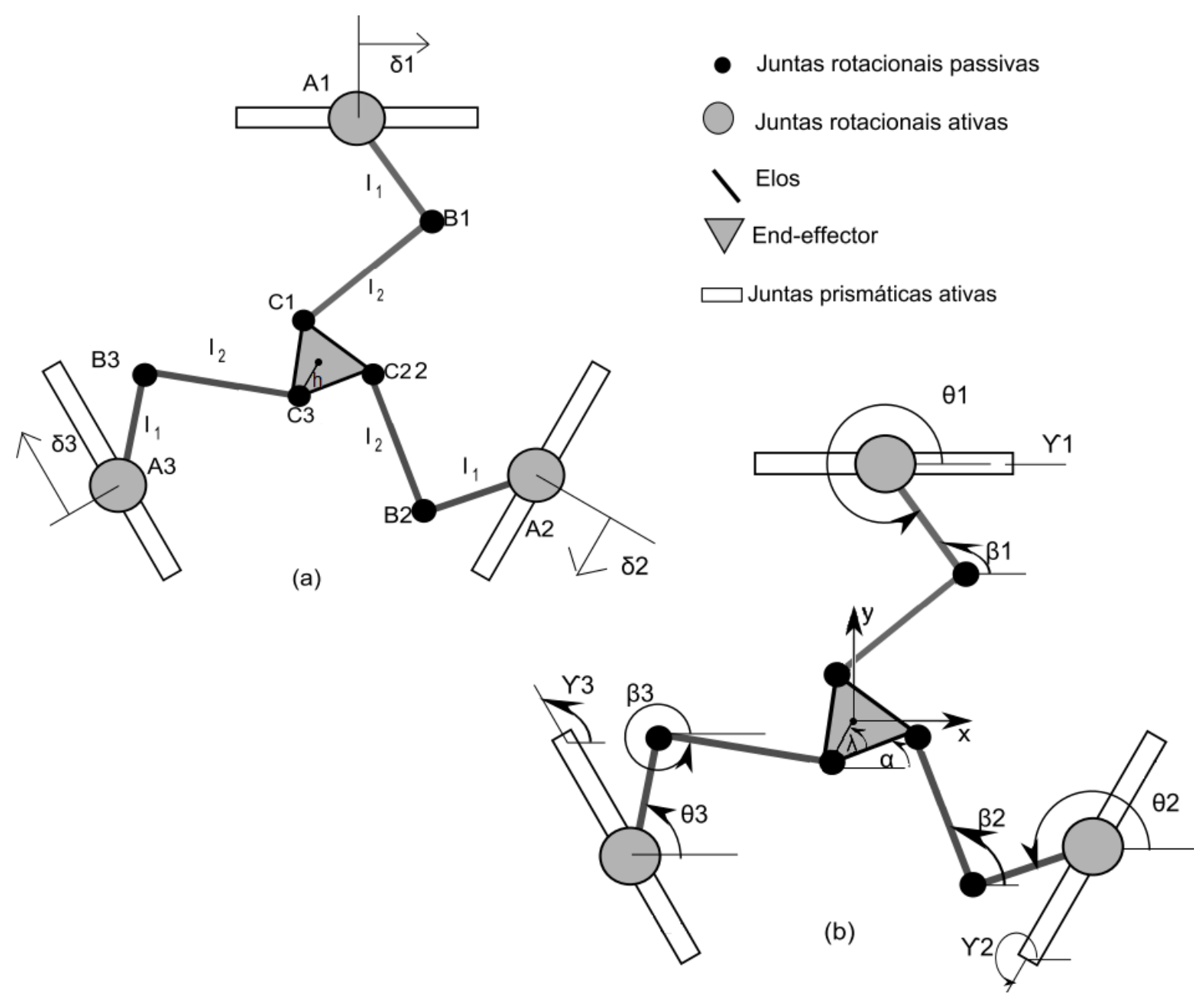

Figura 3.2: Modelo do manipulador $3(\underline{\mathrm{P}}) \underline{R} R R$.

A Fig. (3.2(b)) ilustra as posições angulares dos componentes do manipulador. $\gamma_{i}, \theta_{i}$, $\beta_{i}$ e $\alpha+\lambda_{i}$ são os ângulos entre a horizontal e respectivamente a guia linear, os elos $l_{1}, l_{2}$ 
e a linha imaginária entre o vértice $C_{i}$ e o centróide do efetuador (na imagem o $\lambda$ dado é $\lambda_{3}$ ). A posição do centroide do efetuador é dada por $x$ e $y$.

A posição das juntas $A_{i}, B_{i}$ e $C_{i}$ podem ser escritas como:

$$
\begin{gathered}
\mathbf{r}_{\mathbf{A}_{\mathbf{i}}}=\left[\begin{array}{l}
A_{x_{0 i}} \\
A_{y_{0 i}}
\end{array}\right]+\delta_{i}\left[\begin{array}{l}
\cos \left(\gamma_{i}\right) \\
\sin \left(\gamma_{i}\right)
\end{array}\right] \\
\mathbf{r}_{\mathbf{B}_{\mathbf{i}}}=\mathbf{r}_{\mathbf{A}_{\mathbf{i}}}+l_{1}\left[\begin{array}{l}
\cos \left(\theta_{i}\right) \\
\sin \left(\theta_{i}\right)
\end{array}\right] \\
\mathbf{r}_{\mathbf{C}_{\mathbf{i}}}=\mathbf{r}_{\mathbf{B}_{\mathbf{i}}}+l_{2}\left[\begin{array}{l}
\cos \left(\beta_{i}\right) \\
\sin \left(\beta_{i}\right)
\end{array}\right]
\end{gathered}
$$

onde $\mathbf{r}_{\mathbf{A}_{\mathbf{i}}}=\left(A_{x i}, A_{y_{i}}\right), \mathbf{r}_{\mathbf{B}_{\mathbf{i}}}=\left(B_{x i}, B_{y_{i}}\right)$ e $\mathbf{r}_{\mathbf{C}_{\mathbf{i}}}=\left(C_{x i}, C_{y_{i}}\right)$. Da equação acima, pode-se chegar em:

$$
\left\|\mathbf{r}_{\mathbf{C}_{\mathbf{i}}}-\mathbf{r}_{\mathbf{B}_{\mathbf{i}}}\right\|=l_{2}
$$

Usando a definição de (Fontes et al., 2014), tem-se $\mu_{i}$ e $\rho_{i}$ (Eq. (3.5)):

$$
\left[\begin{array}{c}
\mu_{i} \\
\rho_{i}
\end{array}\right]=\left[\begin{array}{l}
x \\
y
\end{array}\right]-h\left[\begin{array}{c}
\cos \left(\alpha+\lambda_{i}\right) \\
\sin \left(\alpha+\lambda_{i}\right)
\end{array}\right]-\left[\begin{array}{c}
A_{x_{0 i}} \\
A_{y_{0 i}}
\end{array}\right]+\delta_{i}\left[\begin{array}{c}
\cos \left(\gamma_{i}\right) \\
\sin \left(\gamma_{i}\right)
\end{array}\right]
$$

Com isso pode-se reescrever a Eq. 3.4 como a Eq. 3.6:

$$
\left\|\left[\begin{array}{l}
\mu_{i}-l_{1} \cos \left(\theta_{i}\right) \\
\rho_{i}-l_{1} \sin \left(\theta_{i}\right)
\end{array}\right]\right\|=l_{2}
$$

A Eq. 3.6 desenvolve-se em:

$$
-2 l_{1} \rho_{i} \sin \left(\theta_{i}\right)-2 l_{1} \mu_{i} \cos \left(\theta_{i}\right)+\mu_{i}^{2}+\rho_{i}^{2}+l_{1}^{2}-l_{2}^{2}=0
$$

Para descrever o ângulo $\theta_{i}$, a Eq. 3.7 foi dividida em argumentos:

$$
\begin{gathered}
e_{1 i}=-2 l_{1} \rho_{i} \\
e_{2 i}=-2 l_{1} \mu_{i} \\
e_{3 i}=\mu_{i}^{2}+\rho_{i}^{2}+l_{1}^{2}-l_{2}^{2}
\end{gathered}
$$

Usando esses argumentos, podemos definir os ângulos $\theta_{i}$ como (Wu et al., 2010):

$$
\theta_{i}=2 \tan ^{-1}\left(\frac{-e_{1 i} \pm \sqrt{e_{1 i}^{2}+e_{2 i}^{2}-e_{3 i}^{2}}}{e_{3 i}-e_{2 i}}\right)
$$


Com $\theta_{i}$ calculado, pode-se calcular $\beta_{i}$ a partir da Eq. 3.6:

$$
\begin{gathered}
{\left[\begin{array}{l}
\mu_{i}-l_{1} \cos \left(\theta_{i}\right) \\
\rho_{i}-l_{1} \sin \left(\theta_{i}\right)
\end{array}\right]=l_{2}\left[\begin{array}{l}
\cos \left(\beta_{i}\right) \\
\sin \left(\beta_{i}\right)
\end{array}\right]} \\
\beta_{i}=\tan ^{-1}\left(\frac{\rho_{i}-l_{1} \sin \left(\theta_{i}\right)}{\mu_{i}-l_{i} \cos \left(\theta_{i}\right)}\right)
\end{gathered}
$$

\subsubsection{Jacobiana}

A Jacobiana descreve a relação entre as velocidades $\dot{\Theta}$ dos atuadores com a velocidade $\dot{\mathbf{X}}$ do efetuador. Essa relação é definida por:

$$
\dot{\mathbf{X}}=\mathbf{J} \dot{\Theta}
$$

onde $\mathbf{X}=\left[\begin{array}{lll}x & y & \alpha\end{array}\right]^{T}$ e $\boldsymbol{\Theta}=\left[\begin{array}{llllll}\theta_{1} & \theta_{2} & \theta_{3} & \delta_{1} & \delta_{2} & \delta_{3}\end{array}\right]^{T}$.

Note que o vetor $\Theta$ é dependente de $\delta_{i}$, e consequentemente a dimensão desse vetor também é. E isso implica que o vetor $\Theta$ tem dimensão seis para o $3(\underline{P}) \underline{R} R R$. Essa matriz Jacobiana pode ser determinada a partir da manipulação da Eq. 3.7:

$$
e_{1 i} \sin \left(\theta_{i}\right)+e_{2 i} \cos \left(\theta_{i}\right)+e_{3 i}=0
$$

$e_{1 i}, e_{2 i}$ e $e_{3 i}$ foram definidos nas equações 3.8,3.9 e 3.10. Derivando a Eq.3.15, tem-se:

$$
\dot{e}_{1 i} \sin \left(\theta_{i}\right)+\dot{\theta} e_{1 i} \cos \left(\theta_{i}\right)+\dot{e}_{2 i} \cos \left(\theta_{i}\right)-\dot{\theta} e_{2 i} \sin \left(\theta_{i}\right)+\dot{e}_{3 i}=0
$$

Substituindo os valores de $e_{i 1}, e_{i 2}$ e $e_{i 3}$, e posteriormente de $\mu_{i}$ e $\rho_{i}$, tem-se:

$$
\dot{x}\left[l_{2} \cos \left(\beta_{i}\right)\right]+\dot{y}\left[l_{2} \sin \left(\beta_{i}\right)\right]+\dot{\alpha}\left[l_{2} h \sin \left(\beta_{i}-\lambda_{i}-\alpha\right)\right]=\dot{\theta}_{i}\left[l_{1} l_{2} \sin \left(\beta_{i}-\theta_{i}\right)\right]+\dot{\delta}_{i}\left[l_{2} \cos \left(\beta_{i}-\gamma_{i}\right)\right]
$$

Caso na cadeia cinemática $i$ seja utilizada otimização offline, consequentemente a posição dos atuadores será fixa durante o movimento do efetuador e as derivadas de $\mathbf{A}_{\mathbf{x}_{\mathbf{i}}} \mathrm{e}$ $\mathbf{A}_{\mathbf{y}_{\mathbf{i}}}$ serão zero, anulando o termo correspondente. A partir da Eq. 3.17, pode-se definir as matrizes A e B que relacionam $\dot{\Theta} \operatorname{com} \dot{\mathrm{X}}$ :

$$
\begin{gathered}
a_{i 1}=l_{2} \cos \left(\beta_{i}\right) \\
a_{i 2}=l_{2} \sin \left(\beta_{i}\right) \\
a_{i 3}=l_{2} h \sin \left(\beta_{i}-\lambda_{i}-\alpha\right) \\
b_{i i}=l_{1} l_{2} \sin \left(\beta_{i}-\theta_{i}\right) \\
b_{i i+3}=l_{2} \cos \left(\beta_{i}-\gamma_{i}\right)
\end{gathered}
$$


onde:

$$
\begin{gathered}
\mathbf{A}=\left[\begin{array}{lll}
a_{11} & a_{12} & a_{13} \\
a_{21} & a_{22} & a_{23} \\
a_{31} & a_{32} & a_{33}
\end{array}\right] \\
\mathbf{B}=\left[\begin{array}{cccccc}
b_{11} & 0 & 0 & b_{14} & 0 & 0 \\
0 & b_{22} & 0 & 0 & b_{25} & 0 \\
0 & 0 & b_{33} & 0 & 0 & b_{36}
\end{array}\right]
\end{gathered}
$$

A matriz B possui dimensão $3 \times 6$, pois essa matriz está relacionada com $\dot{\Theta}$. Já a matriz A possui dimensão $3 \times 3$, pois relaciona-se com $\dot{\mathbf{X}}$. Com A e B definidos, pode-se relacioná-los com $\dot{\Theta}$ e $\dot{\mathrm{X}}$ da seguinte maneira:

$$
\mathbf{A} \dot{\mathbf{X}}=\mathbf{B} \dot{\Theta}
$$

E com isso, a matriz Jacobiana pode ser expressa como:

$$
\mathbf{J}=\mathbf{A}^{-1} \mathbf{B}
$$

\subsection{Modelo Dinâmico Baseado no Princípio do Trabalho Virtual}

\subsubsection{Velocidades Parciais Lineares e Angulares}

A fim de obter mais simplificadamente o modelo dinâmico, o Princípio do Trabalho Virtual é empregado para derivar o modelo dinâmico. E para isso, primeiramente devem ser calculadas as velocidades parciais lineares e angulares, que são usadas no modelo dinâmico. Para o cálculo das velocidades o ponto de giro do corpo deve ser escolhido de forma a obter as velocidades parciais de maneira mais simplificada (Niu et al., 2013).

A matriz $\mathbf{H}_{\mathbf{i j}}$ é definida para relacionar o vetor $\dot{\Theta}$ de velocidades das juntas com o vetor $\mathbf{r}_{\mathbf{i j}}$ de velocidades lineares do corpo $j$ da cadeia cinemática $i$. O indice $j=1,2,3$ representa o motor rotacional, o braço $A_{i} B_{i}$ e o braço $B_{i} C_{i}$, respectivamente. De maneira semelhante, a matriz $\mathrm{G}_{\mathrm{ij}}$ relaciona o vetor $\dot{\Theta}$ do motor rotacional com a velocidade angular $\dot{\phi_{i j}}$. Com isso, a representação das velocidades em $A_{i}$, que é a derivada da Eq. 3.1, pode ser representada por:

$$
\dot{\mathbf{r}}_{\mathbf{A}_{\mathbf{i}}}=\dot{\mathbf{r}}_{\mathbf{i} 1}=\dot{\delta}_{i}\left[\begin{array}{l}
\cos \gamma_{i} \\
\sin \gamma_{i}
\end{array}\right]
$$


Perceba que a derivada de $\mathbf{r}_{\mathrm{Ai}}$ é nula quando há otimização offline ou quando não há otimização, pois $\delta_{i}$ é constante para toda trajetória. No caso de ocorrer otimização online, os valores não nulos estão na colunas $i+3$. A matriz $\mathbf{H}_{\mathbf{i} 1}$ é denotada por:

$$
\mathbf{H}_{\mathbf{i} 1}=\left[\begin{array}{lllll}
0 & \cdots & \cos \left(\gamma_{i}\right) & \cdots & 0 \\
0 & \cdots & \sin \left(\gamma_{i}\right) & \cdots & 0
\end{array}\right]_{2 \times 6} .
$$

Como a junta ativa $A_{i}$ movimenta apenas linearmente pela guia, consequentemente sua velocidade angular é nula:

$$
\mathbf{G}_{\mathbf{i} 1}=\left[\begin{array}{lll}
0 & \cdots & 0
\end{array}\right]_{1 \times 6} .
$$

Para o braço $A_{i} B_{i}$ a velocidade angular é $\dot{\theta}_{i}$ e a velocidade linear é dada na posição $A_{i}$, com isso:

$$
\mathbf{H}_{\mathrm{i} 2}=\mathbf{H}_{\mathrm{i} 1}
$$

e

$$
\begin{gathered}
\phi_{i 2}=\dot{\theta}_{\mathbf{i}}=\left[\begin{array}{lllll}
0 & \cdots & 1 & \cdots & 0
\end{array}\right]_{1 \times 6}(3.31) \text {, onde o valor } 1 \text { está na coluna } i \text {. Assim: } \\
\mathbf{G}_{\mathbf{i} 2}=\left[\begin{array}{lllll}
0 & \cdots & 1 & \cdots & 0
\end{array}\right]_{1 \times 6} .
\end{gathered}
$$

A velocidade do ponto $B_{i}$ pode ser definida pela derivada da Eq. 3.2 e consequentemente $\mathbf{H}_{\mathbf{i} 3}$ :

$$
\dot{\mathbf{r}}_{\mathrm{B}_{\mathbf{i}}}=\dot{\mathbf{r}}_{\mathrm{i} 3}=\dot{\theta}_{i} l_{1}\left[\begin{array}{c}
-\sin \left(\theta_{i}\right) \\
\cos \left(\theta_{i}\right)
\end{array}\right]+\dot{\delta}_{i}\left[\begin{array}{c}
\cos \left(\gamma_{i}\right) \\
\sin \left(\gamma_{i}\right)
\end{array}\right]
$$

$\mathrm{e}$

$$
\mathbf{H}_{\mathbf{i} 3}=\left[\begin{array}{ccccccccc}
0 & \cdots & l_{1}\left(-\sin \left(\theta_{i}\right)\right) & \cdots & 0 & \cdots & \cos \left(\gamma_{i}\right) & \cdots & 0 \\
0 & \cdots & l_{1} \cos \left(\theta_{i}\right) & \cdots & 0 & \cdots & \sin \left(\gamma_{i}\right) & \cdots & 0
\end{array}\right]_{2 \times 6} .
$$

Com valores não nulos nas colunas $i$ e $i+3$. Na Eq. 3.33, os valores da coluna $i+3$ não são nulos quando há a movimentação das juntas redundantes durante o movimento do manipulador (otimização online), pelo mesmo fato destacado na Eq. 3.27.

Para calcular $\mathrm{G}_{\mathrm{i} 3}$ deriva-se a Eq. 3.3, resultando:

$$
\dot{\mathbf{r}}_{\mathbf{C}_{\mathbf{i}}}=\dot{\mathbf{r}}_{\mathbf{B}_{\mathbf{i}}}+\dot{\beta}_{i} l_{2}\left[\begin{array}{c}
-\sin \left(\beta_{i}\right) \\
\cos \left(\beta_{i}\right)
\end{array}\right] .
$$

Além dessa maneira, pode-se calcular $\dot{\mathbf{r}}_{\mathrm{C}_{\mathrm{i}}}$ a partir da velocidade do efetuador: 


$$
\dot{\mathbf{r}}_{\mathbf{C}_{\mathbf{i}}}=\left[\mathbf{H}_{\mathbf{n}}-h\left[\begin{array}{c}
-\sin \left(\lambda_{i}+\alpha\right) \\
\cos \left(\lambda_{i}+\alpha\right)
\end{array}\right] \mathbf{G}_{\mathbf{n}}\right] \dot{\boldsymbol{\Theta}}
$$

onde $\mathbf{J}=\left[\begin{array}{l}\mathbf{H}_{\mathbf{n}} \\ \mathbf{G}_{\mathbf{n}}\end{array}\right]$ é a matriz Jacobiana $(3 \times 6)$, com $\mathbf{H}_{\mathbf{n}}$ e $\mathbf{G}_{\mathbf{n}}$ matrizes $(2 \times 6)$ e $(1 \times 6)$, respectivamente.

Feito isso, $G_{\mathbf{i} 3}$ pode ser definida por:

$$
\mathbf{G}_{\mathbf{i} 3}=\frac{1}{l_{2}}\left[\begin{array}{ll}
-\sin \left(\beta_{i}\right) & \cos \left(\beta_{i}\right)
\end{array}\right]\left\{\mathbf{H}_{\mathbf{n}}+h\left[\begin{array}{c}
\cos \left(\varphi_{i}+\alpha\right) \\
\sin \left(\varphi_{i}+\alpha\right)
\end{array}\right] \mathbf{G}_{\mathbf{n}}+\mathbf{H}_{\mathbf{i} 3}\right\} .
$$

Assim como $H_{n}$ e $G_{n}$ são relacionadas pela Jacobiana, as matrizes $G_{i j}$ e $H_{i j}$ também têm relação:

$$
\mathbf{K}_{\mathrm{ij}}=\left[\begin{array}{c}
\mathbf{H}_{\mathrm{ij}} \\
\mathbf{G}_{\mathrm{ij}}
\end{array}\right] \text {. }
$$

Daí, as velocidades podem ser expressas como:

$$
\dot{\mathrm{d}_{\mathrm{ij}}}=K_{i j} \dot{\Theta}
$$

onde $\mathbf{d}_{\mathrm{ij}}=\left[\begin{array}{l}\mathbf{r}_{\mathrm{ij}} \\ \phi_{\mathrm{ij}}\end{array}\right]$.

\subsubsection{Análise da Aceleração}

Com as velocidades calculadas, basta derivar no tempo para encontrar as respectivas acelerações:

$$
\ddot{\mathrm{d}_{\mathrm{ij}}}=K_{i j} \ddot{\Theta}+\dot{K_{i j}} \dot{\Theta}
$$

\subsubsection{Forças Inerciais e Momentos das Partes Móveis}

Como a posição, velocidade e aceleração já foram encontradas, a formulação de NewtonEuler pode ser aplicada para encontrar as forças e torques necessários para mover o endeffector. Para isto, $\mathbf{p}_{\mathbf{i j}}$ é definido como a combinação das forças e momentos do corpo $j$ na cadeia $i$ :

$$
p_{i j}=\left[\begin{array}{c}
F_{i j} \\
M_{i j}
\end{array}\right]
$$

onde: 


$$
\mathbf{F}_{\mathbf{i j}}=\left[\begin{array}{c}
m_{j}\left(\ddot{r}_{x_{i j}}+\ddot{\phi}_{i j} s_{j}\left(-\sin \left(\phi_{i j}\right)\right)-\dot{\phi}_{i j}^{2} s_{j} \cos \left(\phi_{i j}\right)\right) \\
m_{j}\left(\ddot{r}_{y_{i j}}+\ddot{\phi}_{i j} s_{j}\left(\cos \left(\phi_{i j}\right)\right)-\dot{\phi}_{i j}^{2} s_{j} \sin \left(\phi_{i j}\right)\right)
\end{array}\right]
$$

$\mathrm{e}$

$$
\mathbf{M}_{\mathbf{i j}}=m_{j} s_{j}\left(\ddot{r}_{x_{i j}}\left(-\sin \left(\phi_{i j}\right)\right)+\ddot{r}_{y_{i j}} \cos \left(\phi_{i j}\right)\right)+I_{j} \ddot{\phi}_{i j},
$$

$s_{j}$ é a distância entre o centro de massa e o ponto de giro do corpo $j$.

Para o efetuador, tem-se de maneira similar o $p_{e e}$, formado pela combinação das forças e momentos aplicados em si:

$$
\mathbf{p}_{\mathrm{ee}}=\left[\begin{array}{c}
F_{e e} \\
M_{e e}
\end{array}\right]
$$

Depois de definidos as forças e momentos de cada corpo, pode-se aplicar o princípio de trabalho virtual para determinar o vetor de torques $\tau$ necessário para a junta ativa realizar o movimento pré-definido. Dessa forma, temos:

$$
\begin{gathered}
\boldsymbol{\tau}^{t} \boldsymbol{\delta} \boldsymbol{\Theta}=\mathrm{p}_{\mathbf{e e}}{ }^{t} \boldsymbol{\delta} X+\sum_{i=1}^{3} \sum_{j=1}^{3} \mathrm{p}_{\mathbf{i j}}{ }^{t} \boldsymbol{\delta} \mathrm{d}_{\mathbf{i j}} \\
\boldsymbol{\tau}^{t} \boldsymbol{\delta} \boldsymbol{\Theta}=\mathrm{p}_{\mathbf{e e}}{ }^{t} \boldsymbol{J} \boldsymbol{\delta} \Theta+\sum_{i=1}^{3} \sum_{j=1}^{3} \mathrm{p}_{\mathbf{i j}}{ }^{t} \boldsymbol{K}_{\boldsymbol{i j}} \boldsymbol{\delta} \boldsymbol{\Theta} \\
\boldsymbol{\tau}=\boldsymbol{J}^{t} \mathbf{p}_{\mathbf{e e}}+\sum_{i=1}^{3} \sum_{j=1}^{3} \boldsymbol{K}_{\boldsymbol{i j}}{ }^{t} \mathbf{p}_{\mathbf{i j}}
\end{gathered}
$$

\subsection{Abordagem Probabilística}

A abordagem probabilística é feita com o intuito de verificar o provável comportamento do manipulador devido a variabilidade em seus componentes causados pela tolerância de manufatura.

\subsubsection{Distribuição Gaussiana de Probabilidades}

Uma distribuição gaussiana de probabilidades é considerada na incerteza de manufatura. Na distribuição normal de probabilidade tem-se o desvio padrão e a média, respectivamente $\sigma$ e $\mu$, e a função densidade de probabilidade (probability density function, PDF) de determinado evento $x$ é dada por:

$$
f(x)=\frac{1}{\sqrt{2 \pi} \sigma} e^{-\frac{(x-\mu)^{2}}{2 \sigma^{2}}}
$$




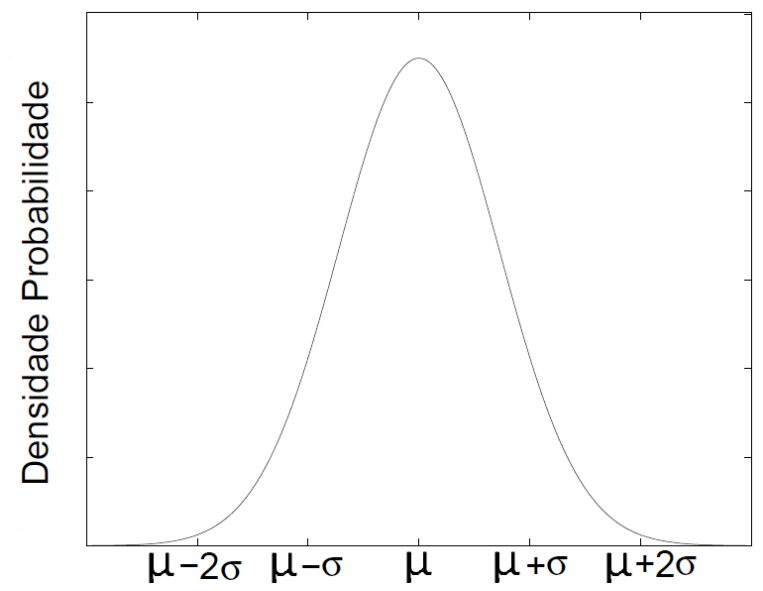

Figura 3.3: Função densidade de probabilidade de um dado $x$.

A $f(x)$ é representada na Fig. 3.3:

Como $f(x)$ é a função densidade de probabilidade, a probabilidade de um valor $x$ pertencer ao intervalo $\left[x_{i}, x_{f}\right]$ é dado pela integral definida da função densidade de probabilidade:

$$
\int_{x_{i}}^{x_{f}} f(x) d x=\int_{x_{i}}^{x_{f}} \frac{1}{\sqrt{2 \pi} \sigma} e^{-\frac{(x-\mu)^{2}}{2 \sigma^{2}}} d x
$$

Tomando $x=[-\infty, X]$, a Fig. 3.4 é a representação da probabilidade (em cinza) de ocorrer o evento entre os valores nesse intervalo.

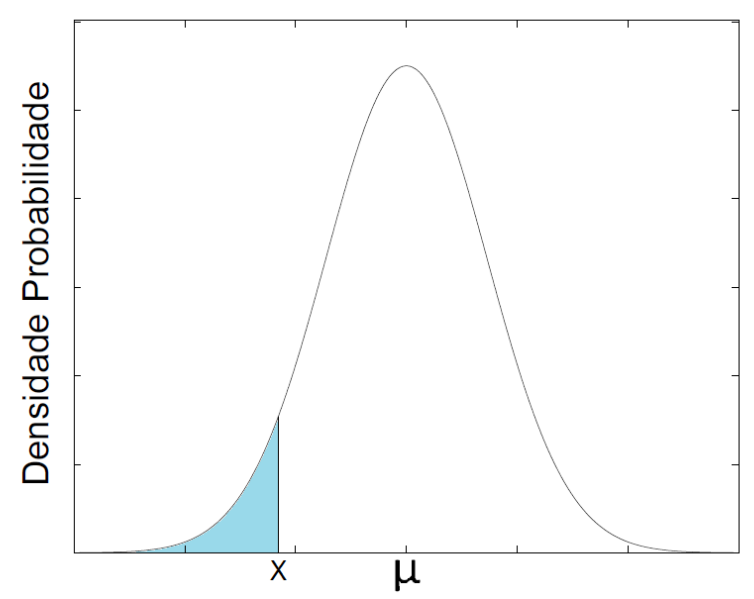

Figura 3.4: Probabilidade de $\mathrm{x}=[-\infty, \mathrm{X}]$ representada pela área em turquesa. 


\subsubsection{Intervalo de Confiança}

O intervalo de confiança é o intervalo onde uma amostra tem certa probabilidade de acontecer, e os limites são igualmente espaçados da média do parâmetro estudado. Nesse trabalho é considerado um intervalo com $95 \%$ de confiabilidade (Fig. 3.5).

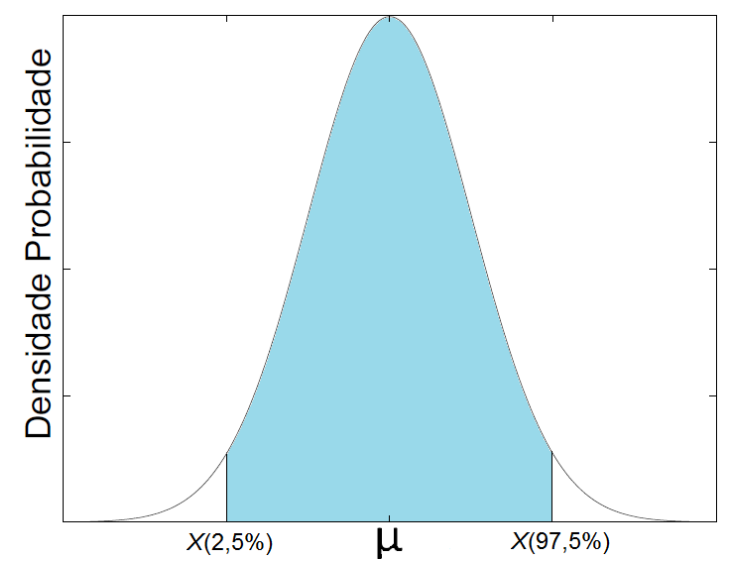

Figura 3.5: Intervalo de confiança para $f(x)$ de $95 \%$ representada pela área em cinza.

Esse intevalo de confiança pode ser feito de forma analítica usando a Eq. 3.49, ou usando as Tabelas B.1 e B.2 que são encontradas pela função $f(Z)$, dada por:

$$
f(Z)=\frac{1}{\sqrt{2 \pi}} e^{-\frac{Z^{2}}{2}}
$$

A $f(Z)$ é a função $f(x)$ considerando a média nula e o desvio padrão unitário. Igualando o exponencial da Eq. 3.49 com o da Eq. 3.50, tem-se:

$$
\begin{gathered}
\frac{Z^{2}}{2}=\frac{(x-\mu)^{2}}{2 \sigma^{2}} \\
Z=\frac{x-\mu}{\sigma}
\end{gathered}
$$

E considerando os valores de $\sigma$ e $\rho$ definidos anteriormente, tem-se $Z=x$. A probabilidade entre valores de $Z=\left[Z_{i}, Z_{f}\right]$ é dado por:

$$
\int_{Z_{i}}^{Z_{f}} f(Z) d Z=\int_{Z_{i}}^{Z_{f}} \frac{1}{\sqrt{2 \pi}} e^{-\frac{Z^{2}}{2}} d Z
$$

Os valores resultantes dessa integral podem ser feitos de forma analítica ou pela tabela de probabilidade padrão normal acumulada (Apêndice B). Nessa tabela o valor de $Z$ para a área da função normal de densidade de probabilidade é encontrado. Encontrado $Z$ para esse intervalo, o valor de $x$ correspondente ao $Z$ é dado por:

$$
x=Z \sigma+\mu
$$


Com a substituição da Eq. 3.51 e 3.52, a função de densidade probabilidade é representada pela Fig. 3.6:

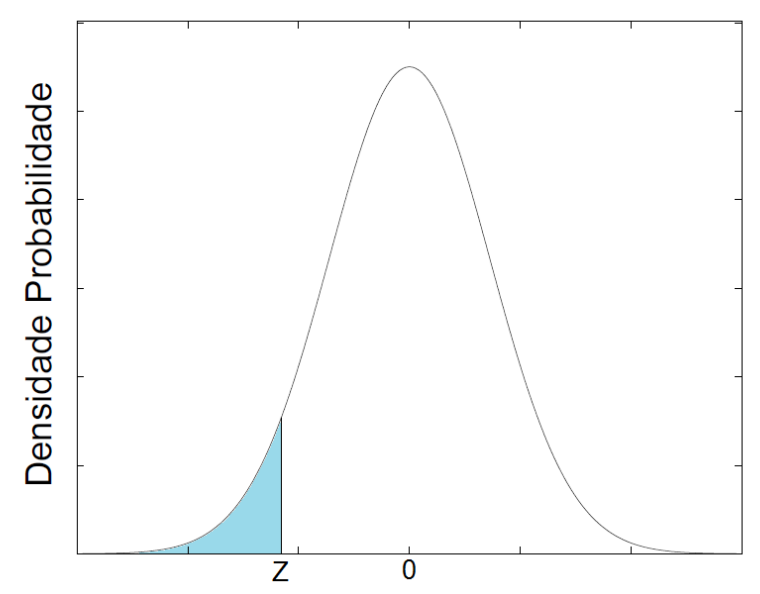

Figura 3.6: Probabilidade de $Z=[-\infty, Z]$ representada pela área em cinza.

Assim os valores limite correspondente aos valores até $2,5 \%$ e $97,5 \%$ de probabilidades são encontrados. Perceba que a área da função entre esses intervalos é dada pelos $95 \%$ de confiabilidade (Fig. 3.7).

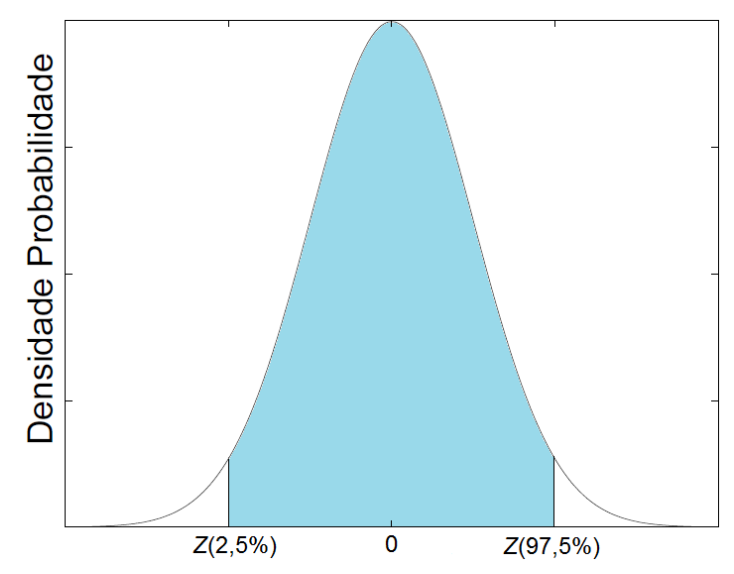

Figura 3.7: Intervalo de confiança para $f(Z)$ de $95 \%$ representada pela área em cinza.

\subsection{Mapa de Singularidades}

Quando um mecanismo paralelo funciona em seus pontos singulares ou próximo a sua região singular, a precisão, rigidez e outros indicadores de desempenho entram em colapso ou degradam significativamente (Wu et al., 2007). Com isso, regiões singulares devem ser identificadas e assim possibilitar o desvio da trajetória dessas regiões. 
Como dito anteriormente, há três diferentes tipos de singularidades. Esses tipos são baseados nas relações de velocidades de entrada e saída, isto é, da matriz Jacobiana e consequentemente de A e B. Nesse trabalho o foco é determinar as possíveis singularidades da cinemática direta relacionada com A. Elas são mais relevantes já que ocorrem no espaço de trabalho (Kotlarski et al., 2009).

O segundo tipo de singularidade ocorre quando o determinante de $\mathbf{A}$ (Eq. 3.25) vai para zero. Para esse tipo de configuração, existem velocidades cartesianas $\dot{X}$ não nulas que são mapeadas no vetor nulo de A (Gosselin e Angeles, 1990).

Para essa análise, é considerada uma malha de pontos nos eixos $x$ e $y$ da área de trabalho do manipulador. E essa malha contém 1201 pontos, percorrendo os eixos de $-0.6 \mathrm{~m}$ até $0.6 \mathrm{~m}$, com pontos igualmente espaçados em $0.001 \mathrm{~m}$. Com essa malha definida é feita a análise de cada ponto, e verificando o $\operatorname{det} \mathbf{A}$ em cada um deles. Encontrado os pontos onde o determinante de $\mathbf{A}$ é nulo, esse ponto é armazenado, e então o mapa da área de trabalho é feito com esses pontos em destaque.

Para esse estudo são considerados:

- Incerteza devido à tolerância de fabricação: é comparada a área singular dada incerteza em cada componente (elos e efetuador) separadamente;

- Posição das guias lineares: diferentes posições das guias lineares são analisadas;

- Orientação do efetuador: diferentes orientações são estudadas.

\subsection{Otimização}

A cinemática inversa de um manipulador com redundância cinemática apresenta infinitas soluções. Dessa maneira, esses manipuladores podem se reconfigurar através da escolha da solução mais adequada aos objetivos do projeto.

Com o objetivo de minimizar o torque necessário para realizar uma determinada trajetória é necessário realizar uma busca para a melhor posição na guia linear para as possibilidades existentes. E essa busca pode ser feita por meio de um problema de otimização.

Para esse problema de otimização foram utilizados a otimização offline e online. A otimização offline é feita de modo que o manipulador reconfigure sua cadeia redundante antes do movimento do efetuador. Já a otimização online é feita com o atuador da cadeia redundante se movendo ao mesmo tempo em que o efetuador se movimente (Kotlarski et al., 2008, 2010, 2011).

Para o problema proposto, é preciso definir a função custo que se deseja minimizar, as variáveis da função e as restrições desse problema. A função custo é o máximo absoluto do torque alcançado na trajetória pré-estabelecida do efetuador. Já as variáveis da função são 
dadas pela posição $\delta_{i}$ da junta ativa $A_{i}$ na respectiva guia linear $i$. Por sua vez, as restrições são as extremidades da guia linear, representados por $-\delta_{\max }$ e $\delta_{\text {max }}$. Assim o problema de otimização pode ser expresso por:

$$
\begin{gathered}
\min _{\delta_{i}(t)}\|\boldsymbol{\tau}\| \\
\text { sujeito } a: \\
-\delta_{\text {max }} \leq \delta_{i}(t) \leq \delta_{\text {max }}
\end{gathered}
$$

O torque $\tau$ definido na Eq. 3.47 é dependente da posição das guias lineares $\delta_{i}$ e consequentemente quando se altera $\delta_{i}, \tau$ também é alterado. O torque $\tau$ usado na Eq. 3.55 é um vetor contendo os torques máximos de cada cadeia cinemática e também das guias lineares, e assim é feita a otimização utilizando a norma desse vetor. Considerando a trajetória pré-definida do efetuador e a modelagem já apresentada, pode-se determinar rotações $\theta_{i}$ das juntas ativas para determinada posição da mesma na guia linear. Mas, como no caso da otimização online, a posição $\delta_{i}$ também varia com o tempo e consequentemente não pode ser usada como variável de otimização. Assim são feitas diferentes abordagens para determinar essas variáveis.

O problema de otimização offline é feito quando as posições ótimas das guias lineares $\delta_{i}$ são determinadas antes da movimentação do efetuador. Após encontrada as posições, a modelagem é feita com as guias lineares fixadas nesse valor, e assim a trajetória é realizada com o menor torque possível para essa movimentação.

Já a otimização online consiste no movimento simultâneo do atuador $A_{i}$ sobre a guia linear $\delta_{i}$ assim como o movimento do efetuador. Esse movimento do atuador $A_{i}$ sobre a guia é também uma trajetória pré-definida de maneira que apenas alguns pontos sejam variáveis da otimização.

A trajetória do atuador $A_{i}$ segue um polinômio de quinto grau que descreve o movimento de $\delta_{i}(t)$, com $\delta_{i}=\left[\delta_{0 i}, \delta_{f i}\right]$. Essa movimentação dura 2 segundos com velocidades e acelerações, iniciais e finais, nulas:

$$
\delta_{i}(t)=\left(\delta_{f_{i}}-\delta_{0_{i}}\right)\left(\left(3 t^{5}\right) / 16-\left(15 t^{4}\right) / 16+\left(5 t^{3}\right) / 4\right)+\delta_{0_{i}}
$$

As otimizações foram feitas no MATLAB utilizando o algoritmo sequential quadratic programming (SQP). Desde a popularização do SQP no final dos anos 70, ele vem se tornando um dos métodos de otimização não-linear com restrições mais bem sucedidas (Boggs e Tolle, 1996). Assim como muitos métodos de otimização, o SQP não é um único algoritmo, mas um método conceitual que a partir do qual numerosos algoritmos específicos evoluíram. 
O SQP foi escolhido para o problema de otimização por se tratar de um algoritmo robusto, além de ser considerado apropriado para esse tipo de tarefa. 


\subsection{Considerações iniciais}

Para comparar o desempenho dinâmica do manipulador considerando incerteza geométrica dos componentes foi considerado o provável erro devido a tolerância de fabricação ISO 286 - 1 : 2010(E), tomando como base o grau de tolerância IT16 (Apêndice A). A Tabela 4.1 mostra os parâmetros fixos do manipulador, enquanto a Tab. 4.2 mostra os parâmetros sujeitos ao erro de manufatura e sua respectiva incerteza.

Tabela 4.1: Representação dos parâmetros fixos

\begin{tabular}{|c|c|}
\hline Parâmetro & valor \\
\hline$m_{g}$ (massa das guias lineares) & $0.4 \mathrm{~kg}$ \\
$m_{1}$ (massa dos braços $\left.\mathrm{l}_{1}\right)$ & $0.2 \mathrm{~kg}$ \\
$m_{2}$ (massa dos braços $\mathrm{l}_{2}$ ) & $0.2 \mathrm{~kg}$ \\
$m_{e e}$ (massa do efetuador) & $0.4 \mathrm{~kg}$ \\
$\delta_{\text {max }}$ (comprimento máximo das guias lineares) & $0.3 \mathrm{~m}$ \\
$I_{1}$ (inércia dos braços $\mathrm{l}_{1}$ ) & $0.00667 \mathrm{~kg} . \mathrm{m}^{2}$ \\
$I_{2}$ (inércia dos braços $\mathrm{l}_{2}$ ) & $0.00667 \mathrm{~kg} . \mathrm{m}^{2}$ \\
$I_{e e}$ (inércia do efetuador) & $0.008 \mathrm{~kg} . \mathrm{m}^{2}$ \\
\hline
\end{tabular}

A variação especificada na Tab. 4.3 são valores determinados pela ISO $286-1$ : 2010(E)(Apêndice A). Essa variação é calculada da seguinte maneira: Como o comprimento nominal dos elos são de $200 \mathrm{~mm}$, a tolerância permitida para comprimentos entre $180 \mathrm{~mm}$ até $250 \mathrm{~mm}$ é de $2,9 \mathrm{~mm}$. Já o efetuador tem seus lados com valor nominal de 
Tabela 4.2: Comprimento dos elos e do parâmetro $h$ do efetuador, o valor nominal e sua respectiva variação devido à manufatura.

\begin{tabular}{|c|c|c|}
\hline Parâmetros & valor nominal & variação \\
\hline$l_{1}$ e $l_{2}$ & $0.2 m$ & $\pm 0.00435 m$ \\
$h$ & $0.05 m$ & $\pm 0.00190 m$ \\
\hline
\end{tabular}

aproximadamente $86,6 \mathrm{~mm}$ e consequentemente está entre $80 \mathrm{~mm}$ e $120 \mathrm{~mm}$, o que resulta em uma tolerância permitida de $2,2 \mathrm{~mm}$. Mas na modelagem do manipulador o parâmetro usado é $h$, que é proporcional ao comprimento dos lados do efetuador, e assim, por meio de relação geométrica entre os dois, tem-se a variação em $h$ que é de $1,27 \mathrm{~mm}$. Para a análise prática, o valor correspondente ao desvio padrão é a metade da tolerância de manufatura. E o valor limite para a variação estudada foi de três vezes o desvio padrão que correspondem a $99,74 \%$ das chances.

Tabela 4.3: Tolerância e limites

\begin{tabular}{|c|c|c|c|c|}
\hline Parâmetros & valor nominal entre & tolerância permitida $(2 \sigma)$ & $\sigma$ & limites $( \pm 3 \sigma)$ \\
\hline$l_{1}$ e $l_{2}$ & 180 e $250 \mathrm{~mm}$ & $2.90 \mathrm{~mm}$ & $1.45 \mathrm{~mm}$ & $\pm 4.35 \mathrm{~mm}$ \\
$h$ & 80 e $120 \mathrm{~mm}$ & $1.26 \mathrm{~mm}$ & $0.63 \mathrm{~mm}$ & $\pm 1.90 \mathrm{~mm}$ \\
\hline
\end{tabular}

O grau de tolerância IT16 foi escolhido por se tratar de uma superestimação do erro, fazendo com que na prática esse erro aconteça em situações críticas. Considerando essa incerteza geométrica nos elos do manipulador, um intervalo de $95 \%$ de confiança desses valores é considerado. Esse intervalo de confiança é baseado em uma distribuição gaussiana de probabilidade do possível tamanho dos componentes do manipulador, tomando o tamanho médio destes como valor nominal.

\subsection{Dados da simulação}

O manipulador 3()RRR e sua trajetória (em vermelho) são ilustrados na Fig. 4.1. As posições espaciais dos atuadores 1,2 e 3 estão representadas por $A_{1}=(-0.17,-0.10)$, $A_{2}=(-0.17,0.10)$ e $A_{3}=(0.00,0.20)$ em metros (somente ilustrativo para o caso $\left.\sigma_{i}=0\right)$. A distância do vértice $C_{i}$ até o centroide do efetuador é $h=50 \mathrm{~mm}$.O ângulo $\alpha$ refere-se à orientação do efetuador. Pelo fato do estudo ser baseado no $3(\underline{P}) \underline{R} R R$, otimiza-se as posições $\delta_{1}, \delta_{2}$ e $\delta_{3}$ para o cálculo da cinemática e dinâmica do manipulador, visando o menor torque máximo requerido pelo manipulador para o efetuador percorrer a trajetória pré-estabelecida. Na Figura 4.1 as guias lineares estão representadas na cor turquesa enquanto a posição da junta ativa está em azul. 


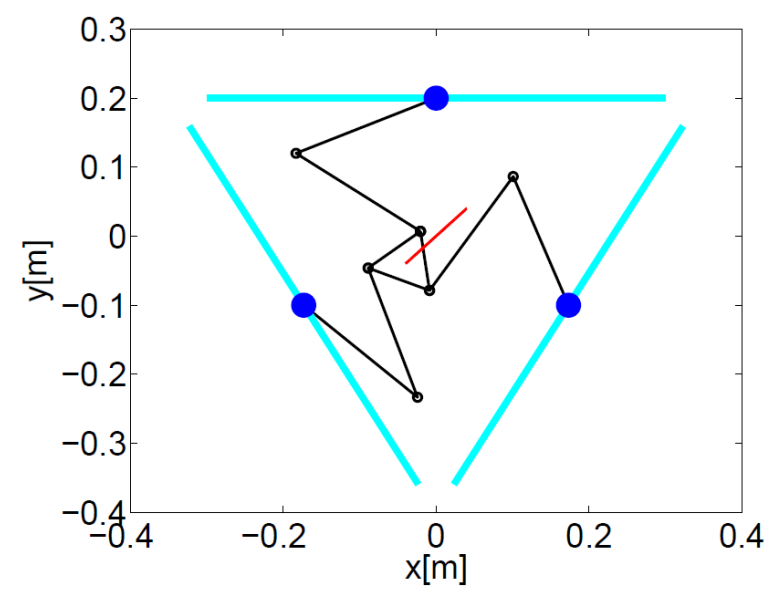

Figura 4.1: 3(P) $\underline{R} R R$ e a trajetória executada (vermelho)

O ângulo $\alpha=\left[\alpha_{0}, \alpha_{f}\right]$, onde $\alpha_{0}$ é o valor inicial da orientação enquanto $\alpha_{f}$ é seu valor final, é a orientação do efetuador e é usada de duas maneiras diferentes nesse trabalho:

- $\alpha=[0,0]$;

- $\alpha=[-\pi / 8, \pi / 8]$;

No segundo item, como há variação na orientação do efetuador, essa variação segue uma função polinomial de quinto grau, baseado na otimização (Eq. 3.57).

Para a dispersão de valores seguir essa tendência, a fabricação desses componentes robóticos deve ser produzidos em alta escala, e assim esse erro pode tender a seguir uma distribuição normal de probabilidade (Eq. 3.48). O estudo é feito considerando nove valores, seis deles estão dados da Tab. 4.4, enquanto os outros três são os limites da função de densidade e probabilidade e o valor nominal do comprimento (Tab. 4.5). Esses limites são $\pm 3 \delta$, que representam $99,7 \%$ das possibilidades. A coluna de probabilidade considera a chance do comprimento do elo estar entre essa faixa de valores. E a Fig. 4.2 representa a função de densidade probabilidade para os prováveis comprimentos dos elos e de $h$. As cores que preenchem as áreas do gráfico são especificadas na Tab. 4.4. Note que a média $(\mu)$ é representado pelo valor nominal do respectivo componente.

Tabela 4.4: Variação do valor nominal e a probabilidade entre esses valores.

\begin{tabular}{|c|c|c|c|}
\hline \multirow{2}{*}{ Cor da Área } & \multicolumn{2}{|c|}{ Variação do valor nominal em } & Probabilidade (\%) \\
\cline { 2 - 3 } & $h(\mathrm{~mm})$ & $l_{1} \mathrm{e} l_{2}(\mathrm{~mm})$ & \\
\hline Azul & \pm 0.5346 & \pm 1.2350 & 60 \\
Azul + turquesa & \pm 0.8139 & \pm 1.8582 & 80 \\
Azul + turquesa + turquesa claro & \pm 1.2448 & \pm 2.8420 & 95 \\
\hline
\end{tabular}


Tabela 4.5: Comprimento de $h$ e dos Elos do manipulador, o valor nominal e seu respectivo limite do intervalo de valores devido a manufatura $( \pm 3 \delta)$.

\begin{tabular}{|c|c|c|}
\hline Parâmetro & valor nominal $(m)$ & Intervalo de Valores $(m)$ \\
\hline$l_{1}$ e $l_{2}$ & 0.2 & {$[0.19565,0.20435]$} \\
$h$ & 0.05 & {$[0.0480947,0.0519053]$} \\
\hline
\end{tabular}
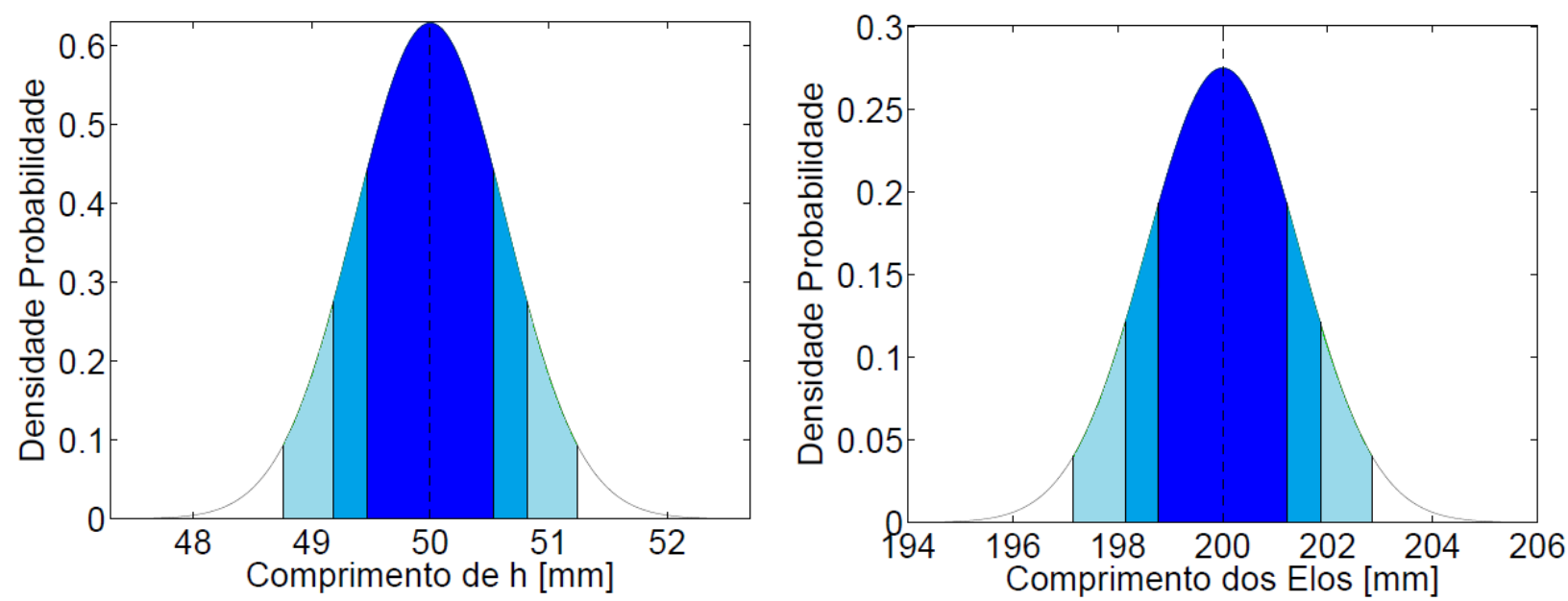

Figura 4.2: Função de densidade probabilidade para os possíveis comprimentos de: h à esquerda e dos elos à direita.

A soma das áreas em tons de azul formam $95 \%$ das possibilidades, e consequentemente o intervalo de confiança são os valores que pertencem a esse intervalo. Os valores das probabilidades foram encontrados a partir da tabela $Z$ (apêndice), por exemplo: o intervalo de confiança de $95 \%$ são os valores correspondentes a $Z$ para $2.5 \%$ e para $97.5 \%$, assim a área entre eles corresponde ao intervalo de confiança. Os valores correspondentes a essas probabilidades são respectivamente $Z=-1.96$ e $Z=1.96$, e subistituindo esses valores na Eq. 3.54, tem-se o valor do comprimento do elo equivalente. Esses valores são dados na Tab. 4.4. Como há simetria considerando o centro da curva, os valores de $Z$ são sempre opostos para valores igualmente espaçados do centro.

Partindo desses valores, o torque necessário para mover o efetuador na trajétoria préestabelicida é calculado. Dois casos são considerados nas seções 4.3 .1 e 4.3.2, e desses casos é encontrado o máximo torque calculado. 


\subsection{Máximo torque calculado}

\subsubsection{Influência de parâmetros com incerteza geométrica considerando $\alpha$ constante e nulo}

Com o objetivo de mensurar a influência da variação do comprimento dos elos e da distância $h$ no desempenho dinâmico do manipulador, são comparado os torques necessários para o efetuador percorrer a trajétoria predefinida. As linhas (1, 2 e 3) das Figs. 4.3, 4.4 e 4.5 mostram o torque requerido para cada atuador (respectivamente $c 1, c 2$ e $c 3$ ) de acordo com os graus de liberdade $\boldsymbol{\Theta}=\left[\begin{array}{lll}\theta_{1} & \theta_{2} & \theta_{3}\end{array}\right]^{T}$. As colunas representam respectivamente a variação no comprimento de $h, l_{1}$ e $l_{2}$. Já as linhas 4,5 e 6 das Figs. 4.4 e 4.5 representam as guias lineares $(g 1, g 2$ e $g 3)$ de acordo com os graus de liberdade $\Theta=\left[\begin{array}{lll}\delta_{1} & \delta_{2} & \delta_{3}\end{array}\right]^{T}$.

Tabela 4.6: Torque máximo (N.m), em módulo, para cada cadeia cinemática (c1, c2 ou c3) e guia linear ( $\mathrm{g} 1, \mathrm{~g} 2$ ou g3), para realizar trajetória pré-determinada considerando otimização para o parâmetro incerto, mas os valores correspondem ao comprimento nominal dos parâmetros, correspondente às linhas tracejadas dos gráficos.

\begin{tabular}{|c|c|c|c|c|c|c|c|}
\hline Incerteza & Otimização & $\mathrm{c} 1$ & $\mathrm{c} 2$ & $\mathrm{c} 3$ & $\mathrm{~g} 1$ & $\mathrm{~g} 2$ & $\mathrm{~g} 3$ \\
\hline$h, l_{1}$ ou $l_{2}$ & - & 0.00704 & 0.01479 & 0.00706 & - & - & - \\
\hline$h$ & offline & 0.00756 & 0.00997 & 0.00996 & 0.00615 & 0.00670 & 0.00151 \\
\hline$l_{1}$ & offline & 0.00637 & 0.01007 & 0.01003 & 0.00584 & 0.00673 & 0.00169 \\
\hline$l_{2}$ & offline & 0.00753 & 0.00996 & 0.00996 & 0.00614 & 0.00670 & 0.00151 \\
\hline$h$ & online & 0.00718 & 0.00916 & 0.00917 & 0.00898 & 0.00911 & 0.00524 \\
\hline$l_{1}$ & online & 0.00697 & 0.00922 & 0.00923 & 0.00919 & 0.00926 & 0.00497 \\
\hline$l_{2}$ & online & 0.00709 & 0.00914 & 0.00914 & 0.00899 & 0.00915 & 0.00566 \\
\hline
\end{tabular}

Tabela 4.7: Torque máximo (N.m), em módulo, para cada cadeia cinemática (c1, c2 ou c3) e guia linear (g1, g2 ou g3), para realizar trajetória pré-determinada considerando um parâmetro incerto.

\begin{tabular}{|c|c|c|c|c|c|c|c|}
\hline Incerteza & Otimização & $\mathrm{c} 1$ & $\mathrm{c} 2$ & $\mathrm{c} 3$ & $\mathrm{~g} 1$ & $\mathrm{~g} 2$ & $\mathrm{~g} 3$ \\
\hline$h$ & - & 0.00707 & 0.01483 & 0.00720 & - & - & - \\
\hline$l_{1}$ & - & 0.00746 & 0.01509 & 0.00746 & - & - & - \\
\hline$l_{2}$ & - & 0.00731 & 0.01494 & 0.00737 & - & - & - \\
\hline$h$ & offline & 0.00775 & 0.01006 & 0.01026 & 0.00628 & 0.00681 & 0.00157 \\
\hline$l_{1}$ & offline & 0.00715 & 0.01087 & 0.01075 & 0.00629 & 0.00720 & 0.00177 \\
\hline$l_{2}$ & offline & 0.00790 & 0.01027 & 0.01020 & 0.00630 & 0.00692 & 0.00151 \\
\hline$h$ & online & 0.00730 & 0.00921 & 0.00928 & 0.00913 & 0.00913 & 0.00531 \\
\hline$l_{1}$ & online & 0.00722 & 0.00972 & 0.00929 & 0.00924 & 0.00951 & 0.00505 \\
\hline$l_{2}$ & online & 0.00715 & 0.00939 & 0.00920 & 0.00912 & 0.00929 & 0.00568 \\
\hline
\end{tabular}


A região preenchida da cor turquesa representa a confiabilidade de $95 \%$, enquanto a área de vermelho é o resto das possibilidades (até 99,74\%), já para o valor nominal do elo a representação é dada pela linha tracejada.

De acordo com a Figs. 4.3, 4.4 e 4.5, nota-se que tanto o intervalo valores do torque calculado, como os valores possíveis para os parâmetros seguem a mesma tendência. $\mathrm{O}$ valor nominal do parâmetro é o centro do intervalo de valores para ambas as curvas, e quando o valor do comprimento desse componente se afasta desse ponto central, o valor do torque se afasta proporcionalmente.

E considerando a Tab. 4.7, perceber-se, com maior clareza na caso da otimização online, uma tentativa de homogeneização dos torques. Nota-se que há pelo menos quatro atuadores chegando muito próximo seus picos de torque. No caso de variações em $h, l_{1} \mathrm{e}$ $l_{2}$, e considerando esses quatro atuadores, há uma variação máxima de 1,6\%, 4, 5\% e 2, 9\% respectivamente.
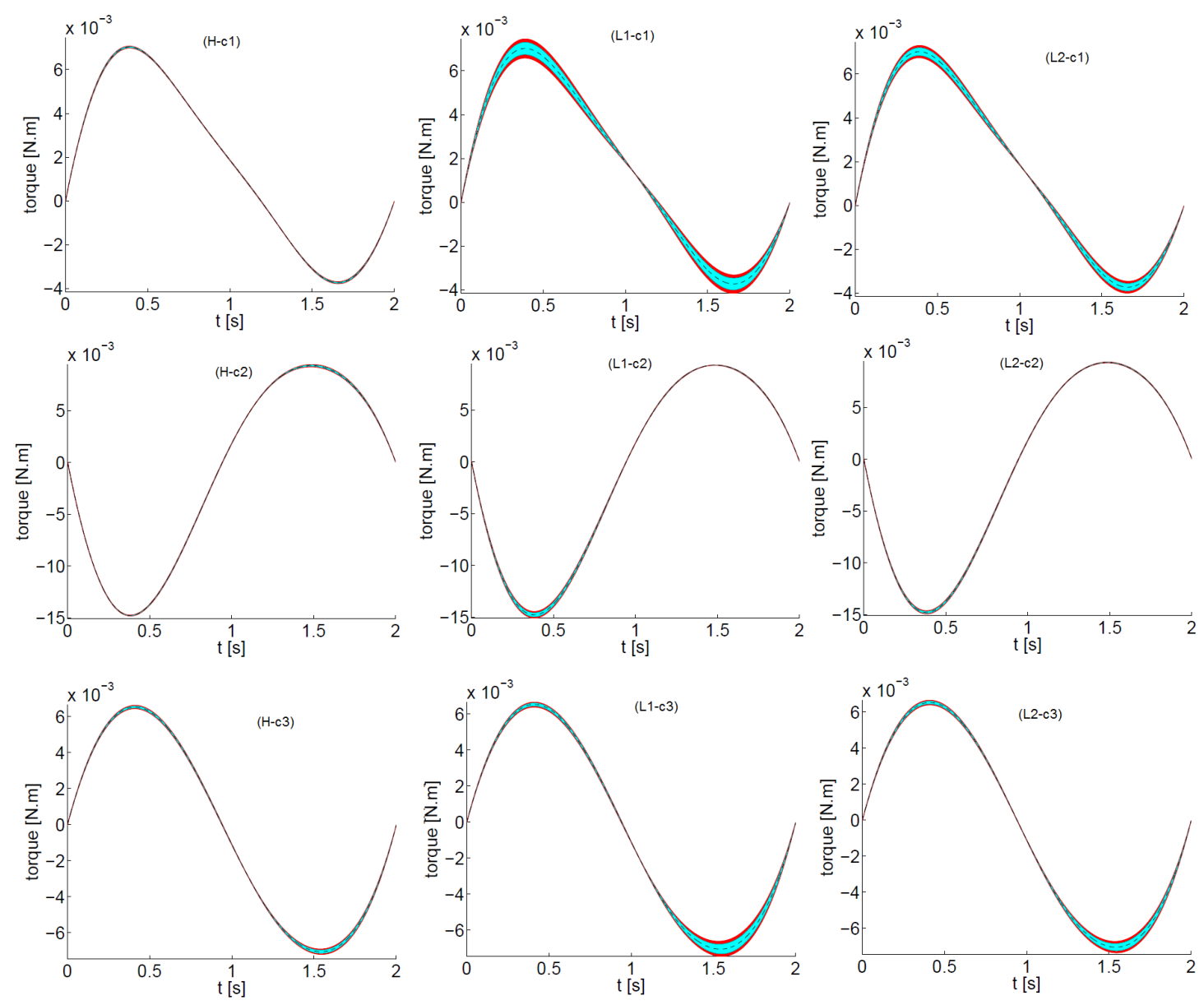

Figura 4.3: Intervalo de valores do torque necessário para realizar a trajetória para o 3RRR com alfa constante e nulo. 
Esse fato está relacionado com o método de otimização, onde a incógnita a ser otimizada é o vetor contendo o máximo torque de cada atuador da cadeia cinemática e guia linear. Assim há melhora em todos os picos de torque, tendendo a essa proximidade.

Se comparar apenas a diferença de comportamento devido aos elos, o caso onde há maior diferença entre os torques é com otimização offline, onde o torque máximo com $l_{2}$ incerto é de $5,5 \%$ menor se comparado com o torque considerando $l_{1}$ variando. Isso não é um resultado intuitivo.

Comparando o 3RRR ao manipulador com otimização offline, o torque máximo devido a variações nos parâmetros $h, l_{1}$ e $l_{2}$ tiveram uma diminuição de 30, 8\%, 28, $0 \%$ e 31, 3\% do pico de torque do manipulador não redundante para a otimização online. Já no caso do pico de torque do $3 \underline{R} R R$ comparado ao manipulador redundante com otimização online, houve uma queda de $37,4 \%, 35,6 \%$ e $37,1 \%$ devido a incerteza nos parâmetros $h$, $l_{1}$ e $l_{2}$ respectivamente.

De acordo com a Figs. 4.3, 4.4 e 4.5 e tabela 4.3.1, pode-se concluir que variações no comprimento de $l_{1}$ tem mais influência na performance dinâmica do manipulador se comparado com os resultados obtidos com variações em $l_{2}$ e $h$. Manipuladores sujeitos a erros de manufatura em $h$ têm maior diminuição, em porcentagem, no pico de torque quando há otimização online.

E comparando as Tabs. 4.6 e 4.7, a maior diferença entre os picos de torque acontece entre o manipulador nominal e com variação no comprimento $l_{1}$, obtendo uma diferença máxima de 7,94\% na otimização offline. Enquanto no manipulador 3RRR e na otimização online há um aumento de 2, $03 \%$ e 4, 97\% respectivamente. E quando é feito essa comparação nos outros componentes, há um aumento máximo de $3,11 \%$ na otimização offline com variação em $l_{2}$. Enquanto o aumento mínimo acontece na variação de $h$ para o 3RRR, com aumento de $0.27 \%$. 

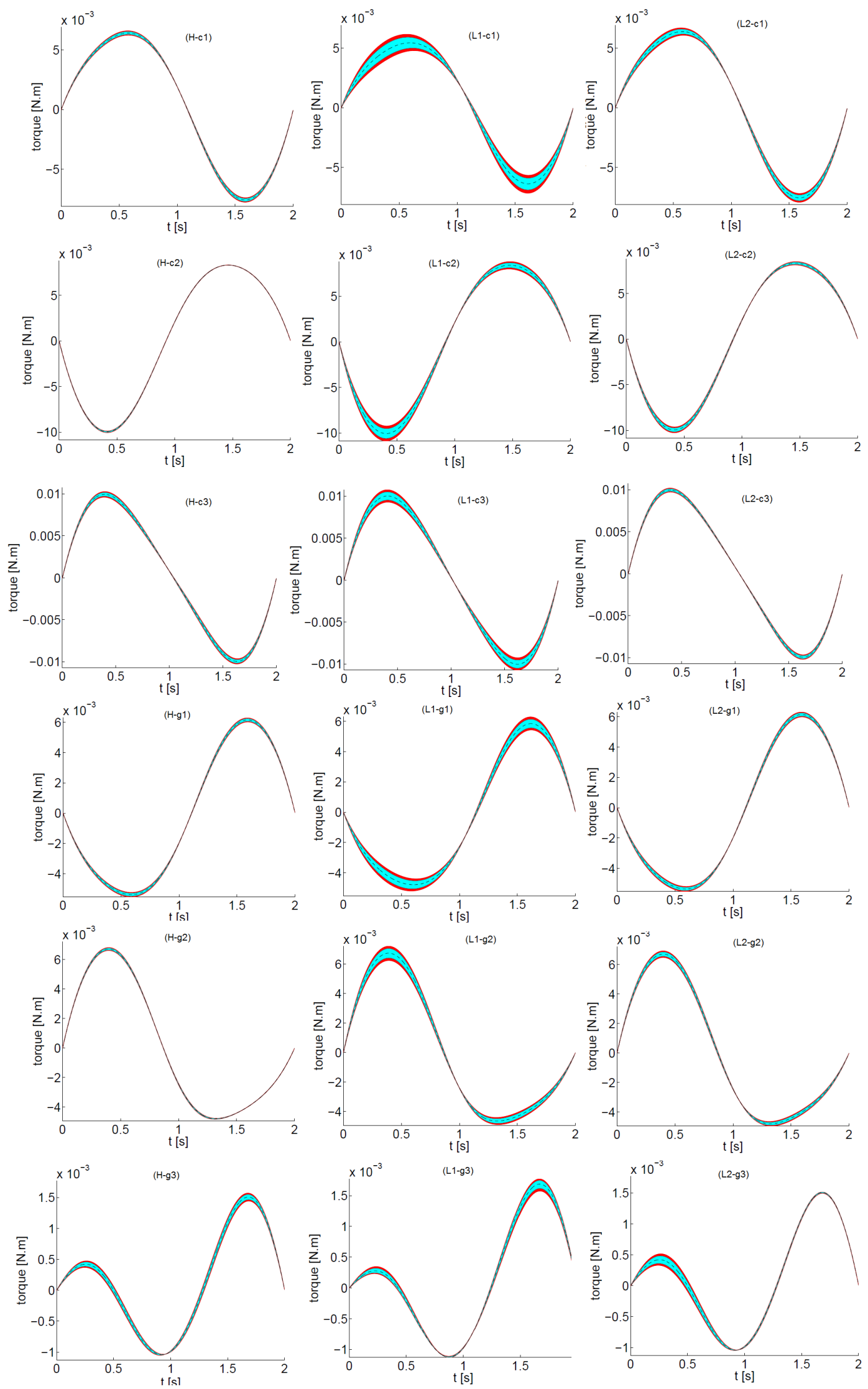

Figura 4.4: Intervalo de valores do torque necessário para realizar a trajetória do 3(P)RRR com Otimização offline com alfa constante e nulo. 

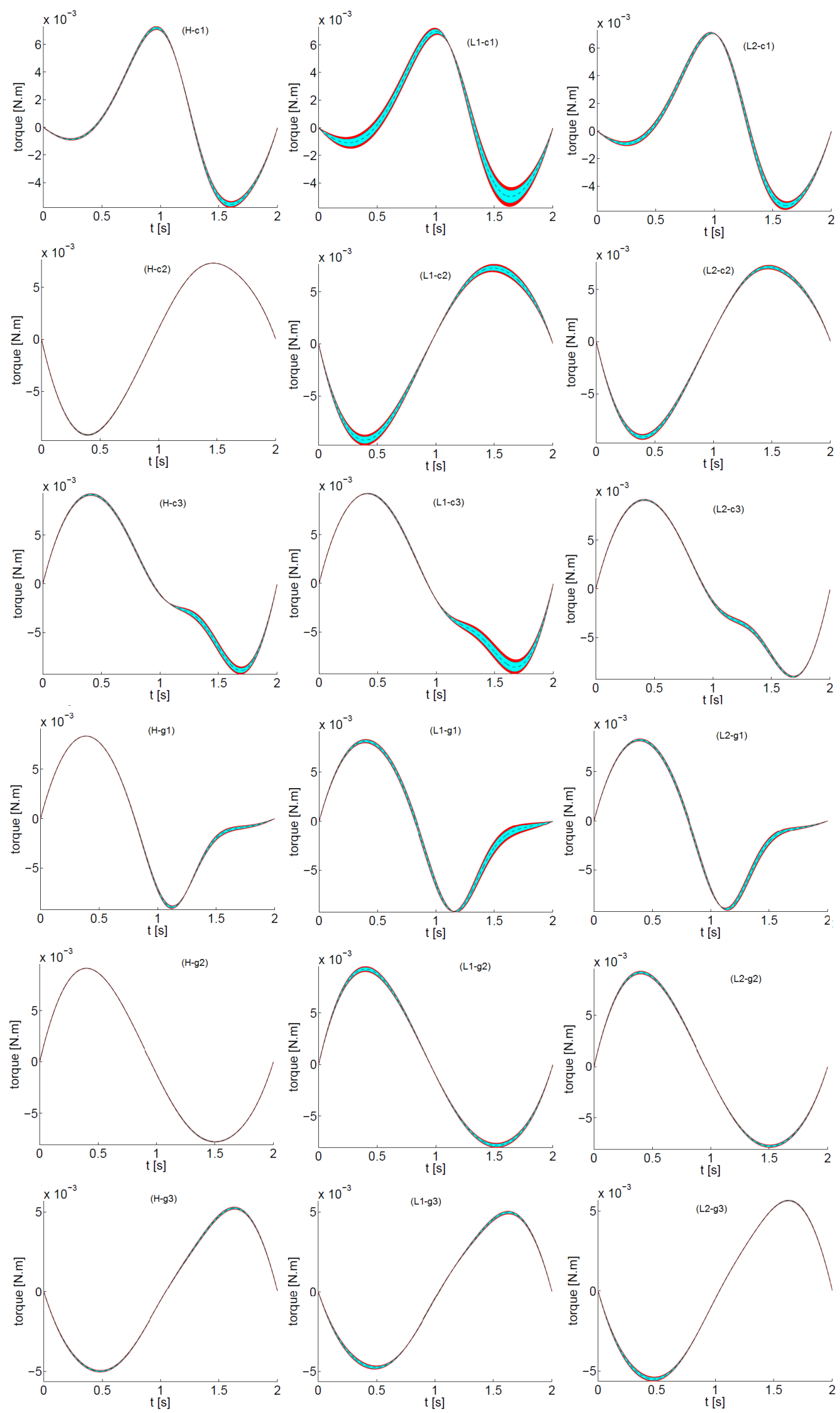

Figura 4.5: Intervalo de valores do torque necessário para realizar a trajetória do 3(므RR com Otimização online com alfa constante e nulo. 


\subsubsection{Influência de parâmetros com incerteza geométrica considerando alfa variável}

Já nesse caso, os torques necessários para realizar a trajetória são analisados considerando as mesmas variações do comprimento dos elos e da distância $h$, mas o ângulo $\alpha$, que representa a orientação do efetuador, é variada. As linhas (1, 2 e 3) das Figs. 4.6, 4.7 e 4.8 mostram o torque requerido para cada atuador (respectivamente $c 1, c 2$ e $c 3$ ) de acordo com os graus de liberdade $\boldsymbol{\Theta}=\left[\begin{array}{lll}\theta_{1} & \theta_{2} & \theta_{3}\end{array}\right]^{T}$. As colunas representam respectivamente a variação no comprimento de $h, l_{1}$ e $l_{2}$. Já as linhas 4,5 e 6 das Figs. 4.7 e 4.8 representam as guias lineares $(g 1, g 2$ e $g 3)$ de acordo com os graus de liberdade $\Theta=\left[\begin{array}{lll}\delta_{1} & \delta_{2} & \delta_{3}\end{array}\right]^{T}$. O ângulo inicial de orientação do efetuador é $\alpha_{i}=-\pi / 8$ enquanto o final é $\alpha_{f}=\pi / 8$.

Tabela 4.8: Torque máximo (N.m), em módulo, para cada cadeia cinemática (c1, c2 ou c3) e guia linear (g1, g2 ou g3), para realizar trajetória pré-determinada considerando otimização para o parâmetro incerto, mas os valores correspondem ao comprimento nominal dos parâmetros.

\begin{tabular}{|c|c|c|c|c|c|c|c|}
\hline Incerteza & Otimização & $\mathrm{c} 1$ & $\mathrm{c} 2$ & $\mathrm{c} 3$ & $\mathrm{~g} 1$ & $\mathrm{~g} 2$ & $\mathrm{~g} 3$ \\
\hline$h, l_{1}$ ou $l_{2}$ & - & 0.01344 & 0.02825 & 0.00365 & - & - & - \\
\hline$h$ & offline & 0.01937 & 0.01980 & 0.01978 & 0.00538 & 0.01426 & 0.01191 \\
\hline$l_{1}$ & offline & 0.01951 & 0.01981 & 0.01917 & 0.00535 & 0.01427 & 0.01218 \\
\hline$l_{2}$ & offline & 0.01965 & 0.01976 & 0.01948 & 0.00545 & 0.01415 & 0.01197 \\
\hline$h$ & online & 0.01743 & 0.01774 & 0.01761 & 0.00179 & 0.01529 & 0.01155 \\
\hline$l_{1}$ & online & 0.01768 & 0.01783 & 0.01717 & 0.00160 & 0.01770 & 0.01118 \\
\hline$l_{2}$ & online & 0.01773 & 0.01777 & 0.01732 & 0.00169 & 0.01762 & 0.01104 \\
\hline
\end{tabular}

Tabela 4.9: Torque máximo (N.m), em módulo, requerido por cada cadeia cinemática (c1, c2 ou c3) e guia linear ( $g 1, g 2$ ou g3), para realizar trajetória pré-determinada considerando um parâmetro incerto.

\begin{tabular}{|c|c|c|c|c|c|c|c|}
\hline Incerteza & Otimização & $\mathrm{c} 1$ & $\mathrm{c} 2$ & $\mathrm{c} 3$ & $\mathrm{~g} 1$ & $\mathrm{~g} 2$ & $\mathrm{~g} 3$ \\
\hline$h$ & - & 0.01404 & 0.02910 & 0.00390 & - & - & - \\
\hline$l_{1}$ & - & 0.01410 & 0.02854 & 0.00397 & - & - & - \\
\hline$l_{2}$ & - & 0.01386 & 0.02840 & 0.00391 & - & - & - \\
\hline$h$ & offline & 0.02027 & 0.02027 & 0.02027 & 0.00572 & 0.01441 & 0.01221 \\
\hline$l_{1}$ & offline & 0.02013 & 0.02011 & 0.02012 & 0.00562 & 0.01450 & 0.01218 \\
\hline$l_{2}$ & offline & 0.02005 & 0.02006 & 0.02006 & 0.00560 & 0.01442 & 0.01210 \\
\hline$h$ & online & 0.01820 & 0.01813 & 0.01823 & 0.00196 & 0.01543 & 0.01184 \\
\hline$l_{1}$ & online & 0.01817 & 0.01833 & 0.01813 & 0.00164 & 0.01799 & 0.01145 \\
\hline$l_{2}$ & online & 0.01801 & 0.01825 & 0.01794 & 0.00175 & 0.01793 & 0.01121 \\
\hline
\end{tabular}

As cores das Figs. 4.6, 4.7 e 4.8 seguem a mesma distribuição das Figs. 4.3, 4.4 e 4.5. O intervalo de valores dos comprimentos dos parâmetros também são os mesmos considerados anteriormente. 

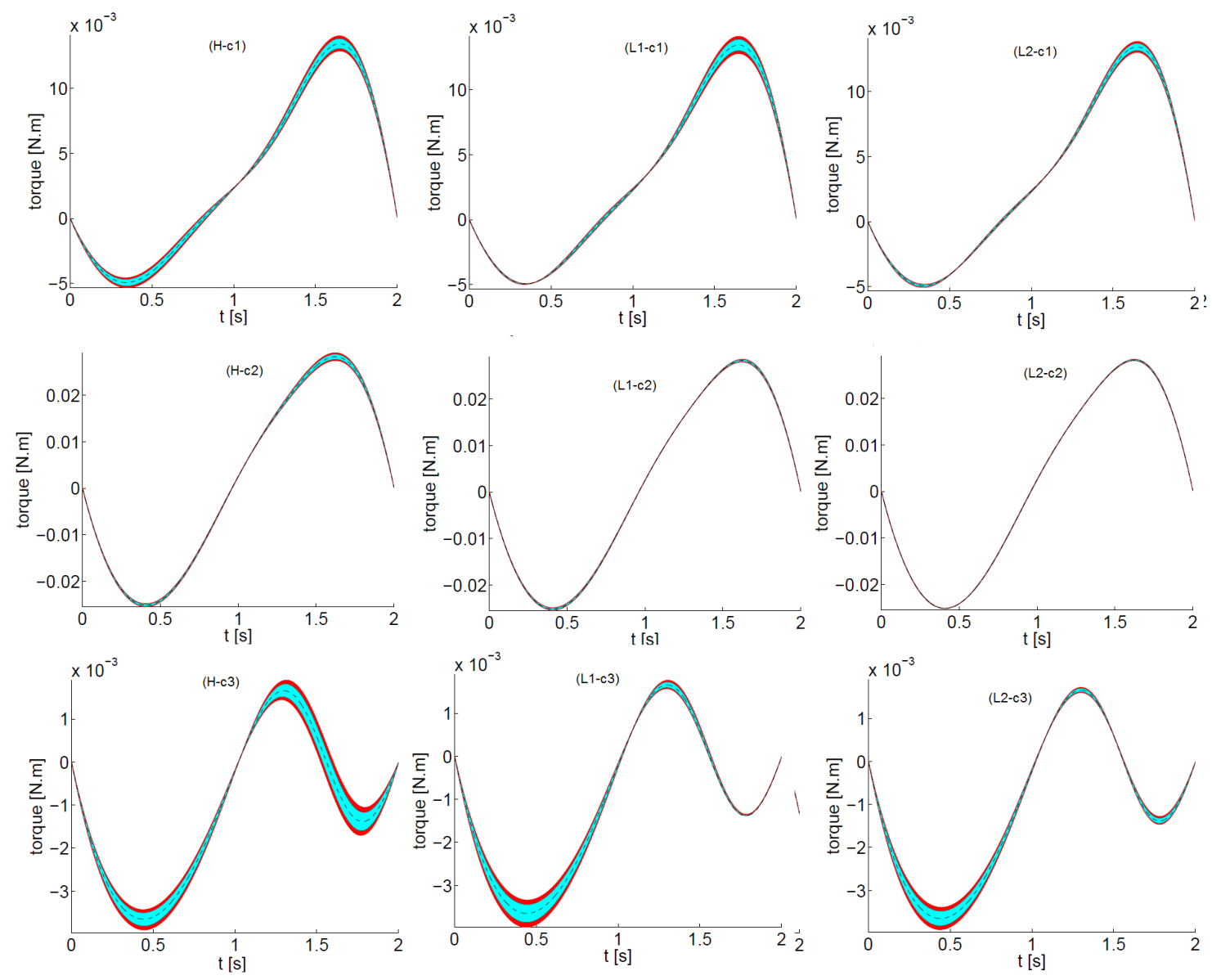

Figura 4.6: Intervalo de valores do torque necessário para realizar a trajetória do 3RRR com alfa variando.

Assim como no caso anterior em que a orientação do efetuador não variava durante a trajetória, nesse caso também há simetria entre os limites do intervalo para os valores de torque calculado. Quando comparado esses limites ao valor correspondente ao encontrado com o tamanho nominal do parâmetro, a proporção é mantida.

E considerando a Tab. 4.9 tambêm há a mesma tendência de homogeneização dos torques. Só que nesse caso, considerando variações em $h$ há somente três atuadores com o torque de pico bastante próximos, chegando a um máximo de $0,5 \%$ de diferença. Se comparado os quatro atuadores com o pico de torque mais próximo, a diferença para variações em $h$ cresce para 15,4\%. Já a essa diferença para os elos $l_{1}$ e $l_{2}$ permanecem pequenas quando comparado os quatro atuadores mais próximos, onde a variação atinge um máximo de 1,8\% e 1,7\% respectivamente.

Se comparado a influência da incerteza na distância $h$ sem variação na orientação ou com variação, há mudanças no comportamento do pico de torque. No caso sem mudança de orientação do efetuador, o pico máximo de torque com $h$ variável foi sempre menor se comparado com os picos quando a variação acontece em algum dos elos. Já quando há

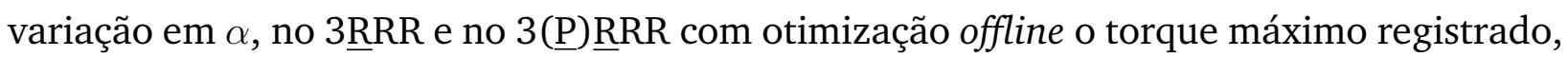


se comparado os três parâmetros variando, foi em $h$. Mas quando a otimização online foi feita, o pico de torque com $h$ incerto voltou a ser o menor.

Nota-se também, que comparando as Tabs. 4.8 e 4.9, sempre a maior diferença entre os picos de torque acontece entre o manipulador nominal e o manipulador sujeito a variação no comprimento de $h$. Com variações de 3,01\%,2,37\% e 2,76\% comparando o manipulador nominal e respectivamente o 3RRR, o 3(P)RRR com otimização offline e otimização online. E quando é feito essa comparação nos outros componentes, o pico de torque sempre aumenta mais considerando variações em $l_{1}$ se comparado com $l_{2}$ variando.

Comparando apenas a diferença de comportamento devido aos elos incertos, não há variação no pico de torque entre eles com mais de $1 \%$ de diferença. Mas sempre o torque no braço $l_{1}$ foi maior se comparado ao braço $l_{2}$.

A diminuição do pico de torque entre o 3 RRR e o manipulador com otimização offline, foi de 30,34\%, 29,4\% e 29,4\%, devido a variações nos parâmetros $h, l_{1}$ e $l_{2}$ respectivamente. Já no caso do pico de torque do $3 \underline{R} R R$ comparado ao manipulador redundante com otimização online, houve uma queda de $37,3 \%, 35,8 \%$ e $35,7 \%$ devido a incerteza nos parâmetros $h, l_{1}$ e $l_{2}$ respectivamente.

De acordo com a Figs. 4.6, 4.7 e 4.8 e tabela 4.3.1, pode-se concluir que variações no comprimento de $l_{1}$ tem uma influência ligeiramente maior na performance dinâmica do manipulador se comparado com os resultados obtidos com variações em $l_{2}$ e $h$. Manipuladores sujeitos a erros de manufatura em $h$ têm maior diminuição no pico de torque, em porcentagem, quando há otimização online. 

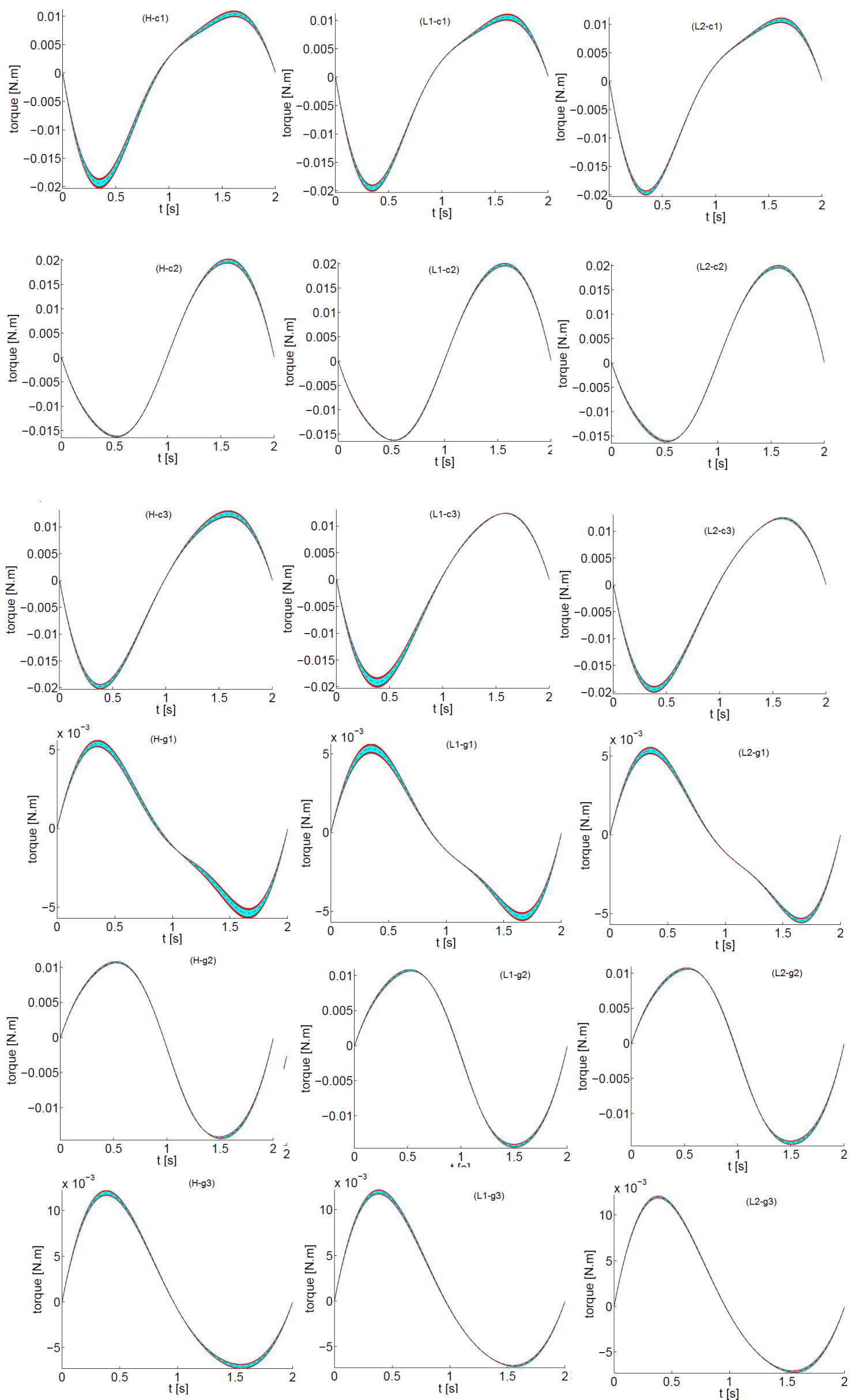

Figura 4.7: Intervalo de valores do torque necessário para realizar a trajetória do 3() RRR com Otimização offline com alfa variando. 

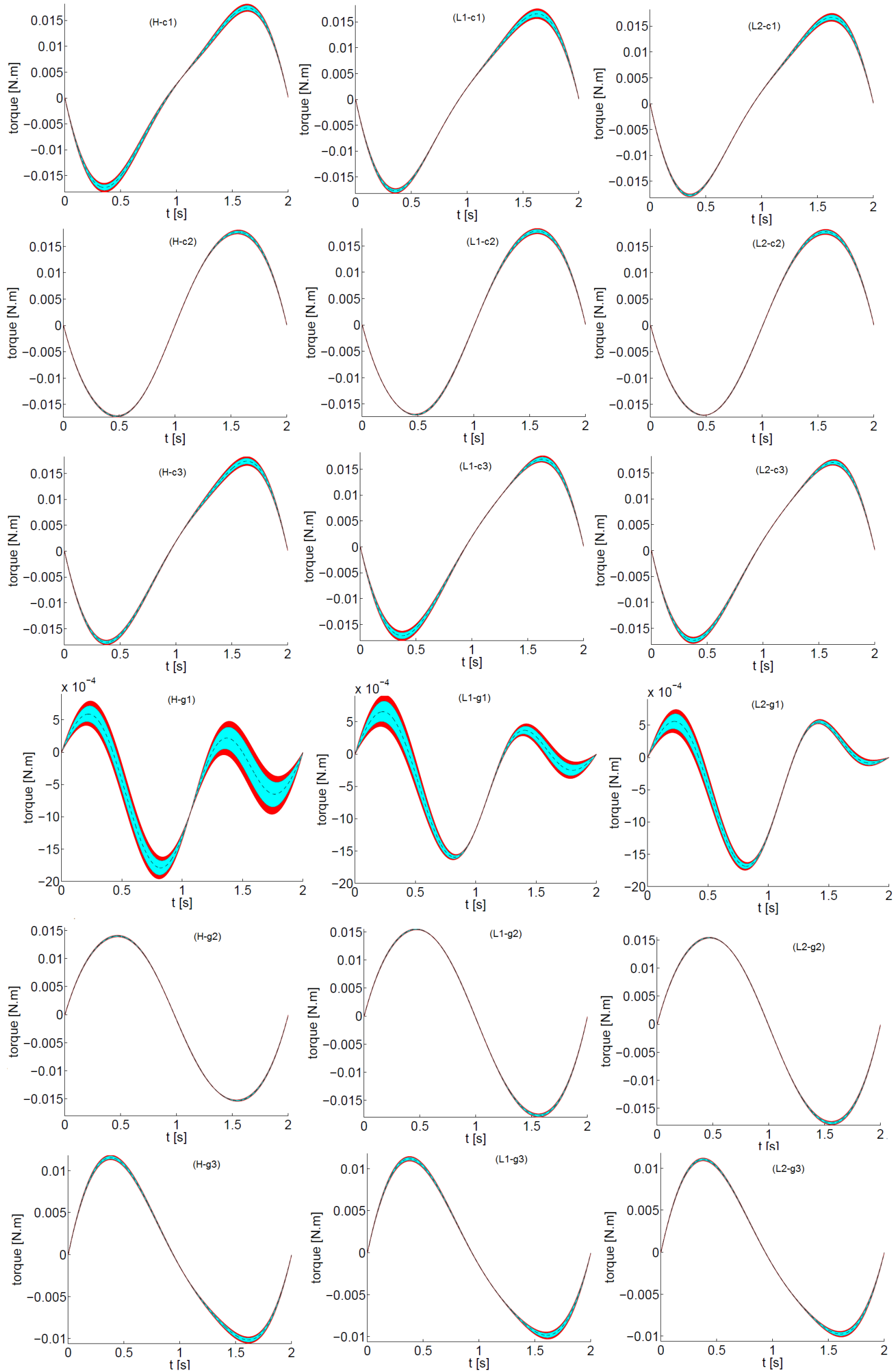

Figura 4.8: Intervalo de valores do torque necessário para realizar a trajetória do 3(P)RRR com Otimização online com alfa variando. 


\subsection{Diferença entre áreas sujeitas a singularidades}

Essa subseção é destinada a comparação entre as áreas sujeitas a singularidades, considerando variação no comprimento dos elos e na distância $h$, e para isso é feito um mapa da área de trabalho dos manipuladores e suas regiões singulares.

Nas Figs. 4.9, 4.10, 4.11 e 4.12 tem-se as prováveis áreas singulares em duas cores: turquesa é a região com $95 \%$ de confiabilidade, enquanto a região em vermelhor é o restante das possibilidades (até 99,74\%). Já a linha em azul marinho é a área considerando os parâmetros com seu valor nominal.

As linhas 1 e 2 das figuras são respectivamente $\operatorname{com} \alpha=0$ e $\alpha=\pi / 8$, enquanto as colunas são variações em $h, l_{1}$ e $l_{2}$ respectivamente. A posição das guias está especificada em cada figura.
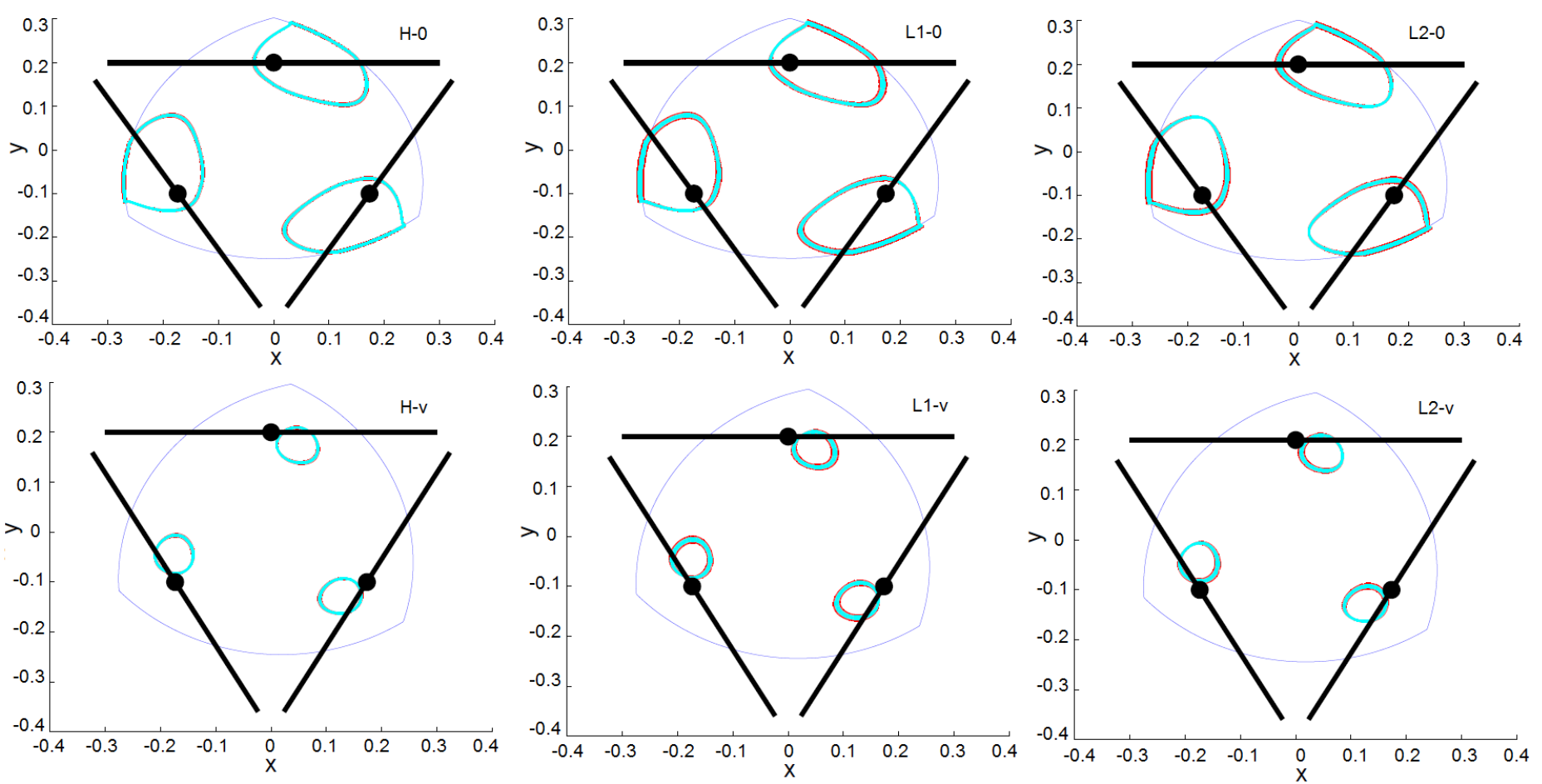

Figura 4.9: Áreas singulares para $A_{1}=(0.00,0.20), A_{2}=(0.17,-0.10) \mathrm{e}$ $A_{3}=(-0.17,-0.10)$, considerando variações nos parâmetros $h, l_{1}$ e $l_{2}$. A orientação do efetuador é dada por $\alpha=0$ e $\alpha=\pi / 8$.

De acordo com as Figs. 4.9, 4.10 e 4.12 percebe-se uma mudança brusca na área de trabalho sujeita a singularidades se comparada a mudança da orientação ou sem mudança do efetuador. Essa área de singularidades também se altera na Fig. 4.11 fazendo essa mesma comparação, mas a mudança é menos acentuada.

Percebe-se nas Figs. 4.9, 4.10, 4.11 e 4.12 que incerteza no parâmetro $h$ gera uma área menor sujeita a singularidades se comparado com essas áreas devido à incerteza nos elos. 

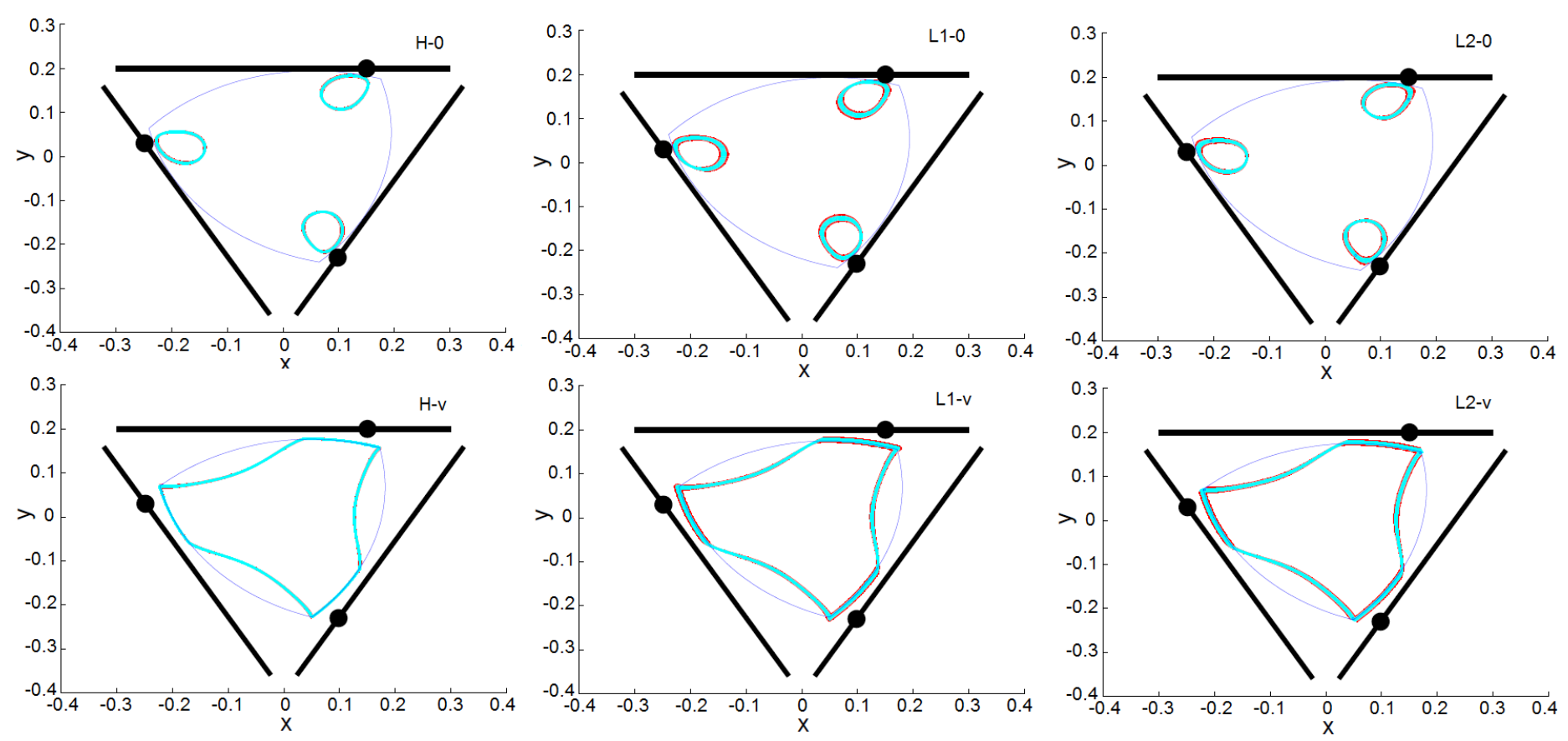

Figura 4.10: Áreas singulares para $A_{1}=(0.15,0.20), A_{2}=(0.10,-0.23) \mathrm{e}$ $A_{3}=(-0.25,0.03)$, considerando variações nos parâmetros $h, l_{1}$ e $l_{2}$. A orientação do efetuador é dada por $\alpha=0$ e $\alpha=\pi / 8$.

Mas essa diferença só é perceptível, com maior clareza, quando vizualizado todo espaço de possibilidades (99,74\%, área em azul turquesa mais área em vermelho) e não somente a parte pertencente a área de confiabilidade (95\%, somente área em azul turquesa).

A Fig. 4.10 é onde há maior mudança na área de trabalho útil. A mudança de orientação do efetuador aumentou significativamente a área sujeita a prováveis singularidades.

Diferentes orientações do atuador resultam em diferentes limites da área de trabalho.

O manipulador com posições dos atuadores em $A_{1}=(0.30,0.20), A_{2}=(0.17,-0.10)$ e $A_{3}=(-0.10,-0.23)$ (Fig. 4.12) é onde acontece maior restrições de trajetórias, principalmente considerando o ângulo do efetuador $\alpha=\pi / 8$. 

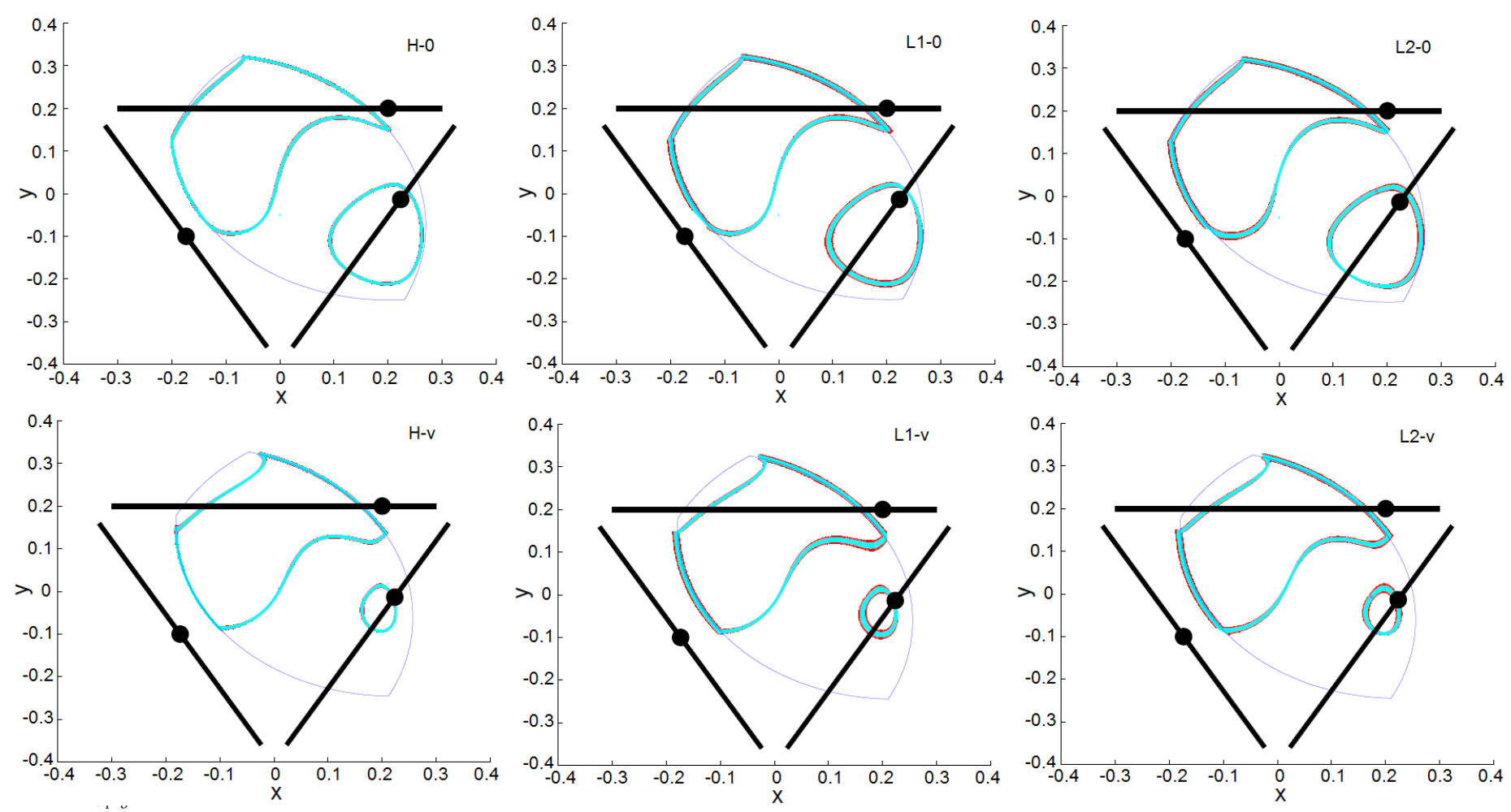

Figura 4.11: Áreas singulares para $A_{1}=(0.20,0.20), A_{2}=(0.22,-0.01) \mathrm{e}$ $A_{3}=(-0.17,-0.10)$, considerando variações nos parâmetros $h, l_{1}$ e $l_{2}$. A orientação do efetuador é dada por $\alpha=0$ e $\alpha=\pi / 8$.
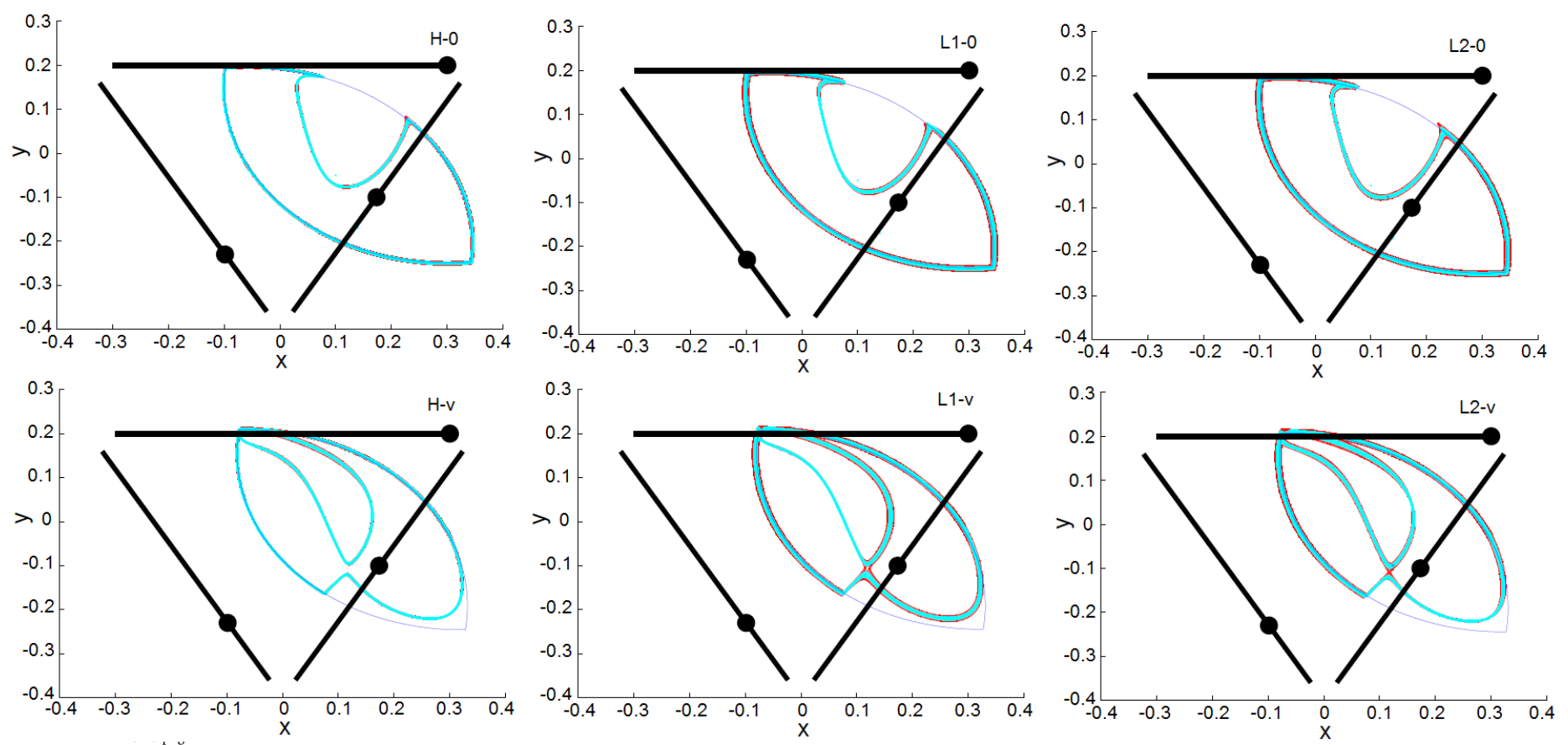

Figura 4.12: Áreas singulares para $A_{1}=(0.30,0.20), A_{2}=(0.17,-0.10) \mathrm{e}$ $A_{3}=(-0.10,-0.23)$, considerando variações nos parâmetros $h, l_{1}$ e $l_{2}$. A orientação do efetuador é dada por $\alpha=0$ e $\alpha=\pi / 8$. 



\section{Conclusão e considerações para trabalhos futuros}

Manipuladores de cinemática paralela têm vantagens em relação aos manipuladores de arquitetura serial. A alta capacidade de carga e a rigidez elevada contribuiem para esse tipo de arquitetura de alcançar alta aceleração/velocidade. E essa alta aceleração/velocidade contribui para maior rapidez na conclusão de tarefas, sendo muito vantajoso na área industrial. Entretanto, uma das desvantagens dos manipuladores paralelos é a presença de regiões singulares na área de trabalho, o que diminui a área de trabalho útil. Além disso, essas singularidades provocam um perda de rigidez própria do mecanismo resultando em instabilidades e esforços elevados.

De acordo com a revisão bibliográfica realizada, já foram mostradas as vantagens da adiação de redundâncias em manipuladores de cinemática paralela. A capacidade de desviar de singularidades ou até mesmo eliminá-las é uma dessas vantagens. Tendo como objetivo mensurar o impacto do dimensionamento dos componentes sobre o torque aplicado nas juntas, nesta dissertação de mestrado foi investigado o desempenho cinemático e dinâmico do manipulador robótico planar com redundância cinemática considerando erros de manufatura de seus componentes. Para isso foram comparados os picos de torque necessário para o manipulador percorrer a trajetória pré-definida considerando os elos e o efetuador com dimensões incertas. Além dessa comparação, a parte da área de trabalho sujeita a singularidades também foi comparada, para essa mesma incerteza nos componentes. 
Para essa comparação ser feita, a trajetória foi mantida para todos os casos. E quando houve otimização para diminuição dos picos de torques, foi comparado o mesmo tipo de otimização com variações em cada componente, ocorrendo variação em um por um.

Trabalhos na área mostram que singularidades na área de trabalho de manipuladores de cinemática paralela são afetados pela posição das juntas ativas. No entanto, essa região sujeita a singularidades não foi estudada para diferentes tamanhos dos elos ou das dimenções do efetuador. E com os resultados apresentados, nota-se que cada componente tem influência distinta na provável área sujeita a singularidades. Mudança de orientação do efetuador, mantendo a mesma posição dos atuadores, apresenta mudança quase sempre significativa na região sujeita a singularidades. Com isso, notou-se que com um estudo mais bem elaborado, seria possível encontrar uma posição ótima para os atuadores e orientação do efetuador, para assim conseguir uma área de trabalho com maior área útil possível.

A comparação entre o desempenho dinâmico do manipulador, considerando os componentes incertos, demonstrou que o braço $l_{1}$ é o componente que tem maior influência nos picos de torque necessário para o manipulador realizar a trajetória. Além disso, o braço $l_{1}$ também é o componente que sofre maior aumento de torque se comparado o máximo torque com os componentes do manipulador de tamanho nominal e o torque variando o comprimento de seus parâmetros. Notou-se também que o comprimento $h$ teve mais influência quando considerado mudança na orientação do efetuador, mas essa influência foi suavizada com a otimização do posicionamento das guias lineares. A mudança de orientação do efetuador gera acréscimo no pico de torque para essa trajétoria.

O estudo dinâmico do manipulador cosiderando erros de manufatura nos componentes é limitado pelo fato do estudo não ser em toda área de trabalho, o que seria o ideal. Outro fator é o método de otimização das posições das juntas. Esses métodos são limitados pela quantidade de variáveis de otimização impostas, e quanto mais variáveis otimizadas, melhores resultados são atingidos.

A principal contribuição desse trabalho é saber que o braço $l_{1}$ tem maior influência no desempenho dinâmico do manipulador se comparado com os outros componentes estudados. O que sugere que a manufatura desse componente deve ser feita com menor tolerâncias, diminuindo esse pico de torque. Além disso, notou-se que posições dos atuadores e orientação do efetuador podem ser otimizadas para encontrar posições ótimas com o objetivo de obter maior área de trabalho útil.

Com isso, seguem algumas propostas para trabalhos futuros:

- Efetuar estudos considerando os componentes flexiveis;

- Estudar o efeito de folga nas juntas dos componentes do manipulador; 
- Realizar estudos com incerteza dinâmica, por exemplo, rigidez variável no movimento dos elos;

- Efetuar estudos de métodos de otimização para a área de trabalho útil, encontrando posições ótimas dos atuadores na guia linear e também a orientação do efetuador;

- Adaptar esses estudos para validação experimental. 



\section{Referências}

Bengtsson, K.; Manager, P. Klas Bengtsson, Product Manager, 20 Sep 2013. 2013.

Binaud, N.; CARO, S.; Wenger, P. Comparison of 3-RPR planar parallel manipulators with regard to their kinetostatic performance and sensitivity to geometric uncertainties. Meccanica, v. 46, n. 1, p. 75-88, 2011.

Boggs, P. T.; Tolle, W. J. Sequential Quadratic Programming. Acta Numerica, , n. January 1995, p. 1-52, 1996.

Caro, S.; Binaud, N.; Wenger, P. Sensitivity Analysis of 3-RPR Planar Parallel Manipulators. Journal of Mechanical Design, v. 131, n. 12, p. 121005, 2009.

Chen, G.; WAnG, H.; Lin, Z. A unified approach to the accuracy analysis of planar parallel manipulators both with input uncertainties and joint clearance. Mechanism and Machine Theory, v. 64, p. 1-17, 2013.

Disponível em: http://dx.doi.org/10.1016/j.mechmachtheory.2013.01.005

Clavel, R. A fast robot with parallel geometry. In: Proc. Int. Symposium on Industrial Robots, 1988, p. 91-100.

DEVORE, J. Probability and statistics for engineering and the sciences. Cengage Learning, 2015.

Donatelli, G. D.; Konrath, A. C. Simulação de monte carlo na avaliação de incertezas de medição. 2005.

Donelan, P. Singularities of Robot Manipulators. Singularity Theory - Dedicated to Jean-Paul Brasselet on His 60th Birthday - Proceedings of the 2005 Marseille Singularity School and Conference, p. 199-200, 2007.

Disponível em: http://eproceedings.worldscinet.com/9789812707499/ 9789812707499_0006.html 
EARL, C.; RoONEY, J. Some kinematic structures for robot manipulator designs. Journal of Mechanisms, Transmissions, and Automation in Design, v. 105, n. 1, p. 15-22, 1983.

Fontes, J. V.; SAntos, J. C.; Silva, M. M. D. Optimization Strategies for Actuators of Kinematically Redundant Manipulators to Achieve High Dynamic Performance. 2014 Joint Conference on Robotics: SBR-LARS Robotics Symposium and Robocontrol, v. 2, p. 31-36, 2014.

Disponível em: http://ieeexplore.ieee.org/lpdocs/epic03/wrapper.htm? arnumber $=7024092$

Gosselin, C.; Angeles, J. Singularity analysis of closed-loop kinematic chains. IEEE Transactions on Robotics and Automation, v. 6, n. 3, p. 281-290, 1990.

KLUZ, R.; TRZEPIECIŃski, T. The repeatability positioning analysis of the industrial robot arm. Assembly Automation, v. 34, n. 3, p. 285-295, 2014.

Kotlarski, J.; ABDEllatif, H.; Heimann, B. Improving the pose accuracy of a planar 3(R)under-barRR parallel manipulator using kinematic redundancy and optimized switching patterns. 2008 Ieee International Conference on Robotics and Automation, Vols 1-9, p. 3863-3868, 2008.

Disponível em: files/469/04543804.pdf\$\delimiter"026E30F\$nhttp://ieeexplore. ieee.org/lpdocs/epic03/wrapper.htm?arnumber $=4543804$

Kotlarski, J.; Abdellatif, H.; Ortmaier, T.; Heimann, B. Enlarging the useable workspace of planar parallel robots using mechanisms of variable geometry. 2009 ASME/IFToMM International Conference on Reconfigurable Mechanisms and Robots, p. 6372, 2009.

Kotlarski, J.; Do Thanh, T.; Heimann, B.; Ortmaier, T. Optimization strategies for additional actuators of kinematically redundant parallel kinematic machines. Proceedings - IEEE International Conference on Robotics and Automation, p. 656-661, 2010.

Kotlarski, J.; HeIMANN, B.; ORTMAiER, T. Experimental Validation of the Influence of Kinematic Redundancy on the Pose Accuracy of Parallel Kinematic Machines, p. 19231929. 2011.

MERLET, J.-P. Redundant parallel manipulators. Laboratory Robotics and Automation, v. 8, n. 1, p. 17-24, 1996.

Disponível em: http://dx.doi.org/10.1002/(SICI) 1098-2728(1996)8:1<17: : AID-LRA3>3.0.CO;2-\#

Merlet, J.-P. Interval Analysis and Robotics. In: KANEKO, M.; NAKAMURA, Y., eds. Robotics Research SE - 13, v. 66 de Springer Tracts in Advanced Robotics, Springer Berlin 
Heidelberg, p. 147-156, 2011.

Disponível em: http://dx.doi.org/10.1007/978-3-642-14743-2_13

Mooring, B.; PACK, T. Determination and specification of robot repeatability. In: Robotics and Automation. Proceedings. 1986 IEEE International Conference on, IEEE, 1986, p. 1017-1023.

MÜllER, A. Consequences of geometric imperfections for the control of redundantly actuated parallel manipulators. IEEE Transactions on Robotics, v. 26, n. 1, p. 21-31, 2010.

NiU, X. M.; GAO, G. Q.; LIU, X. J.; BAO, Z. D. Dynamics and control of a novel 3-DOF parallel manipulator with actuation redundancy. International Journal of Automation and Computing, v. 10, n. 6, p. 552-562, 2013.

NOH, Y.; IKJIN, K. K. C.; GORSICH, D.; LAMB, D. Reliability-based design optimization with confidence level under input model uncertainty due to limited test data, p. 443458. 2011.

RAmsli, E. Probability Distribution of Repeatability of Industrial Robots, p. 276-283. 1988.

RAO, S. S.; BнAтt, P. K. Probabilistic approach to manipulator kinematics and dynamics. v. $72,2001$.

RochA, D. M.; SILVA, M. M. Workspace and singularity analysis of redundantly actuated planar parallel kinematic machines. In: Proc. of the XV International Symposium on Dynamic Problems of Mechanics, Búzios, RJ, Brazil, 2013, p. 1-10.

SilVA, M. M.; GonÇAlVES, L. A. M. Mechatronic design concept and its application to pick-and-place robotic systems. Journal of the Brazilian Society of Mechanical Sciences and Engineering, v. 35, n. 1, p. 31-40, 2013.

Disponível em: http://link.springer.com/10.1007/s40430-013-0002-5

Silva, M. M.; Oliveira, L. P. R.; Brüls, O.; Michelin, M.; Baradat, C.; Tempier, O.; CAigny, J. D.; Swevers, J.; Desmet, W.; Brussel, H. V. Integrating structural and input design of a 2-DOF high-speed parallel manipulator: A flexible model-based approach. Mechanism and Machine Theory, v. 45, n. 11, p. 1509-1519, 2010.

Disponível em: http://www.sciencedirect.com/science/article/pii/ S0094114X10001217

TAnnous, M.; CARO, S.; GoldszTEJn, A. Sensitivity analysis of parallel manipulators using an interval linearization method. Mechanism and Machine Theory, v. 71, p. 93- 
114, 2014.

Disponível em: http://dx.doi.org/10.1016/j.mechmachtheory.2013.09.004

TsAI, M. J.; LAI, T. H. Kinematic sensitivity analysis of linkage with joint clearance based on transmission quality. Mechanism and Machine Theory, v. 39, n. 11, p. 1189-1206, 2004.

TSAI, M. J.; LAI, T. H. Accuracy analysis of a multi-loop linkage with joint clearances. Mechanism and Machine Theory, v. 43, n. 9, p. 1141-1157, 2008.

WU, J.; WANG, J.; LI, T.; WANG, L. Performance analysis and application of a redundantly actuated parallel manipulator for milling. Journal of Intelligent and Robotic Systems: Theory and Applications, v. 50, n. 2, p. 163-180, 2007.

WU, J.; WANG, J.; WANG, L.; You, Z. Performance comparison of three planar 3-DOF parallel manipulators with 4-RRR, 3-RRR and 2-RRR structures. Mechatronics, v. 20, n. 4, p. 510-517, 2010.

Disponível em: http://dx.doi.org/10.1016/j.mechatronics.2010.04.012

WU, W.; RAO, S. Uncertainty analysis and allocation of joint tolerances in robot manipulators based on interval analysis. Reliability Engineering \& System Safety, v. 92, n. 1, p. 54-64, 2007. 


\section{Apêndice}

\section{$A$}

\section{Tabela IT16}

Table 1 - Values of standard tolerance grades for nominal sizes up to $3150 \mathrm{~mm}$

\begin{tabular}{|c|c|c|c|c|c|c|c|c|c|c|c|c|c|c|c|c|c|c|c|c|c|}
\hline \multirow{2}{*}{\multicolumn{2}{|c|}{$\begin{array}{c}\text { Nominal size } \\
\mathrm{mm}\end{array}$}} & \multicolumn{20}{|c|}{ Standard tolerance grades } \\
\hline & & IT01 & ITO & IT1 & IT2 & IT3 & IT4 & IT5 & IT6 & IT7 & IT8 & IT9 & IT10 & IT11 & IT12 & IT13 & IT14 & IT15 & IT16 & IT17 & IT18 \\
\hline Above & $\begin{array}{l}\text { Up to } \\
\text { and } \\
\text { inclu- } \\
\text { ding }\end{array}$ & \multicolumn{20}{|c|}{ Standard tolerance values } \\
\hline- & 3 & 0,3 & 0,5 & 0,8 & 1,2 & 2 & 3 & 4 & ( & 10 & 14 & 25 & 40 & 60 & 0,1 & 0,14 & 0,25 & 0,4 & 0,6 & 1 & 1,4 \\
\hline 3 & 6 & 0,4 & 0,6 & 1 & 1,5 & 2,5 & 4 & 5 & 8 & 12 & 18 & 30 & 48 & 75 & 0,12 & 0,18 & 0,3 & 0,48 & 0,75 & 1,2 & 1,8 \\
\hline 6 & 10 & 0,4 & 0,6 & 1 & 1,5 & 2,5 & 4 & 6 & 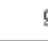 & 15 & 22 & 36 & 58 & 90 & 0,15 & 0,22 & 0,36 & 0,58 & 0,9 & 1,5 & 2,2 \\
\hline 10 & 18 & 0,5 & 0,8 & 1,2 & 2 & 3 & 5 & 8 & 1 & 18 & 27 & 43 & 70 & 110 & 0,18 & 0,27 & 0,43 & 0,7 & 1,1 & 1,8 & 2,7 \\
\hline 18 & 30 & 0,6 & 1 & 1,5 & 2,5 & 4 & 6 & 9 & $1:$ & 21 & 33 & 52 & 84 & 130 & 0,21 & 0,33 & 0,52 & 0,84 & 1,3 & 2,1 & 3,3 \\
\hline 30 & 50 & 0,6 & 1 & 1,5 & 2,5 & 4 & 7 & 11 & 16 & 25 & 39 & 62 & 100 & 160 & 0,25 & 0,39 & 0,62 & 1 & 1,6 & 2,5 & 3,9 \\
\hline 50 & 80 & 0,8 & 1,2 & 2 & 3 & 5 & 8 & 13 & 15 & 30 & 46 & 74 & 120 & 190 & 0,3 & 0,46 & 0,74 & 1,2 & 1,9 & 3 & 4,6 \\
\hline 80 & 120 & 1 & 1,5 & 2,5 & 4 & 6 & 10 & 15 & 2 & 35 & 54 & 87 & 140 & 220 & 0,35 & 0,54 & 0,87 & 1,4 & 2,2 & 3,5 & 5,4 \\
\hline 120 & 180 & 1,2 & 2 & 3,5 & 5 & 8 & 12 & 18 & 2 & 40 & 63 & 100 & 160 & 250 & 0,4 & 0,63 & 1 & 1,6 & 2,5 & 4 & 6,3 \\
\hline 180 & 250 & 2 & 3 & 4,5 & 7 & 10 & 14 & 20 & 25 & 46 & 72 & 115 & 185 & 290 & 0,46 & 0,72 & 1,15 & 1,85 & 2,9 & 4,6 & 7,2 \\
\hline 250 & 315 & 2,5 & 4 & 6 & 8 & 12 & 16 & 23 & 32 & 52 & 81 & 130 & 210 & 320 & 0,52 & 0,81 & 1,3 & 2,1 & 3,2 & 5,2 & 8,1 \\
\hline 315 & 400 & 3 & 5 & 7 & 9 & 13 & 18 & 25 & 36 & 57 & 89 & 140 & 230 & 360 & 0,57 & 0,89 & 1,4 & 2,3 & 3,6 & 5,7 & 8,9 \\
\hline 400 & 500 & 4 & 6 & 8 & 10 & 15 & 20 & 27 & 40 & 63 & 97 & 155 & 250 & 400 & 0,63 & 0,97 & 1,55 & 2,5 & 4 & 6,3 & 9,7 \\
\hline 500 & 630 & & & 9 & 11 & 16 & 22 & 32 & 4 & 70 & 110 & 176 & 280 & 440 & 0,7 & 1,1 & 1,75 & 2,8 & 4,4 & 7 & 11 \\
\hline 630 & 800 & & & 10 & 13 & 18 & 25 & 36 & 5 & 80 & 125 & 200 & 320 & 500 & 0,8 & 1,25 & 2 & 3,2 & 5 & 8 & 12,5 \\
\hline 800 & 1000 & & & 11 & 15 & 21 & 28 & 40 & 5 & 90 & 140 & 230 & 360 & 560 & 0,9 & 1.4 & 2,3 & 3,6 & 5,6 & 9 & 14 \\
\hline 1000 & 1250 & & & 13 & 18 & 24 & 33 & 47 & 68 & 105 & 165 & 260 & 420 & 660 & 1,05 & 1,65 & 2,6 & 4,2 & 6.6 & 10.5 & 16,5 \\
\hline 1250 & 1600 & & & 15 & 21 & 29 & 39 & 55 & 7 & 125 & 195 & 310 & 500 & 780 & 1,25 & 1,95 & 3,1 & 5 & 7,8 & 12,5 & 19,5 \\
\hline 1600 & 2000 & & & 18 & 25 & 35 & 46 & 65 & 92 & 150 & 230 & 370 & 600 & 920 & 1,5 & 2,3 & 3.7 & 6 & 9.2 & 15 & 23 \\
\hline 2000 & 2500 & & & 22 & 30 & 41 & 55 & 78 & 110 & 175 & 280 & 440 & 700 & 1100 & 1,75 & 2,8 & 4,4 & 7 & 11 & 17,5 & 28 \\
\hline 2500 & 3150 & & & 26 & 36 & 50 & 68 & 96 & 13 & 210 & 330 & 540 & 860 & 1350 & 2,1 & 3,3 & 5,4 & 8,6 & 13,5 & 21 & 33 \\
\hline
\end{tabular}

Figura A.1: Tabela IT16, ISO $286-1: 2010$ (E). 

Apêndice

$B$

Tabela Z

Escores z

NEGATIVOS

\begin{tabular}{|c|c|c|c|c|c|c|c|c|c|c|}
\hline \multirow[b]{2}{*}{$z$} & \multicolumn{10}{|c|}{ Distribuição Normal Padrão (z): Área Acumulada à ESQUERDA } \\
\hline & 0,00 & 0,01 & 0,02 & 0,03 & 0,04 & 0,05 & 0,06 & 0,07 & 0,08 & 0,09 \\
\hline $\begin{array}{c}-3,50 \\
\mathrm{e} \\
\text { menor }\end{array}$ & 0,0001 & & & & & & & & & \\
\hline$-3,4$ & 0,0003 & 0,0003 & 0,0003 & 0,0003 & 0,0003 & 0,0003 & 0,0003 & 0,0003 & 0,0003 & 0,0002 \\
\hline$-3,3$ & 0,0005 & 0,0005 & 0,0005 & 0,0004 & 0.0004 & 0.0004 & 0,0004 & 0.0004 & 0,0004 & 0.0003 \\
\hline$-3,2$ & 0,0007 & 0,0007 & 0,0006 & 0,0006 & 0.0006 & 0,0006 & 0,0006 & 0,0005 & 0,0005 & 0,0005 \\
\hline$-3,1$ & 0,0010 & 0.0009 & 0,0009 & 0.0009 & 0,0008 & 0,0008 & 0,0008 & 0,0008 & 0.0007 & 0,0007 \\
\hline$-3,0$ & 0,0013 & 0,0013 & 0,0013 & 0,0012 & 0,0012 & 0,0011 & 0,0011 & 0,0011 & 0,0010 & 0,0010 \\
\hline$-2,9$ & 0,0019 & 0,0018 & 0,0018 & 0,0017 & 0,0016 & 0,0016 & 0,0015 & 0,0015 & 0,0014 & 0,0014 \\
\hline$-2,8$ & 0,0026 & 0,0025 & 0,0024 & 0,0023 & 0,0023 & 0,0022 & 0,0021 & 0,0021 & 0,0020 & 0,0019 \\
\hline$-2,7$ & 0,0035 & 0,0034 & 0,0033 & 0,0032 & 0,0031 & 0,0030 & 0,0029 & 0,0028 & 0.0027 & 0.0026 \\
\hline$-2,6$ & 0,0047 & 0,0045 & 0,0044 & 0,0043 & 0,0041 & 0,0040 & 0,0039 & 0,0038 & 0,0037 & 0,0036 \\
\hline$-2,5$ & 0,0062 & 0,0060 & 0,0059 & 0,0057 & 0,0055 & 0,0054 & 0,0052 & 0,0051 & 0,0049 & 0,0048 \\
\hline$-2,4$ & 0,0082 & 0,0080 & 0,0078 & 0,0075 & 0,0073 & 0,0071 & 0,0069 & 0,0068 & 0,0066 & 0,0064 \\
\hline$-2,3$ & 0,0107 & 0,0104 & 0,0102 & 0,0099 & 0,0096 & 0,0094 & 0,0091 & 0,0089 & 0,0087 & 0,0084 \\
\hline$-2,2$ & 0,0139 & 0,0136 & 0,0132 & 0,0129 & 0,0125 & 0,0122 & 0,0119 & 0,0116 & 0,0113 & 0,0110 \\
\hline$-2,1$ & 0,0179 & 0,0174 & 0.0170 & 0,0166 & 0,0162 & 0,0158 & 0,0154 & 0,0150 & 0,0146 & 0,0143 \\
\hline$-2,0$ & 0,0228 & 0,0222 & 0,0217 & 0,0212 & 0,0207 & 0,0202 & 0,0197 & 0,0192 & 0,0188 & 0,0183 \\
\hline$-1,9$ & 0,0287 & 0,0281 & 0,0274 & 0,0268 & 0,0262 & 0,0256 & 0,0250 & 0,0244 & 0,0239 & 0,0233 \\
\hline$-1,8$ & 0,0359 & 0,0351 & 0,0344 & 0,0336 & 0.0329 & 0,0322 & 0,0314 & 0,0307 & 0,0301 & 0,0294 \\
\hline$-1,7$ & 0,0446 & 0,0436 & 0,0427 & 0,0418 & 0,0409 & 0.0401 & 0,0392 & 0,0384 & 0,0375 & 0,0367 \\
\hline$-1,6$ & 0,0548 & 0,0537 & 0,0526 & 0,0516 & 0,0505 & 0,0495 & 0,0485 & 0,0475 & 0,0465 & 0,0455 \\
\hline$-1,5$ & 0,0668 & 0,0655 & 0,0643 & 0,0630 & 0,0618 & 0,0606 & 0,0594 & 0,0582 & 0,0571 & 0,0559 \\
\hline$-1,4$ & 0,0808 & 0,0793 & 0,0778 & 0,0764 & 0,0749 & 0,0735 & 0,0721 & 0,0708 & 0,0694 & 0,0681 \\
\hline$-1,3$ & 0,0968 & 0,0951 & 0,0934 & 0,0918 & 0,0901 & 0,0885 & 0,0869 & 0,0853 & 0,0838 & 0,0823 \\
\hline$-1,2$ & 0,1151 & 0,1131 & 0,1112 & 0,1093 & 0,1075 & 0,1056 & 0,1038 & 0,1020 & 0,1003 & 0,0985 \\
\hline$-1,1$ & 0,1357 & 0,1335 & 0,1314 & 0,1292 & 0,1271 & 0,1251 & 0,1230 & 0,1210 & 0,1190 & 0,1170 \\
\hline$-1,0$ & 0,1587 & 0,1562 & 0,1539 & 0,1515 & 0,1492 & 0,1469 & 0,1446 & 0,1423 & 0,1401 & 0,1379 \\
\hline$-0,9$ & 0,1841 & 0,1814 & 0,1788 & 0,1762 & 0,1736 & 0,1711 & 0,1685 & 0,1660 & 0,1635 & 0,1611 \\
\hline$-0,8$ & 0,2119 & 0,2090 & 0,2061 & 0,2033 & 0,2005 & 0,1977 & 0,1949 & 0,1922 & 0,1894 & 0,1867 \\
\hline$-0,7$ & 0,2420 & 0,2389 & 0,2358 & 0,2327 & 0,2296 & 0,2266 & 0,2236 & 0,2206 & 0,2177 & 0,2148 \\
\hline$-0,6$ & 0,2743 & 0,2709 & 0,2676 & 0,2643 & 0,2611 & 0,2578 & 0,2546 & 0,2514 & 0,2483 & 0,2451 \\
\hline-0.5 & 0,3085 & 0,3050 & 0.3015 & 0,2981 & 0,2946 & 0.2912 & 0.2877 & 0,2843 & 0,2810 & 0,2776 \\
\hline$-0,4$ & 0,3446 & 0,3409 & 0,3372 & 0,3336 & 0,3300 & 0,3264 & 0,3228 & 0,3192 & 0,3156 & 0,3121 \\
\hline$-0,3$ & 0,3821 & 0,3783 & 0,3745 & 0,3707 & 0,3669 & 0,3632 & 0,3594 & 0,3557 & 0,3520 & 0,3483 \\
\hline$-0,2$ & 0,4207 & 0,4168 & 0,4129 & 0,4090 & 0,4052 & 0,4013 & 0,3974 & 0,3936 & 0,3897 & 0,3859 \\
\hline$-0,1$ & 0,4602 & 0,4562 & 0,4522 & 0,4483 & 0,4443 & 0,4404 & 0,4364 & 0,4325 & 0,4286 & 0,4247 \\
\hline$-0,0$ & 0,5000 & 0,4960 & 0,4920 & 0,4880 & 0,4840 & 0,4801 & 0,4761 & 0,4721 & 0,4681 & 0,4641 \\
\hline
\end{tabular}

NOTA: Para valores de $z$ abaixo de $-3,49$, use 0,0001 para a área.

Figura B.1: Retirado de

http://www.ufvjm.edu.br/disciplinas/eco009/files/2012/03/TABELA-

distribui\%C3\%A7\%C3\%A3o-normal.pdf. 


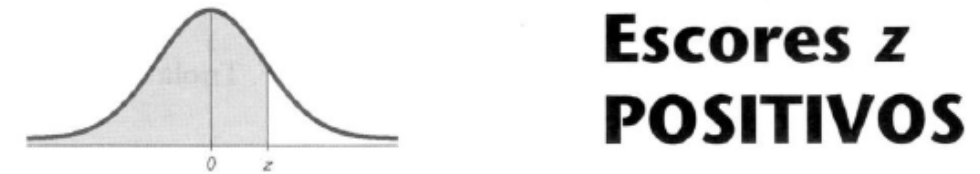

\begin{tabular}{|c|c|c|c|c|c|c|c|c|c|c|}
\hline \multirow[b]{2}{*}{$z$} & \multicolumn{6}{|c|}{ (continuação) Área Acumulada à ESQUERDA } & \multirow[b]{2}{*}{0,06} & \multirow[b]{2}{*}{0,07} & \multirow[b]{2}{*}{0,08} & \multirow[b]{2}{*}{0.09} \\
\hline & 0,00 & 0,01 & 0,02 & 0,03 & 0,04 & 0,05 & & & & \\
\hline 0,0 & 0,5000 & 0,5040 & 0,5080 & 0,5120 & 0.5160 & 0,5199 & 0,5239 & 0,5279 & 0.5319 & 0,5359 \\
\hline 0,1 & 0,5398 & 0,5438 & 0,5478 & 0,5517 & 0,5557 & 0,5596 & 0,5636 & 0,5675 & 0,5714 & 0,5753 \\
\hline 0,2 & 0,5793 & 0,5832 & 0,5871 & 0,5910 & 0,5948 & 0,5987 & 0,6026 & 0,6064 & 0,6103 & 0,6141 \\
\hline 0,3 & 0,6179 & 0,6217 & 0,6255 & 0,6293 & 0,6331 & 0,6368 & 0,6406 & 0,6443 & 0,6480 & 0,6517 \\
\hline 0,4 & 0,6554 & 0,6591 & 0,6628 & 0,6664 & 0.6700 & 0,6736 & 0,6772 & 0,6808 & 0,6844 & 0,6879 \\
\hline 0,5 & 0,6915 & 0,6950 & 0,6985 & 0.7019 & 0,7054 & 0.7088 & 0,7123 & 0.7157 & 0,7190 & 0,7224 \\
\hline 0,6 & 0,7257 & 0,7291 & 0,7324 & 0,7357 & 0,7389 & 0,7422 & 0,7454 & 0,7486 & 0,7517 & 0,7549 \\
\hline 0,7 & 0,7580 & 0,7611 & 0,7642 & 0,7673 & 0.7704 & 0.7734 & 0,7764 & 0.7794 & 0.7823 & 0,7852 \\
\hline 0,8 & 0,7881 & 0,7910 & 0,7939 & 0,7967 & 0,7995 & 0,8023 & 0,8051 & 0,8078 & 0,8106 & 0,8133 \\
\hline 0,9 & 0,8159 & 0,8186 & 0,8212 & 0,8238 & 0.8264 & 0.8289 & 0,8315 & 0,8340 & 0,8365 & 0,8389 \\
\hline 1,0 & 0,8413 & 0,8438 & 0,8461 & 0,8485 & 0,8508 & 0,8531 & 0,8554 & 0,8577 & 0,8599 & 0,8621 \\
\hline 1,1 & 0,8643 & 0,8665 & 0,8686 & 0,8708 & 0,8729 & 0,8749 & 0,8770 & 0,8790 & 0,8810 & 0,8830 \\
\hline 1,2 & 0,8849 & 0,8869 & 0,8888 & 0,8907 & 0,8925 & 0,8944 & 0,8962 & 0,8980 & 0,8997 & 0,9015 \\
\hline 1,3 & 0,9032 & 0,9049 & 0,9066 & 0,9082 & 0,9099 & 0,9115 & 0,9131 & 0,9147 & 0.9162 & 0,9177 \\
\hline 1.4 & 0,9192 & 0,9207 & 0,9222 & 0,9236 & 0,9251 & 0,9265 & 0,9279 & 0,9292 & 0,9306 & 0,9319 \\
\hline 1,5 & 0.9332 & 0,9345 & 0,9357 & 0,9370 & 0.9382 & 0.9394 & 0,9406 & 0.9418 & 0,9429 & 0,9441 \\
\hline 1,6 & 0,9452 & 0,9463 & 0,9474 & 0,9484 & $0,9495 *$ & 0,9505 & 0,9515 & 0,9525 & 0,9535 & 0,9545 \\
\hline 1,7 & 0,9554 & 0,9564 & 0.9573 & 0,9582 & $0.9591 \uparrow$ & 0,9599 & 0,9608 & 0,9616 & 0,9625 & 0,9633 \\
\hline 1,8 & 0,9641 & 0,9649 & 0,9656 & 0,9664 & 0,9671 & 0,9678 & 0,9686 & 0,9693 & 0,9699 & 0,9706 \\
\hline 1,9 & 0,9713 & 0,9719 & 0,9726 & 0.9732 & 0,9738 & 0,9744 & 0.9750 & 0.9756 & 0,9761 & 0,9767 \\
\hline 2,0 & 0,9772 & 0,9778 & 0,9783 & 0,9788 & 0,9793 & 0,9798 & 0,9803 & 0,9808 & 0,5040 & 0,9817 \\
\hline 2,1 & 0,9821 & 0,9826 & 0,9830 & 0,9834 & 0.9838 & 0.9842 & 0,9846 & 0,9850 & 0,9854 & 0,9857 \\
\hline 2,2 & 0,9861 & 0,9864 & 0,9868 & 0,9871 & 0,9875 & 0,9878 & 0,9881 & 0,9884 & 0,5040 & 0,9890 \\
\hline 2,3 & 0,9893 & 0,9896 & 0,9898 & 0,9901 & 0,9904 & 0,9906 & 0,9909 & 0,9911 & 0,9913 & 0,9916 \\
\hline 2,4 & 0,9918 & 0,9920 & 0,9922 & 0,9925 & 0,9927 & 0,9929 & 0.9931 & 0,9932 & 0,9934 & 0,9936 \\
\hline 2,5 & 0,9938 & 0,9940 & 0.9941 & 0,9943 & 0,9945 & 0,9946 & 0,9948 & $0,9949 *$ & * 0,9951 & 0,9952 \\
\hline 2.6 & 0,9953 & 0,9955 & 0,9956 & 0,9957 & 0,9959 & 0,9960 & 0.9961 & $0,9962 \uparrow$ & 0.5040 & 0,9964 \\
\hline 2,7 & 0,9965 & 0,9966 & 0,9967 & 0,9968 & 0,9969 & 0.9970 & 0.9971 & 0,9972 & 0,9973 & 0,9974 \\
\hline 2,8 & 0,9974 & 0,9975 & 0,9976 & 0,9977 & 0,9977 & 0,9978 & 0,9979 & 0,9979 & 0,9980 & 0,9981 \\
\hline 2,9 & 0,9981 & 0,9982 & 0,9982 & 0.9983 & 0,9984 & 0,9984 & 0,9985 & 0,9985 & 0,9986 & 0,9986 \\
\hline 3,0 & 0,9987 & 0,9987 & 0.9987 & 0,9988 & 0,9988 & 0,9989 & 0,9989 & 0,9989 & 0,9990 & 0,9990 \\
\hline 3,1 & 0,9990 & 0,9991 & 0,9991 & 0,9991 & 0,9992 & 0,9992 & 0.9992 & 0.9992 & 0,9993 & 0.9993 \\
\hline 3,2 & 0,9993 & 0,9993 & 0,9994 & 0,9994 & 0,9994 & 0,9994 & 0,9994 & 0,9995 & 0,9995 & 0,9995 \\
\hline 3,3 & 0,9995 & 0,9995 & 0,9995 & 0,9996 & 0,9996 & 0,9996 & 0,9996 & 0,9996 & 0,9996 & 0,9997 \\
\hline 3,4 & 0,9997 & 0,9997 & 0,9997 & 0,9997 & 0,9997 & 0,9997 & 0,9997 & 0,9997 & 0,9997 & 0,9998 \\
\hline \multicolumn{11}{|l|}{$\begin{array}{l}\mathrm{e} \\
\text { maior }\end{array}$} \\
\hline \multicolumn{6}{|c|}{$\begin{array}{l}\text { NOTA: Para valores de } z \text { maiores que } 3,49 \text {, use o valor } 0,9999 \text { para a área. } \\
\text { "Use esses valores comuns que resultam de interpolaçö: }\end{array}$} & & & & \multicolumn{2}{|c|}{ Valores Críticos Comuns } \\
\hline$\underline{\text { Escore } z}$ & $\frac{\text { Área }}{0.500}$ & & & & & & & & $\begin{array}{c}\text { Nivel de } \\
\text { Confiança }\end{array}$ & $\begin{array}{c}\text { Valor } \\
\text { Critico } \\
\end{array}$ \\
\hline 1,645 & 0,9500 & & & & & & & & 0.90 & 1,645 \\
\hline 2,575 & 0,9950 & & & & & & & & $\begin{array}{l}0,95 \\
0.99\end{array}$ & 1,96 \\
\hline
\end{tabular}

Figura B.2: Retirado de

http://www.ufvjm.edu.br/disciplinas/eco009/files/2012/03/TABELAdistribui\%C3\%A7\%C3\%A3o-normal.pdf). 